\title{
Active vs. Passive Decisions and Crowd-Out in Retirement Savings Accounts: Evidence from Denmark
}

\section{Citation}

Chetty, R., J. N. Friedman, S. Leth-Petersen, T. H. Nielsen, and T. Olsen. 2014. "Active Vs. Passive Decisions and Crowd-Out in Retirement Savings Accounts: Evidence from Denmark." The Quarterly Journal of Economics 129 (3) (May 9): 1141-1219. doi:10.1093/qje/qju013.

\section{Published Version}

doi:10.1093/qje/qju013

\section{Permanent link}

http://nrs.harvard.edu/urn-3:HUL.InstRepos:27304884

\section{Terms of Use}

This article was downloaded from Harvard University's DASH repository, and is made available under the terms and conditions applicable to Other Posted Material, as set forth at http:// nrs.harvard.edu/urn-3:HUL.InstRepos:dash.current.terms-of-use\#LAA

\section{Share Your Story}

The Harvard community has made this article openly available.

Please share how this access benefits you. Submit a story.

\section{Accessibility}




\title{
ACTIVE VS. PASSIVE DECISIONS AND CROWD-OUT IN RETIREMENT SAVINGS ACCOUNTS: EVIDENCE FROM DENMARK*
}

\author{
Raj Chetty, Harvard University and NBER \\ John N. Friedman, Harvard University \\ Søren Leth-Petersen, University of Copenhagen \\ Torben Heien Nielsen, University of Copenhagen \\ Tore Olsen, Centre for Applied Microeconometrics and NBER
}

December 2013

\begin{abstract}
Using 41 million observations on savings for the population of Denmark, we show that the impacts of retirement savings policies on wealth accumulation depend on whether they change savings rates by active or passive choice. Subsidies for retirement accounts, which rely upon individuals to take an action to raise savings, primarily induce individuals to shift assets from taxable accounts to retirement accounts. We estimate that each $\$ 1$ of government expenditure on subsidies increases total saving by only 1 cent. In contrast, policies that raise retirement contributions if individuals take no action - such as automatic employer contributions to retirement accounts - increase wealth accumulation substantially. We estimate that approximately $15 \%$ of individuals are "active savers" who respond to tax subsidies primarily by shifting assets across accounts. $85 \%$ of individuals are "passive savers" who are unresponsive to subsidies but are instead heavily influenced by automatic contributions made on their behalf. Active savers tend to be wealthier and more financially sophisticated. We conclude that automatic contributions are more effective at increasing savings rates than subsidies for three reasons: (1) subsidies induce relatively few individuals to respond, (2) they generate substantial crowd-out conditional on response, and (3) they do not increase the savings of passive individuals, who are least prepared for retirement.
\end{abstract}

${ }^{*}$ We thank Christopher Carroll, James Choi, Gary Engelhardt, William Gale, Nathan Hendren, Lawrence Katz, Patrick Kline, David Laibson, Brigitte Madrian, Jonathan Parker, James Poterba, Emmanuel Saez, Andrew Samwick, Laszlo Sandor, Karl Scholz, Jesse Shapiro, Jonathan Skinner, Danny Yagan, anonymous referees, and numerous seminar participants for helpful comments and discussion. Sarah Abraham, Shelby Lin, Alex Olssen, Heather Sarsons, Michael Stepner, and Evan Storms provided outstanding research assistance. This research was supported by The Danish Council for Independent Research and by the U.S. Social Security Administration through grant \#5 RRC08098400-05-00 to the National Bureau of Economic Research as part of the SSA Retirement Research Consortium. The findings and conclusions expressed are solely those of the authors and do not represent the views of SSA, any agency of the Federal Government, or the NBER. John Friedman is currently on leave from Harvard, working at the National Economic Council. This work does not represent the views of the NEC. 


\section{Introduction}

Do retirement savings policies - such as tax subsidies, employer-provided pensions, and savings mandates - raise total wealth accumulation or simply induce individuals to shift savings across accounts? Despite extensive research, the answer to this question remains unclear, largely due to limitations in data and research designs (Bernheim, 2002).

In this paper, we revisit this question using a panel data set with 41 million observations on savings in both retirement and non-retirement accounts for the population of Denmark. We organize our empirical analysis using a stylized model in which the government uses two policies to raise saving: a price subsidy and an automatic contribution that puts part of an individual's salary in a retirement account. We analyze the impacts of these policies on two types of agents: active savers and passive savers. Active savers make savings decisions by maximizing utility, taking into account the subsidies and automatic contributions. Passive savers make fixed pension contributions that are invariant to the automatic contribution and subsidy.

The model predicts that automatic contributions should have no impact on total saving total flows into non-retirement and retirement accounts - for active savers who can fully offset the automatic contribution by reducing their own voluntary pension contributions. In contrast, the impact of automatic contributions on total saving is ambiguous for passive savers. If passive savers absorb the reduction in disposable income due to the automatic contribution by maintaining a fixed consumption plan and running down their bank balance, automatic contributions have no impact on total saving even though they increase savings within retirement accounts. But if passive savers absorb the reduction in disposable income by reducing consumption and maintaining a fixed savings target in non-retirement accounts, automatic contributions increase total saving. Price subsidies have no impact on passive savers' decisions. Subsidies induce active savers to save more in retirement accounts, but their impacts on total saving are once again ambiguous and depend upon the relative magnitude of price and wealth effects.

We analyze the impacts of price subsidies and automatic contributions empirically and estimate the fraction of active vs. passive savers using Danish income tax records. These data provide deidentified information on savings for all Danish citizens from 1995-2009. The Danish pension system - which has individual and employer defined-contribution accounts and a government definedbenefit plan - is similar in structure to that in the U.S. and other developed countries. The Danish data and institutional environment have two primary benefits. First, they offer high quality, third- 
party-reported information on savings for a much larger number of individuals than recent studies based on survey data, which typically have fewer than 1,000 observations in their analysis samples (e.g., Gelber, 2011). Second, a series of sharp reforms in Denmark provide quasi-experimental research designs to identify the impacts of retirement savings policies.

We divide our empirical analysis into three sections. First, we analyze the impacts of definedcontribution employer pension plans and government mandates, both of which are "automatic contributions" in the sense that they raise retirement saving if individuals take no action. Using event studies of individuals who switch firms, we find that individuals' total saving rises by approximately 80 cents ( $\varnothing$ re in Danish) when they move to a firm that contributes DKr 1 more to their retirement account even if they could have fully offset the increase. Increases in compensation in the form of automatic retirement contributions raise total saving much more than equivalent increases in disposable earnings. Most individuals do not change voluntary pension contributions, savings in taxable accounts, or liabilities at all when they switch to firms that contribute more to their retirement account, consistent with passive behavior. The savings impacts are equally large when we restrict attention to the subset of individuals who switch firms because of a mass-layoff at their prior firm, showing that our estimates are not biased by endogenous sorting. The changes in savings behavior persist for at least ten years after the firm switch and ultimately result in higher wealth balances at the age of retirement. We complement our analysis of employer pensions by studying the impacts of a government-imposed Mandatory Savings Plan (MSP) that required Danish citizens above an income eligibility cutoff to contribute $1 \%$ of their earnings to a retirement savings account starting in 1998. Using a regression discontinuity design, we show that the MSP raised total saving by nearly $1 \%$ of earnings on average even for individuals who were previously saving more than $1 \%$ of their earnings in voluntary retirement savings accounts. Overall, we estimate that at least $85 \%$ of individuals respond passively to changes in automatic contributions, leaving their own pension contributions and taxable saving unchanged when employer or government contributions rise.

In the second part of our empirical analysis, we study the impacts of subsidies for retirement savings. Denmark has two types of tax-deferred savings accounts: capital pensions that are paid out as a lump sum upon retirement and annuity pensions that are paid out as annuities. In 1999, the government reduced the subsidy for contributing to capital pension accounts by 14 cents per Danish Kroner (DKr) for individuals in the top income tax bracket. Using a difference-in-difference design around the top tax cutoff, we find that capital pension contributions fell sharply for individuals in the top income tax bracket. The aggregate reduction in capital pension contributions is entirely 
driven by just $19 \%$ of prior contributors, most of whom stop making capital pension contributions in 1999. The remaining $81 \%$ of prior contributors do not change their capital pension contributions. Since utility maximization would call for some non-zero change in contributions when prices change at an interior optimum, we infer that $81 \%$ of individuals behave passively with respect to changes in subsidies.

Next, we investigate whether the changes in pension contributions induced by the subsidy change led to changes in total wealth accumulation. We estimate two crowd-out parameters: the degree of shifting between different pension accounts and the degree of shifting from pension accounts to taxable savings accounts. First, we find that 57 cents of each DKr that would have been contributed to capital pensions is shifted to annuity pension accounts (whose tax treatment was unchanged) when the capital pension subsidy was reduced. Hence, total pension contributions fall by 43 cents for each DKr of reduction in capital pensions. Second, focusing on this reduction in total pension contributions, we estimate that 99 cents of each DKr contributed to retirement accounts comes from money that would have been saved in a taxable account. This 99 cent crowd-out estimate determines the overall impact of retirement savings subsidies on total saving and can be compared to prior estimates (e.g., Engen, Gale and Scholz, 1996; Poterba, Venti and Wise, 1996). Based on this estimate, we calculate that each DKr 1 of government expenditure on subsidies for retirement saving generates less than 1 cent of net new saving. The upper bound on the $95 \%$ confidence interval is 28 cents of new saving per DKr 1 of expenditure on subsidies.

In the final part of our empirical analysis, we investigate heterogeneity in responses across individuals. We document three pieces of evidence which suggest that active vs. passive choice is a key reason that automatic contributions and subsidies have very different effects on total saving. First, the 1999 subsidy reduction has much larger effects on individuals starting a new pension in that year relative to those making pension contributions in previous years, consistent with evidence on inertial behavior in other domains (Samuelson and Zeckhauser, 1988; Ericson, 2012). Second, individuals who actively change their pension contributions more frequently in other years are more responsive to the price subsidy change and more likely to offset automatic contributions by changing their own individual pension contributions. Third, individuals who are wealthier, older, or have economics training are more responsive to price subsidies and more likely to offset automatic contributions. In sum, "active savers" - those who are more responsive to price subsidies and less influenced by automatic contributions - tend to be financially sophisticated individuals who plan for retirement. 
We conclude that the impacts of retirement savings policies on wealth accumulation depend on whether they change behavior through active or passive choice. Policies that rely upon individuals to take an action to raise savings have significantly smaller impacts on total saving than policies that raise savings automatically even if individuals take no action.

Our results build on a large literature in public finance estimating crowdout in retirement savings accounts reviewed by Poterba, Venti and Wise (1996) and Engen, Gale and Scholz (1996). Some recent studies in this literature (e.g., Gelber (2011)) present evidence that increases in IRA or 401(k) savings represent increases in total saving, while others (e.g., Benjamin (2003) and Engelhardt and Kumar (2007)) find that much of the increase in 401(k) savings represents substitution from other accounts. Although some of the difference between the results of these studies likely stems from differences in econometric assumptions, the variation that drives changes in contributions to 401(k)'s could also explain the differences in results. For instance, increases in 401(k) contributions by employers may generate less crowd-out than tax incentives or programs that require active individual choice, an idea foreshadowed in early work by Cagan (1965) and Green (1981).

Our results also relate to a more recent literature in behavioral economics showing that defaults significantly increase saving within retirement accounts (e.g., Madrian and Shea, 2001; Thaler and Benartzi, 2004). This prior work has not investigated whether defaults raise total saving or simply induce individuals to save less in non-retirement accounts. Our finding that policies that change saving passively do raise total saving thus significantly strengthens the argument for policies such as automatic enrollment and defaults if a policy maker's goal is to increase savings rates.

Finally, our analysis provides three facts that could be useful to test between macroeconomic models of household behavior. First, the marginal propensity of consumption (MPC) depends critically on the form of compensation: the MPC out of disposable income is an order of magnitude larger than the MPC out of pension contributions. This finding is consistent with evidence that consumption behavior departs from the predictions of frictionless life-cycle models (e.g., Johnson, Parker and Souleles, 2006), but suggests that factors such as inattention (Reis (2006)) or unawareness may be as important as liquidity constraints and buffer stock behavior in explaining such departures. Second, our findings are consistent with a model of "spenders" and "savers" (Campbell and Mankiw, 1989; Mankiw, 2000), in which some agents follow a rule-of-thumb based on current disposable income and others optimize according to the life-cycle model. We estimate that approximately $85 \%$ of individuals are rule-of-thumb spenders who make consumption choices based on disposable income. Third, our results imply that the interest elasticity of savings is low, both 
because the savings rates of active savers are inelastic with respect to net-of-tax interest rates and because many individuals react passively with respect to changes in net-of-tax returns.

The paper is organized as follows. Section II presents a stylized model to organize our reducedform empirical analysis. Section III describes the data and institutional background. Sections IV, V, and VI present the empirical results on automatic contributions, price subsidies, and heterogeneity across individuals, respectively. Section VII concludes.

\section{Conceptual Framework}

In this section, we set up a stylized two-type model of savings behavior and characterize its comparative statics to structure our empirical analysis.

\section{II.A Setup}

Individuals live for two periods. They earn a fixed amount $W$ in period 1 , which they can either consume or save in one of two risk-free accounts: a retirement account or a taxable savings account. Let $r$ denote the net-of-tax interest rate that individuals earn in the taxable account. The government offers a subsidy $\psi$ that increases the return to saving in the retirement account to $r+\psi$. To simplify notation, we abstract from income and capital gains taxes and let $\psi$ represent the net subsidy to retirement accounts taking all taxes into account. We assume that the subsidy is financed by a tax on future generations or other agents outside the model. This assumption is appropriate for our empirical application because the variation in $\psi$ we study affects a small set of agents and is financed out of general revenues.

Let $S_{i}$ represent the amount that individual $i$ saves in the non-retirement (taxable) savings account. Let $P_{i}^{I}$ denote the amount that individual $i$ contributes to the retirement account, $P^{E}$ the amount his employer contributes to his retirement account, and $P^{G}$ the amount the government requires the individual to contribute to a retirement account. ${ }^{1}$ Let $P_{i}=P_{i}^{I}+P^{E}+P^{G}$ denote total retirement saving. We treat $P^{E}$ and $P^{G}$ as exogenous parameters because our goal is to characterize individual responses to exogenous changes in these policies. Both $P^{E}$ and $P^{G}$ are "automatic contributions" in the sense that they are involuntary contributions that do not require any active choice by the individual. We model $P^{E}$ and $P^{G}$ as coming out of gross earnings $W$, so that disposable income $W-P^{E}-P^{G}$ remains to be allocated between consumption, taxable

\footnotetext{
${ }^{1}$ To simplify notation, we assume that $P^{E}$ and $P^{G}$ do not vary across individuals in our model; in our empirical analysis, we exploit variation in $P^{E}$ and $P^{G}$ across individuals for identification.
} 
savings, and individual pension contributions. ${ }^{2}$ With this notation, a $\$ 1$ increase in $P^{E}$ or $P^{G}$ leads to a $\$ 1$ reduction in disposable income, leaving total compensation fixed and eliminating any income effects from changes in retirement benefits. Note that in our model, $P^{E}$ and $P^{G}$ are interchangeable; however, we distinguish between employer and government contributions to retirement accounts in our empirical analysis.

The individual chooses $P_{i}^{I}$ and $S_{i}$ taking the policies $\left\{P^{E}, P^{G}, \psi\right\}$ as exogenous. To eliminate mechanical effects of changes in $P^{E}$ or $P^{G}$ that force individuals to save more, we assume that there are no constraints on $S_{i}$ and $P_{i}^{I} \cdot{ }^{3}$ Consumption in the two periods is given by

$$
\begin{aligned}
& c_{i, 1}\left(S_{i}, P_{i}^{I}\right)=W-S_{i}-P^{G}-P^{E}-P_{i}^{I} \\
& c_{i, 2}\left(S_{i}, P_{i}^{I}\right)=(1+r) S_{i}+(1+r+\psi)\left(P_{i}^{I}+P^{E}+P^{G}\right) .
\end{aligned}
$$

In this two period setting, saving in the retirement account strictly dominates saving in taxable accounts, and hence all individuals would optimally set $S_{i}=0$. In practice, retirement accounts are illiquid and cannot be accessed prior to retirement, leading many individuals to save outside retirement accounts despite their tax disadvantage. We model the value of liquidity as a concave benefit $g\left(S_{i}\right)$ of saving in the non-retirement account. ${ }^{4}$ Accounting for the value of liquidity, individuals have utility

$$
u\left(c_{i, 1}\right)+\delta u\left(c_{i, 2}\right)+g\left(S_{i}\right) .
$$

where $u(c)$ is a smooth, concave function and $\delta<1$ denotes the individual's discount factor.

Active vs. Passive Savers. There are two types of agents, active savers and passive savers, who differ in the way they choose $S_{i}$ and $P_{i}^{I}$. Let $\alpha$ denote the fraction of active savers. Active savers choose $S_{i}$ and $P_{i}^{I}$ to maximize utility (2) given $\left\{P^{E}, P^{G}, \psi\right\}$ as in the neoclassical model. Passive savers set retirement contributions at an exogenous level $P_{i}^{I}=\bar{P}_{i}$ that does not vary with $\left\{P^{E}, P^{G}, \psi\right\}$. There are several models in the literature for why individuals' retirement savings plans are insensitive to incentives, such as fixed costs of adjustment that generate inertia, hyperbolic discounting that leads to procrastination in updating plans (Carroll et al., 2009), or a lack of

\footnotetext{
${ }^{2}$ This is purely a notational convention because we can always redefine earnings as gross payments. For example, if the individual receives a take-home salary of 20,000 and retirement benefits of $P_{E}=1000$, we would define $W=21,000$.

${ }^{3}$ In practice, individuals face a constraint of $P_{I} \geq 0$ and also a limit on total pension contributions. We focus on the behavior of individuals in the interior of the choice set in our empirical analysis to obtain estimates that correspond to parameters in our model.

${ }^{4}$ Gale and Scholz (1994) develop a three period model in which individuals face uncertainty in the second period, motivating them to keep some assets in a liquid buffer stock. Our model can be loosely interpreted as a reduced-form of the Gale and Scholz model.
} 
information. The results that follow do not depend upon which of these micro-foundations drives passive behavior, and we therefore do not specify a particular model of passive choice.

Regardless of how passive savers make choices, they must satisfy the budget constraint in (1), which can be rewritten as

$$
c_{i, 1}+S_{i}=W-P^{G}-P^{E}-\bar{P}_{i}^{I}=W-P_{i}
$$

i.e. consumption plus taxable saving equals income net of pension contributions. We assume that passive savers choose $S_{i}$ (or, equivalently, $c_{i, 1}$ ) as a function of net income $W-P_{i}$, so that changes in retirement savings policies affect behavior in period 1 only if they affect retirement contributions. Again, we do not posit a specific model of how passive savers choose $S_{i}$. Instead, we show how the impacts of government policy depend upon the way in which passive savers adjust $c_{i, 1}$ and $S_{i}$ when net income changes.

\section{II.B Comparative Statics}

Table I summarizes the comparative static predictions of our model. We begin by characterizing the impacts of automatic contributions in Columns 1 and 2 of the table. Because voluntary pension contributions are a perfect substitute for automatic contributions, active savers will undo changes in $P^{E}$ and $P^{G}$ 1-for-1 by reducing $P_{i}^{I}$. Automatic contributions therefore do not affect their total contributions to retirement accounts $P_{i}$. In contrast, passive savers leave $P_{i}^{I}$ fixed by definition and hence their total retirement contributions $P_{i}$ rise with $P^{E}$ and $P^{G}$. Let $P^{I}, P$, and $S$ denote the mean level of individual pension contributions, total pension contributions, and taxable saving in the population. We refer to $d P / d P^{E}$ as the degree of "pass-through" of employer pensions to total pensions (i.e., pass-through is one minus the rate of offset). We define pass-through of government pensions $d P / d P^{G}$ analogously. If we restrict attention to individuals who are not constrained by a corner, we can estimate the fraction of active savers directly from the rates of pass-through in the population:

$$
\begin{aligned}
& \widehat{\alpha}_{E}=1-d P / d P^{E} \\
& \widehat{\alpha}_{G}=1-d P / d P^{G}
\end{aligned}
$$

Next, consider impacts of automatic contributions on the mean level of total saving $(P+S)$. The total saving of active savers is unaffected by changes in $P^{E}$ and $P^{G}$. The impact of $P^{E}$ and $P^{G}$ on the total saving of passive savers depends on whether they cut consumption $c_{i, 1}$ or non-retirement 
savings $S_{i}$ to meet the budget constraint in (3). Two cases span the potential responses. At one extreme, if an individual has a fixed consumption plan $\bar{c}_{i, 1}$ and does not pay attention to retirement savings, he will end up with a smaller bank balance $S_{i}$ at the end of the year. In this case, changes in $P^{E}$ and $P^{G}$ will have no impact on total saving. At the other extreme, if an individual has a fixed target for his bank balance $\bar{S}_{i}$, he will absorb the reduction in disposable income by reducing consumption $c_{i, 1}$. In this case, a $\$ 1$ increase in $P^{E}$ or $P^{G}$ will increase total saving by $\$ 1$. These extreme cases illustrate that existing evidence that automatic contributions increase saving within retirement accounts $\left(d P / d P^{E}>0\right)$ should not necessarily make us expect that such policies will raise total saving. In general, we may observe $d(P+S) / d\left(P^{E}+P^{G}\right)$ ranging from 0 to 1 depending upon the way in which passive savers set their budgets. If individuals are either pure consumption or savings targeters, we can estimate the fraction of savings targeters as $\frac{d(P+S)}{d\left(P^{E}+P^{G}\right)} / \frac{d P}{d\left(P^{E}+P^{G}\right)}$, i.e. the fraction of passive savers who do not change $S$ when $P$ rises.

Next, we turn to the impacts of price subsidies (Columns 3 and 4 of Table I). By definition, price subsidies have no impact on $P_{i}^{I}$ for passive savers. The impacts of an increase in the price subsidy on active savers have been characterized in prior work (e.g., Gale and Scholz, 1994; Bernheim, 2002). Increases in the subsidy $\psi$ affect $P_{i}^{I}$ through three channels: (1) by reducing the price of $P_{i}^{I}$ relative to $S_{i}$, leading to substitution across accounts; (2) by reducing the price of $c_{i, 2}$ relative to $c_{i, 1}$, raising total saving; and (3) by increasing total lifetime wealth, which raises period 1 consumption $c_{i, 1}$ and hence reduces saving. Prior empirical work (e.g., Duflo et al., 2006; Engelhardt and Kumar, 2007) consistently finds positive effects of subsidies on retirement contributions $\left(d P^{I} / d \psi>0\right)$, suggesting that in practice the price effects dominate the wealth effect on average. Note that $d P_{i}^{I} / d \psi=0$ only if the wealth effect exactly offsets the two price effects. Treating this as a measure zero knife-edge case, we can obtain another estimate of the fraction of active savers based on responses to changes in the subsidy:

$$
\widehat{\alpha}_{S}=1-\operatorname{frac}\left(d P_{i}^{I} / d \psi=0\right)
$$

where $\operatorname{frac}\left(d P_{i}^{I} / d \psi=0\right)$ denotes the fraction of individuals who do not change their individual pension contributions at all in response to changes in $\psi$.

Lastly, consider the impacts of the subsidy on total saving. Since changes in the subsidy rate $\psi$ have no impact on net income $W-P_{i}$ in period 1 when individuals do not change $P_{i}^{I}$, they also do not affect $P_{i}+S_{i}$ for passive savers. For active savers, the effects of price subsidies on total saving $P_{i}+S_{i}$ are ambiguous. If the elasticity of intertemporal substitution (EIS) is small, the increase in $P_{i}$ induced by a price subsidy could come largely from shifting assets across accounts, with little 
impact on total saving. If the EIS is large, an increase in $\psi$ would increase total saving. Hence, estimating $d(P+S) / d \psi$ is of interest for policy independent of estimating $\widehat{\alpha}_{S}$.

An important implication of this simple framework is that the degree to which pension contributions are offset by reduced saving in taxable accounts depends upon the policy instrument used to increase retirement savings. Automatic contributions affect the pension contributions of passive savers, whereas price subsidies affect the pension contributions of active savers. Because active optimizers are likely to be cognizant of all the accounts in which they might save, they may be more likely to re-optimize by shifting assets across accounts in response to a price subsidy than are passive savers in response to an automatic contribution.

Our stylized two-type model predicts that an individual who is passive with respect to price subsidies will also be passive with respect to automatic contributions, and hence that $\widehat{\alpha}_{E}=\widehat{\alpha}_{G}=$ $\widehat{\alpha}_{S}$. This strict prediction would not hold in a more general and realistic environment, as individuals may fluctuate between being active and passive over time and individuals may be more cognizant of some policies than others. Nevertheless, if the mechanism of active vs. passive choice is important in driving differential responses to retirement savings policies, one would expect to see certain correlations in the heterogeneity of responses across individuals. First, individuals who are currently making active choices for other reasons - e.g. those who are starting new pension accounts - should presumably be more responsive to price subsidies (e.g., Ericson 2012). Second, individuals who actively respond to price subsidies should also be more likely to offset automatic contributions. Third, typical micro-foundations for active vs. passive choice predict that active savers should have higher levels of total saving $P_{i}+S_{i}$. For instance, in Carroll et al.'s (2009) model, individuals with low discount factors $\delta$ - who have low savings rates - tend to be passive savers because the fixed up-front costs of planning for retirement outweigh their NPV gains from planning. More generally, the same characteristics that make some individuals actively optimize with respect to retirement savings incentives, such as financial literacy or attentiveness, are also likely to make these individuals plan for retirement to begin with. This leads to the testable prediction that automatic contributions should increase saving more for low-wealth individuals, while price subsidies should generate larger responses among high-wealth individuals.

In the remainder of the paper, we analyze the impacts of retirement savings policies empirically, focusing on three objectives that emerge from our conceptual framework: (1) estimating the fraction of active vs. passive savers using the estimators developed above, (2) quantifying the impacts of automatic contributions and subsidies on total saving, and (3) testing the mechanism of active vs. 
passive choice by analyzing heterogeneity across individuals.

\section{Data and Institutional Background}

Institutional Background. This section provides institutional background relevant for the research designs we implement below. See OECD (2009) or Bingley et al. (2007) for a comprehensive description of the Danish retirement system and Danish Ministry of Taxation (2002) for a description of the income tax system. Note that over the period we study, the exchange rate was approximately DKr 6.5 per US $\$ 1$.

The Danish pension system consists of three components that are typical of retirement savings systems in developed countries: a state-provided defined benefit (DB) plan (analogous to Social Security in the U.S.), employer-provided defined contribution (DC) accounts (analogous to 401(k)'s in the U.S.), and individual retirement accounts (analogous to IRA's in the U.S.).

The defined-benefit pension in Denmark pays a fixed benefit subject to earnings tests. For example, in 1999 the DB pension paid a benefit of DKr 95,640 (US \$14,700) for most single individuals over the age of 67 . Because our analysis focuses exclusively on DC accounts, we do not summarize the DB system further here. The structure of the DB pension system did not change in a way that affects our analysis of DC accounts over the period we study.

Most jobs in Denmark are covered by collective bargaining agreements between workers' unions and employer associations. These agreements set wage rates and often include a pension plan in which a fixed proportion of an individual's earnings is paid into a retirement account that is managed by an independent pension fund. Typically, $2 / 3$ of the contribution to employeradministered pension accounts is made by the employer, with the remaining $1 / 3$ deducted from the individual's paycheck (with no individual discretion). Because the distinction between these two sources of payment has no bearing on our empirical analysis, we refer to the sum of the employer $(2 / 3)$ and worker $(1 / 3)$ portions as the "employer-provided pension contribution," denoted by $P^{E}$.

Individual DC accounts are completely independent of employer accounts but have equivalent tax properties. Individual contributions do not need to be updated once they are set up, and in particular do not necessarily need to be changed as individuals change employers.

Within both the employer and individual DC pensions, there are two types of accounts: "capital pension" accounts and "annuity pension" accounts. ${ }^{5}$ These two accounts have different payout

\footnotetext{
${ }^{5}$ Annuity pensions can be further broken into two sub-categories labeled "rate" and "annuity" pensions, which pay out over a different number of years. We use the term "annuity pension" for simplicity here to refer to both of these accounts because the difference between these sub-categories does not matter for our empirical analysis.
} 
profiles and tax consequences. Balances accrued in capital pension accounts are paid out as a lump sum and taxed at $40 \%$ on payout. Balances accrued in annuity pension accounts are paid out over several years - e.g., as a 10-year annuity or a lifetime annuity - and are taxed as regular income. Contributions to both types of accounts are tax deductible at the time of contribution. Capital gains in both capital and annuity retirement accounts are taxed at approximately 15\%, compared with an average of approximately $29 \%$ for assets in taxable accounts. Withdrawals prior to retirement from either account incur a tax of $60 \%$ plus administrative fees prior to age 60 ; as a result, only $2.2 \%$ of individuals in a given year withdraw money prior to age 60 .

Employers set the amount that they contribute to capital and annuity pension accounts for their workers. The sum of employer and individual contributions to each type of account is capped at limits that have gradually increased over time. In 1999, total contributions to each account (capital or annuity) were limited to DKr 34,000 (US $\$ 5,200$ ); in 2009 , the cap was DKr 46,000. The cap binds for relatively few people. For example, conditional on having positive individual capital pension contributions, $4.6 \%$ of individuals are at the contribution limit for capital pensions.

Sample and Variable Definitions. We merge data from several administrative registers - the income tax register, the population register, and the Danish Integrated Database for Labor Market Research (IDA) - to obtain annual information for the Danish population from 1995 to 2009. Starting from the population data set, we impose two restrictions to obtain our primary analysis sample. First, we exclude observations in which individuals are below the age of 18 or over 60 , at which point early retirement schemes begin. Second, we exclude observations with self-employment income because business wealth and income are not measured precisely for the self-employed. This leaves us with an (unbalanced) panel of approximately 41 million observations for 4 million individuals.

All income and savings variables are based on third-party reports. Earnings and pension contributions are reported directly by employers and pension funds to the tax authority. End-of-year assets and liabilities in taxable accounts are reported directly to the tax authority by banks and financial institutions. These wealth data are collected because Denmark levied a wealth tax until 1996; data collection continued after that point and the tax authorities use the third-party reported wealth data to cross check if reported income is consistent with the level of asset accumulation. ${ }^{6}$

\footnotetext{
${ }^{6}$ Prior to 1997 , the tax authority also required individuals to self-report some components of their wealth to administer the wealth tax. Leth-Petersen (2010) uses these wealth data in his analysis. Here, we use only thirdparty reported data, which are available starting in 1995. Kleven et al. (2011) conducted a randomized tax audit in collaboration with the Danish tax authorities and found that tax evasion is negligible among wage earners. Their finding suggests that the third-party reported information we use here are of high quality and accurately capture real economic behavior.
} 
We observe flows into retirement accounts in each year, but have no information on total wealth balances in these accounts. In contrast, we observe total wealth balances in taxable accounts, but not the flow of saving into such accounts. We therefore define a (noisy) measure of gross taxable saving as the change in an individual's taxable asset holdings.

We define net saving as gross savings minus the change in liabilities. Our measure of liabilities covers all forms of secured and unsecured debt (such as credit cards) except home mortgages. We use gross saving as our baseline measure because liabilities are measured with substantial noise, yielding less precise estimates, particularly when analyzing heterogeneity; however, we show that we obtain similar point estimates when using net saving in all cases in the full sample.

Our measures of taxable saving suffer from three limitations. First, because we do not directly observe home equity wealth and mortgage debt, we miss investments in home improvements and payments to home equity. We assess whether this is a significant source of bias by replicating our analysis on the subsample of renters. Second, our definition of saving also does not account for investments in other durables, such as cars or appliances. To test for intertemporal substitution in durable goods purchases, we analyze policy impacts on savings behavior over several years. Third, the wealth data exclude some assets such as cash holdings outside bank accounts and exotic assets such as yachts. Such assets likely account for a small fraction of total wealth and are unlikely to be the main substitutes for savings in retirement accounts.

We top code pension contributions above the 99 th percentile to the 99th percentile in each account in each year, as these values are above the contribution limit and hence may be erroneous. In some specifications, we measure pension contributions and savings rates as a percentage of labor income. To reduce the influence of outliers on these estimates, we code as missing all rates as well as all measures of taxable saving that are below the 1st or above the 99th percentiles of their distributions in the relevant estimation sample, as described in the notes to each table.

We use three concepts of income in our empirical analysis. First, we define "labor income" $Y_{i, t}$ as labor earnings before the deduction of any taxes, excluding contributions to employer-administered pensions. Second, we define "total compensation" $W_{i, t}$ as labor earnings plus (both employer and employee) contributions to employer-administered retirement accounts. This concept matches the definition of total compensation $W$ in the model in Section II. Third, we define "taxable income" $Y_{i, t}^{\operatorname{tax}}$ as labor income plus other forms of income (e.g., unemployment insurance payments) that affect the computation of the individual's tax liability.

We analyze income and saving at the individual (rather than household) level because Denmark 
effectively has an individual tax system and thus the key incentives operate at the individual level. The tax authority divides balances held in joint accounts equally among the account's owners to obtain measures of individual capital income for tax purposes, and we use these individualspecific measures to compute saving in our analysis. To ensure that our results are not biased by resource pooling within couples, we directly test for offsets in the partner's account and analyze the subsample of individuals without partners. ${ }^{7}$

Summary Statistics. Table II presents summary statistics for the full sample and the "top tax threshold sample" used in our analysis of price subsidies, which includes observations with taxable income within DKr 75,000 of the top tax bracket cutoff. We report all monetary values in nominal terms. The asset positions of individuals in our sample are similar to those of individuals in the U.S. on average. The median savings rate (including pension contributions) in our sample is $8.7 \%$. The median savings rate for households in the U.S. Panel Study of Income Dynamics is approximately 14\% (Dynan et al., 2004). 18.7\% of individuals own stock in non-retirement accounts and $73.3 \%$ hold non-mortgage debt in Denmark; the corresponding fractions in the 2001 U.S. Survey of Consumer Finances are 21.3\% and 75.1\% (Aizcorbe et al., 2003).

A key feature of the data is that savings rates in taxable accounts vary considerably both across individuals and over time for a given individual. The standard deviation of taxable savings rates (as a percentage of labor income) in the full sample is $30.5 \%$; the within-person standard deviation of savings rates is $22.6 \%$ on average across individuals in the full sample. Savings rates are highly variable despite the fact that our administrative records have little measurement error for two reasons. First, fluctuations in asset returns generate noise in flow savings rates because we measure saving as the difference in wealth in taxable accounts. Second, the timing of durable goods and service purchases (e.g., a new fridge) and lumpy non-durables (e.g., an end-of-year vacation) generate true fluctuations in balances and savings rates. This latter channel is very important quantitatively: for individuals who own no stocks in taxable accounts, for whom the first channel is essentially shut down, the within-person standard deviation of savings rates across years remains at 19.5\%. The fluctuation in savings rates across years makes it challenging to obtain precise estimates of policy impacts on saving in taxable accounts, a problem that is likely to arise in any empirical analysis of savings behavior. The econometric methods we use are specifically designed to account for such noise and maximize the precision of estimates of taxable saving responses.

\footnotetext{
${ }^{7}$ Our definition of partners includes cohabitation, which is common in Denmark. The administrative records identify partners as individuals who (1) are married, (2) live together and have one or more children together, or (3) live together, are of opposite gender, differ in age by less than 15 years, and are not blood relatives.
} 


\section{Impacts of Automatic Contributions}

The ideal experiment to analyze the impacts of automatic pension contributions on saving would be to randomize automatic contributions holding fixed total compensation. For example, we would set up automatic pension contributions for a random subset of individuals of say DKr 1,000 and reduce their take-home pay by DKr 1,000 so that total compensation is held fixed. We approximate this ideal experiment using two quasi-experimental research designs: (1) changes in employer provided pensions and (2) the introduction of a mandated government savings plan (MSP). The employer pension variation provides much more precise estimates because it generates idiosyncratic variation at the individual level, while the MSP is a purer approximation of the ideal policy experiment.

\section{IV.A Employer Provided Pensions}

Contributions to employer-administered retirement accounts $\left(P_{i}^{E}\right)$ vary significantly across firms because of differences in collective bargaining agreements. To isolate variation in $P_{i}^{E}$ that is orthogonal to unobserved determinants of workers' savings rates, we study changes in workers' savings rates when they switch jobs. ${ }^{8}$ Although job changes are endogenous, they generate high-frequency changes in employer pension contributions that are plausibly orthogonal to tastes for saving, which presumably evolve more smoothly over time. We evaluate this orthogonality condition in detail after presenting a set of baseline results.

Throughout this subsection, we restrict attention to the subgroup of individuals who switch between firms at some point in our sample. We define an individual as switching firms in year $t$ if he has earnings from two distinct firms in year $t$ and $t-1 .^{9}$ To limit the sample to individuals switching between full-time jobs rather than entering or exiting the labor force, we exclude observations in which earnings either fell by more than half or more than doubled, which account for approximately $25 \%$ of the switches in our sample. ${ }^{10}$ This leaves us with 4.10 million job-switches in the data.

\footnotetext{
${ }^{8} \mathrm{An}$ alternative source of variation is changes in firm pension policies over time. Firm-level policy changes were very gradual and relatively small on an annual basis during the period we study, making it difficult to disentangle the causal impacts of changes in firms' policies from other confounding factors that trend over time. Arnberg and Barslund (2012) correlate changes in savings rates with changes in employer pensions and, consistent with our results, find little evidence of crowd-out. We also studied changes in individual saving rates when they first start receiving employer pension contributions, following Gelber (2011). We estimate a pass-through rate exceeding $90 \%$ using this design, which is similar to our estimates below based on job changes and indicates that most individuals are unresponsive to changes in their employer's pension policies.

${ }^{9}$ The firm identifiers were changed in 2003, 2005, and 2007; we therefore define the firm switch variable as missing for observations in these years. For individuals who hold multiple jobs within a single year, we define a firm switch as having a different "primary job" in the next year. We also confirm that our results hold for the subsample of individuals who have only one job in each year.

${ }^{10}$ Our results are insensitive to this restriction provided that we exclude the $1 \%$ of individuals who experience earnings changes exceeding $250 \%$ or below $-80 \%$.
} 
Because firms' pension contributions are typically denominated as a percentage of worker's salaries, we scale all variables in this subsection as a percentage of labor income $Y_{i, t}$. We begin by illustrating the research design using event studies around firm switches and then present regression estimates that pool all the available variation and control for income effects.

Event Studies. Figure Ia plots an event study of individuals who move to a firm that contributes at least 3 percentage points more of labor income to retirement accounts than their previous firm. Let year 0 denote the year in the sample that an individual switches firms and define all years relative to that year (e.g., if the individual switches firms in 2001, year 1998 is -3 and year 2003 is +2 ). To hold sample composition fixed across years, we include only individuals with at least 4 years of data both before and after the year of the switch. The series in squares in Figure Ia plots employer contributions (to capital plus annuity accounts) for these individuals. By construction, employer pensions jump in year 0 , by an average of $5.57 \%$ of labor income for individuals in this sample.

How does this jump in employer pensions affect individual pension contributions? The series in triangles in Figure 1a plots individual pension contributions $\left(P_{i}^{I}\right)$ around the firm switch. Individual pension contributions fall by $0.11 \%$ of income from year -1 to year 0 . Under the identification assumption that the distribution of individual pension contributions would have remained unchanged between periods $t$ and $t-1$ absent the change in employer pensions, we infer that a DKr 1 increase in $P^{E}$ causes a $0.11 / 5.57=2$ cent reduction in individual contributions $P^{I}$.

Under the assumptions of our stylized two-type framework in Section II, the 2 cent estimate would imply that $\widehat{\alpha}_{E}=2 \%$ of individuals are active savers who offset the increase in employer contributions by reducing individual contributions to retirement accounts. However, the stylized model ignores the fact that individuals face limits in the amount they can contribute to retirement accounts, which affect the estimation of $\widehat{\alpha}_{E}$ for two reasons. First, $62.2 \%$ of individuals in Figure Ia are at the lower corner $\left(P_{i, t=-1}^{I}=0\right)$ prior to the firm switch. These individuals cannot offset the increase in employer pensions even if they want to do so. Second, $7.6 \%$ of the individuals in Figure Ia have total contributions at the contribution limit $\left(P_{i, t-1}^{I}+P_{i, t-1}^{E}=P_{\max }\right)$ prior to the switch. ${ }^{11}$ In this subgroup, even passive individuals who are not actively responding to changes in $P_{i}^{E}$ are forced to reduce $P_{i}^{I}$ to meet the contribution limit after the firm switch. ${ }^{12}$ The first

\footnotetext{
${ }^{11}$ More precisely, $7.6 \%$ of individuals are at the corner in either annuity or capital pension accounts and hence may be constrained.

${ }^{12}$ This adjustment occurs automatically because individuals receive the tax deduction only for pension contributions up to the limit, and we measure $P^{I}$ in our data as the tax-deductible portion of individual pension contributions.
} 
constraint makes the $2 \%$ cent figure an underestimate of the degree of active behavior, while the second works in the opposite direction.

Because of these corners, the increase in total pension contributions in Figure Ia is driven by a combination of mechanical effects - i.e., being forced to save more in pensions - and passive behavior, i.e. not offsetting increases in automatic employer contributions even when it is feasible to do so. The mechanical effect is determined by the fraction of individuals at the corner with respect to a particular policy change, whereas the degree of passive behavior is likely to be relevant for predicting behavioral responses to policy changes more broadly. We use two methods to isolate passive behavior: conditioning on positive lagged contributions and studying thresholds instead of levels.

Figure Ib replicates Figure Ia, restricting the sample to individuals who make positive individual pension contributions in the year before the firm switch $\left(P_{i, t=-1}^{I}>0\right)$. In this sample, only $12.1 \%$ of individuals make zero contributions in year 0 after the firm switch, but the rate of pass-through remains high at $1-0.56 / 5.64=90 \%$. This result shows that most individuals do not offset the increase in employer pensions even if they are able to do so, but still does not yield a point estimate of the fraction of active savers $\widehat{\alpha}_{E}$ that is completely unaffected by corners.

To obtain such a point estimate, we analyze whether individuals in the interior of the choice set change $P_{i}^{I}$ when $P_{i}^{E}$ rises. In particular, we calculate the fraction of individuals whose total pension contributions $P_{i}^{I}+P_{i}^{E}$ exceed the new level of employer pensions (measured in levels):

$$
\begin{aligned}
& f_{t}=E_{i}\left[P_{i, t}^{I}+P_{i, t=-1}^{E}>P_{i, t=0}^{E}\right] \text { for } t<0 \\
& f_{t}=E_{i}\left[P_{i, t}^{I}+P_{i, t=0}^{E}>P_{i, t=0}^{E}\right] \text { for } t \geq 0
\end{aligned}
$$

For example, for individuals whose employer pension contribution rose from DKr 2000 to 5000 in year $0, f_{t}$ is the fraction whose total pension contributions exceed DKr 5,000 in each year $t .^{13}$ Because the change in employer pensions is inframarginal relative to this threshold, the fraction of individuals with total contributions of more than DKr 5,000 should be unaffected by this increase in employer pensions if all individuals are active savers, irrespective of corners.

Figure Ic plots $f_{t}$ for the same sample as in Figure Ia. The fraction $f_{t}$ jumps at $t=0$, implying that the distribution of total pension contributions shifts upward in the interior of the choice set

\footnotetext{
${ }^{13}$ When defining $f_{t}$, we fix employer pensions at $P_{i, t=0}^{E}$ for all $t>0$ rather than using the current level of $P_{i, t}^{E}$ because there are fluctuations in employer pensions over time due to changes in policies and subsequent firm switches that can affect $f_{t}$ even if the individual does not change his own contributions. We fix employer pensions at $P_{i, t=-1}^{E}$ for all $t<0$ for the same reason.
} 
when $P^{E}$ rises. To quantify the degree of pass-through implied by this treatment effect, we calculate the extent to which $f_{t}$ would rise if everyone were a passive saver under the maintained assumption that the distribution of $P_{i}^{I}$ is stationary between periods $t=-1$ and $t=0$. We calculate the predicted change in $f_{t}$ under $100 \%$ pass-through as

$$
\Delta f_{t}^{\text {pred }}=E_{i}\left[P_{i, t=-1}^{I}+P_{i, t=0}^{E}>P_{i, t=0}^{E}\right]-E_{i}\left[P_{i, t=-1}^{I}+P_{i, t=-1}^{E}>P_{i, t=0}^{E}\right] .
$$

The dashed line in Figure Ic depicts the predicted change $\Delta f_{t}^{\text {pred }}$ between periods -1 and 0 . We calculate the degree of pass-through as the ratio of the actual change in period 0 to the predicted change under full pass-through, $\Delta f_{t} / \Delta f_{t}^{\text {pred }}$. This statistic measures how far between the extremes of all active savers (with $\Delta f_{t}=0$ ) and all passive savers (with $\Delta f_{t}=\Delta f_{t}^{\text {pred }}$ ) the data lie. In the two-type model in Section II - in which individuals either fully offset the change in $P_{i}^{E}$ to the extent possible or make no change at all - this estimate corresponds to the mean rate of passthrough $d P / d P^{E}$. We present evidence below which indicates that individuals' responses follow this binary form in practice. We obtain an estimate of $d P / d P^{E}=\Delta f_{t} / \Delta f_{t}^{\text {pred }}=0.948$ using the threshold estimator, implying that only $\widehat{\alpha}_{E}=5.2 \%$ of individuals who are not constrained by a corner respond actively to changes in $P_{i}^{E}$.

Next, we analyze whether individuals offset the increase in pension contributions by saving less in taxable accounts. The series in circles in Figure Ia plots taxable saving $S_{i}$. There is little change in the level of taxable saving, implying that the increase in employer pension contributions raises total savings rates. Figure Ib shows that we obtain similar results when we restrict the sample to individuals who were making voluntary individual pension contributions in the year before the switch.

In Figure Ic, we implement the threshold approach by analyzing whether total saving - including both retirement and taxable non-retirement accounts - exceeds the new level of employer pension contributions. When defining total saving, one must account for the difference in the tax treatment of saving in retirement and non-retirement accounts. Because pension contributions are tax-deductible, one has to reduce consumption by only $\left(1-M T R_{i t}\right) P_{i t}$ to save $P_{i t}$ in a retirement account, where $M T R_{i t}$ is the individual's marginal tax rate. In contrast, one must reduce consumption by $S_{i t}$ to save $S_{i t}$ in a taxable savings account. Hence, total saving - the amount of disposable income an individual chooses not to consume - is $\left(1-M T R_{i t}\right) P_{i t}+S_{i t}$ in post-tax dollars. Because we measure pension contributions in pre-tax dollars (as in prior work), we measure total saving in 
pre-tax dollars as well and define total saving as

$$
S_{i t}^{t o t}=P_{i t}^{E}+P_{i t}^{I}+S_{i t} /\left(1-M T R_{i t}\right)
$$

The series in triangles in Figure Ic plots the fraction of individuals $f_{t}$ with total saving $S_{i t}^{t o t}$ above the new level of employer pension contributions, $P_{i, t=0}^{E} \cdot{ }^{14}$ The fraction of individuals with total saving above this amount jumps sharply after the firm switch. Comparing the observed change to the predicted change with no offset, pass-through to total saving is $d S^{t o t} / d P^{E}=0.618$.

As noted above, the identification assumption underlying our research design is that an individual's preferences for saving would not have jumped sharply in year 0 in the absence of the change in firm policies. Two pieces of evidence suggest that the identification assumption is likely to be satisfied. First, there is no trend toward higher individual pension contributions prior to year 0 in Figure Ia, as one would expect if individuals' tastes for saving were changing around the job switch.

Second, many individuals literally do not change their individual pension contributions at the time of the job switch. This is illustrated in Figure Id, which plots histograms of percentage changes in individual contributions from the year before the firm switch to the year of the firm switch for two groups of individuals who were making voluntary contributions prior to switching firms. The first group consists of those whose employer pension contribution increases by at least 3 percentage points, the same individuals as in Figure 1b. The second group consists of individuals whose employer pension contributions changed by less than 0.5 percentage points when they switched jobs. In the latter group, $52 \%$ of individuals leave their individual pension contributions unchanged when they switch jobs, compared with $42 \%$ in the former group. The fact that individuals' propensity to adjust their pension contributions rises by only $\frac{1-0.42}{1-0.52}-1=21 \%$ when they switch to a firm with much higher employer contributions implies that most individuals behave passively with respect to changes in $P^{E}$. For these individuals, total pension contributions change by exactly the same amount as the change in employer contributions, strongly suggesting that the increase in saving at $t=0$ reflects the causal effect of employer pensions rather than other factors. ${ }^{15}$

Regression Estimates of Pass-Through. We now estimate regression models that generalize the event studies in Figure I to include changes in employer pension contributions of varying sizes and control for income effects. Let $\Delta z_{i}=\Delta Z_{i} / Y_{i, t=-1}$ denote the change in a variable $Z_{i}$ from the year

\footnotetext{
${ }^{14}$ As above, when defining $f_{t}$, we fix employer pensions at $P_{i, t=0}^{E}$ for all $t>0$ and $P_{i, t=-1}^{E}$ for all $t<0$.

${ }^{15}$ Given switching costs and search frictions, it is unlikely that individuals who want to save say $3.3 \%$ more of their labor income in a given year could manage to switch to firms that contribute exactly $3.3 \%$ more to retirement savings. Moreover, because individual and employer contributions have identical tax benefits, there is no reason to switch firms to save more; it would be much easier to simply raise one's own contributions to the same retirement accounts.
} 
before to the year after a firm switch, scaled as a percentage of labor income $Y_{i, t=-1}$ prior to the switch. We quantify pass-through by estimating variants of the following regression specification using OLS:

$$
\Delta z_{i}=\beta_{0}+\phi_{E} \Delta p_{i}^{E}+\beta_{1} \Delta w_{i}+\beta_{X} X_{i}+\varepsilon_{i}^{E}
$$

where $\Delta z_{i}$ denotes the change in total pension contributions or savings rate, $\Delta p_{i}^{E}$ denotes the change in the employer pension contribution rate, $\Delta w_{i}$ denotes the change in total compensation as a percentage of per-switch labor income, and $X_{i}$ denotes a vector of covariates. In this equation, $\phi_{E}$ represents the impact of a DKr 1 increase in employer pensions while holding total compensation fixed (i.e., by reducing labor income by DKr 1), as in the ideal experiment described at the beginning of this section. Under the identification assumption $\operatorname{Cov}\left(\varepsilon_{i}^{E}, \Delta p_{i}^{E}\right)=0$, estimating (4) using OLS yields an unbiased estimate of $\phi_{E}$. If individuals are not at a corner, the pass-through rate $\phi_{E}=$ $1-\alpha_{E}$ identifies the fraction of passive savers.

Table III reports estimates of (4). We restrict the sample to individuals switching firms and use only data from the year before and the year after the firm switch (years -1 and 0 ). We cluster standard errors by destination firm to account for the correlation in employer pensions across employees of the same firm.

We begin in Column 1 of Table III by analyzing impacts on total pension contributions $\left(P^{E}+\right.$ $P^{I}$ ). We estimate three variants of this regression. In Panel A, we estimate (4) without any additional controls (no $X$ vector). To reduce mechanical effects due to corners, we restrict the sample to individuals who are making individual pension contributions $\left(P_{i, t=-1}^{I}>0\right)$ prior to the firm switch. ${ }^{16}$ We estimate that total pension contributions $P^{E}+P^{I}$ rise by 94.9 cents on average when employer pensions are increased by DKr 1. In contrast, a DKr 1 increase in labor income (i.e., an increase in total compensation holding $P_{i}^{E}$ fixed) increases saving by only 0.7 cents.

Figure IIa presents a binned scatter plot that is the non-parametric analog of the linear regression in Column 1 of Table IIIA. This figure plots changes in total pension contributions $\left(\Delta\left(p^{I}+p^{E}\right)\right)$ from year -1 to year 0 vs. changes in employer pension contributions $\Delta p^{E}$, controlling for changes in total compensation. To construct this figure, we first regress $\Delta\left(p^{I}+p^{E}\right)$ and $\Delta p^{E}$ on total compensation $\Delta w$ (using two separate OLS regressions) and calculate residuals. We then divide the residuals of $\Delta p^{E}$ into twenty equal-sized groups (vingtiles) and plot the mean of the $\Delta\left(p^{I}+p^{E}\right)$

\footnotetext{
${ }^{16}$ Importantly, we condition only on per-switch pension contributions being positive; we do not condition on $P_{i, t=0}^{I}$, which is endogenous to the change. For completeness, we estimate pass-through to total savings in the full sample in Column 1 of Appendix Table I. As expected, the pass-through estimates are similar in the full sample, since individuals at a corner must behave like passive savers.
} 
residuals in each bin against the mean of the $\Delta p^{E}$ residuals in each bin. This binned scatter plot provides a non-parametric representation of the conditional expectation function of $\Delta\left(p^{I}+p^{E}\right)$ given $\Delta p^{E}$, controlling for $\Delta w$. The regression coefficient and standard error reported in this and all subsequent binned scatter plots are estimated on the microdata using OLS regressions as in (4).

Figure IIa shows that changes in employer pensions increase total pension contributions throughout the distribution. Large changes (e.g. $+/-5 \%$ of earnings) continue to have significant impacts on savings behavior, challenging models of rational inattention (Cochrane, 1991; Browning and Crossley, 2001; Reis, 2006; Chetty, 2012). At the least, the costs of attention are large enough such that in the policy-relevant domain - which is unlikely to include automatic retirement contributions of more than $10 \%$ of income - most individuals behave passively.

In Panel B of Table III, we replicate the specification in Panel A, adding the following vector of covariates $X_{i}$ : age, gender, marital status, an indicator for attending college, and two-digit occupation indicators. Not surprisingly, the coefficient is virtually unchanged, as the sharp change in employer pensions at the time of the job switch is essentially orthogonal to these covariates.

Finally, in Panel C, we use a threshold-based approach to obtain an estimate of the fraction of active savers that is not biased by corners, as in Figure Ic. To implement this approach in a regression that pools both increases and decreases in pension contributions, we define the threshold as $\bar{P}=\max \left(P_{i, t=0}^{E}, P_{i, t=-1}^{E}\right)$. We define the change in an indicator for having total pension contributions greater than this threshold:

$$
\Delta \theta_{i}=I\left[P_{i, t=0}^{I}+P_{i, t=0}^{E}>\bar{P}\right]-I\left[P_{i, t=-1}^{I}+P_{i, t=-1}^{E}>\bar{P}\right]
$$

We then define an analogous variable measuring whether an individual would cross the same threshold if he behaved passively and left $P^{I}$ at the year $t-1$ level:

$$
\Delta \theta_{i}^{\text {pred }}=I\left[P_{i, t=-1}^{I}+P_{i, t=0}^{E}>\bar{P}\right]-I\left[P_{i, t=-1}^{I}+P_{i, t=-1}^{E}>\bar{P}\right] .
$$

We estimate a regression of the following form on the full sample of all firm switchers using 2SLS:

$$
\Delta \theta_{i}=\beta_{0}+\phi_{E} \Delta \theta_{i}^{\text {pred }}+\beta_{1} \Delta w_{i}+\beta_{2}\left[\Delta p_{i}^{E}>0\right]+\varepsilon_{i}^{E}
$$

instrumenting for the predicted change $\Delta \theta_{i}^{\text {pred }}$ with the change in employer pension rate $\Delta p_{i}^{E}$. The resulting 2SLS coefficient is an estimate of pass-through analogous to that in Figure Ib. Intuitively, the 2SLS coefficient is the ratio of the fraction of agents who actually cross the threshold to the fraction who would cross the threshold if they were totally passive. This is equivalent to the 
fraction of agents who undo the change in employer pensions in a model with two types, implying that $\phi_{E}=1-\widehat{\alpha}_{E}$. The resulting estimate is $\phi_{E}=93.9$ cents of pass-through to total pensions per DKr 1 of employer contributions.

Next, we turn to impacts on total saving $\left(S^{t o t}\right)$, including saving in taxable non-retirement accounts. Column 2 of Table III replicates the same triplet of specifications using changes in total savings rates instead of total pension contributions as the dependent variable. In Panel A, we condition on having liquid wealth of more than $10 \%$ of income or having positive individual pension contributions in the year before the firm switch to reduce the influence of corners. ${ }^{17}$ We estimate that a DKr 1 increase in $P^{E}$, holding fixed total compensation $W$, increases total saving by 77.7 cents. A DKr 1 increase in labor income raises total saving by only 11.8 cents. Comparing the coefficients on $\Delta p^{E}$ in Column 2 and Column 1, we infer that $77.7 / 94.9=82 \%$ of passive savers target a fixed level of taxable saving rather than consumption in a two-type model. The fact that most individuals have fixed savings targets in taxable accounts that are invariant to $P^{E}$ explains why automatic contributions are very effective in increasing total saving. Panels $\mathrm{B}$ and $\mathrm{C}$ show that we obtain similarly high rates of pass-through to total saving when we include controls or use the threshold approach to account for corners.

Figure IIb replicates Figure IIa for total saving, using the sample in Column 2 of Panel A. Consistent with the regression estimates, we observe systematic pass-through of changes in employer pensions to total saving throughout the distribution. Figure IIc presents a binned scatter plot of the change in total savings rates vs. changes in total compensation $\Delta w$, controlling for changes in employer pension contributions $\Delta p^{E}$. This figure confirms that the marginal propensity to save out of labor income is substantially smaller than the marginal propensity to save out of automatic employer pension contributions. As a result, automatic contributions that reduce disposable income lead to reductions in consumption and increase total saving.

In Column 3, we address potential concerns about endogenous sorting by limiting the sample to individuals who left their old firm in a mass layoff, which we define as more than $90 \%$ of workers leaving a firm that had at least 50 employees in a single year. ${ }^{18}$ By this measure, $1.8 \%$ of the

\footnotetext{
${ }^{17}$ Because early withdrawal penalties make retirement savings illiquid, individuals may seek to maintain a buffer stock in taxable accounts in an environment with uncertainty (Carroll, 1997). Since there is no exogenously defined wealth constraint in a buffer-stock model, we use $10 \%$ of income as a baseline definition of the lower corner for liquid wealth. Samwick (2003, Table 5b) calibrates a life-cycle model and shows that individuals with high discount rates maintain approximately $10 \%$ of income in non-retirement financial wealth as precautionary savings when they have access to tax-deferred retirement accounts. Our results are robust to alternative definitions of this threshold because very few individuals change taxable saving when $P^{E}$ changes. Moreover, our estimates using the interior threshold approach in Panel $\mathrm{C}$ do not rely on this assumption.

${ }^{18}$ To ensure that such mass layoffs are not simply a relabeling of the firm ID, e.g. due to a change in ownership,
} 
firm-switches occur because of mass layoffs. In this sample, we estimate pass-through of employer contribution changes to total saving of approximately 0.82 , similar to the estimate in the full sample. Since those who lost their jobs in a mass layoff are unlikely to be switching firms purely because of their pension plans, this result supports the validity of our research design.

In Column 4, we replicate the baseline specification in Column 2 for individuals who are within DKr 75,000 of the top tax cutoff, the sample we use to identify the impacts of subsidies in Table VI below. The pass-through rates of employer pensions to total saving remain very similar in this subgroup, showing that the differences we document below between the impacts of price subsidies and automatic contributions are not due to differences in sample composition.

Column 5 replicates the baseline specification in Column 2 with savings net of liabilities as the dependent variable. The pass-through estimates are virtually unchanged, implying that changes in employer pensions do not have significant effects on debt. We assess the robustness of our findings to additional measures of total saving in Appendix Table I. First, our baseline measure of net saving does not include mortgage debt. In Column 2 of Appendix Table I, we replicate the specification in Column 2, Panel A for the subsample of renters. Pass-through rates again remain similar, indicating that changes in the rate of home mortgage repayment do not drive our findings. Second, our baseline measure of savings is defined at the individual level; if individuals respond to employer pensions by changing savings in their partner's account, we would understate crowdout. In Column 3, we define total saving at the household level (summing individual savings for partners). In Column 4, we replicate the baseline specification but restrict the sample to individuals who do not have a partner. In both columns, the pass-through estimates remain similar, allaying the concern that resource pooling in couples leads us to understate crowd-out.

Long-Term Impacts. In Figure III, we investigate the persistence of the increases in saving over time. Figure IIIa replicates the regression specification in Column 2 of Table IIIA at various horizons. To simplify computation, we only include the first firm switch for each individual in the sample. Each point in this figure is the regression coefficient $\phi_{E, t}$ from a regression of the form in (4), where $\Delta p_{i}^{E}$ is measured as the change in employer pensions from the year -1 before the switch to year $t$. The first point, $\phi_{E, 0}=0.784$, corresponds to the one-year pass-through estimate to total saving shown in Column 6 of Table IIIA. The remaining points show that there is no discernible trend in pass-through over the subsequent 10 years.

we also restrict to firm closures in which no more than $50 \%$ of workers from the old firm end up at the same new firm in the next year. 
Figure IIIb shows the consequence of this persistent change in savings behavior on wealth when individuals begin to retire. This figure restricts attention to the subset of individuals whose first firm-switch occurs between ages 46-54 and who reach age 60 within our sample frame. We define total wealth accrued from the date of the switch up to age 60 as the cumulative sum of savings in retirement and non-retirement accounts. ${ }^{19}$ Figure IIIb plots total accrued wealth vs. the change in employer pensions at the time of the switch. Individuals who happened to switch to firms that had employer pension contribution rates that were 5 percent higher end up accruing additional wealth equivalent to more than $25 \%$ of annual labor income when they reach age $60{ }^{20}$ Column 7 of Table III replicates this specification and shows that it is robust to controlling for the standard vector of covariates. This is perhaps the most direct evidence that automatic employer contributions raise total saving in the long run: they substantially increase the amount of wealth with which individuals enter retirement.

\section{IV.B Government Mandatory Savings Plan}

We complement our analysis of employer pensions by studying a government policy that directly implemented automatic pension contributions by reducing individuals' earnings. In 1998, the Danish government introduced a Mandatory Savings Plan (MSP) with the goal of reducing consumption to lower the risk of an "overheating" economy (Green-Pedersen, 2007). ${ }^{21}$ The MSP took $1 \%$ of individuals' labor income and automatically allocated it to a separate retirement savings account managed by an independent pension fund. Individuals with labor incomes below DKr 34,500 (US $\$ 5,300)$ were exempted from the program in 1998 . The MSP accounts were distinct from other retirement accounts, but functioned like individual capital pension accounts when they were set up. Individuals received annual notifications of the balances in their MSP accounts as for other retirement savings accounts; see Appendix Figure I for an example.

Methodology. We analyze the impacts of the MSP on savings using a regression discontinuity design. Figure IVa illustrates the design by plotting MSP contributions in $1998\left(P_{i}^{G}\right)$ vs. labor income $\left(Y_{i}\right)$, the income base used to determine the MSP, in DKr 1,000 income bins. Individuals

\footnotetext{
${ }^{19}$ This measure of wealth accrued includes investment returns in taxable accounts (because our definition of savings in taxable accounts is computed based on changes in wealth in those accounts), but does not include investment returns in retirement accounts because we only observe flows into retirement accounts.

${ }^{20}$ The increase in accrued wealth is smaller than what one would predict based on the mean age at the point of the firm switch (51) and the $90 \%$ pass-through estimate in Figure IIIa: $(60-51) \cdot 5 \% \cdot 90=41 \%$. This is because not all individuals stay at the same firm after the initial switch, and thus the actual increase in employer contribution rates shrinks on average over time.

${ }^{21}$ The government's intention of reducing consumption is consistent with our empirical findings and suggests that policymakers implicitly viewed most individuals as passive savings-targeters.
} 
who earn just below DKr 34,500 make no contribution to the MSP; individuals who earn DKr 34,500 are forced to make a contribution of DKr 345 out of their own income. The size of the contribution then increases linearly (with a slope of $1 \%$ ) with income.

We estimate the impacts of the MSP on savings using OLS regressions of the following form:

$$
\Delta Z_{i}=\beta_{0}+\phi_{G} \cdot 345 \cdot\left[Y_{i} \geq 34,500\right]+\beta_{1} Y_{i}+\beta_{2}\left(Y_{i}-34,500\right) \cdot\left[Y_{i} \geq 34,500\right]+\beta_{X} X_{i}+\varepsilon_{i}^{G}
$$

where $\Delta Z_{i}$ denotes the change in total pension contributions or savings (measured in levels) from 1997 to $1998, Y_{i}$ denotes individual $i$ 's labor income in 1998, and $X_{i}$ denotes a vector of covariates. We estimate this regression on the sample of individuals who have labor income within DKr 25,000 of the MSP cutoff in $1998 .{ }^{22}$ We cluster standard errors by DKr 1,000 income bins to account for specification error in the control function (Card and Lee, 2008).

In $(6), \phi_{G}$ represents the pass-through of government pension contributions to saving, as identified from the discontinuous jump in the level of MSP contributions of DKr 345 at the cutoff. ${ }^{23}$ Unlike with employer pensions, there is no need to account for income effects here because the government mandate was financed by reducing the individual's disposable income by an equivalent amount. Hence, the MSP policy change corresponds exactly to the ideal experiment described above and we can identify the fraction of passive savers directly from $\phi_{G}$.

The identification assumption underlying (6) is that unobserved determinants of savings rates $\varepsilon_{i}^{G}$ evolve smoothly around the MSP eligibility cutoff. Following standard practice (e.g., Imbens and Lemieux 2008), we evaluate this assumption by first analyzing the density of the running variable (labor income) around the cutoff. Figure IVb plots a histogram of the income distribution around the eligibility cutoff. There is no evidence of manipulation of income around the cutoff, consistent with prior evidence that individuals are typically unable to sharply manipulate their wage earnings to take advantage of even much larger tax incentives (Chetty et al., 2011, 2013). We also test whether observable characteristics such as age and gender are smooth around the cutoff and find no evidence of discontinuities in these variables (not reported). These tests support the identification assumption underlying the RD design.

\footnotetext{
${ }^{22}$ Certain Ph.D. students in Denmark received a stipend of exactly DKr 48,987.50 in 1998. This creates a mass point at DKr 48,987.50 with very different demographics and savings rates in the window used to estimate the control functions for the RD design. We exclude this group of 401 observations in this section.

${ }^{23}$ One could also identify the impact of the policy from the change in the marginal propensity to save $\left(\beta_{2}-\beta_{1}\right)$ at the cutoff. This approach yields similar results; we only report estimates based on the discontinuity in levels in the interest of space.
} 
Results. We begin by analyzing whether the MSP was offset by reductions in contributions to individual or employer pension accounts. In Column 1 of Table IV, we estimate (6) with total pension contributions $\left(P_{i}=P_{i}^{I}+P_{i}^{E}+P_{i}^{G}\right)$ as the dependent variable $Z_{i}$. We condition on having positive pension contributions in the year before the MSP was implemented $\left(P_{i, 1997}^{I}+P_{i, 1997}^{E}>0\right)$ to reduce the mechanical effect of corners. In this group, $22 \%$ of individuals are at the lower corner in 1998, so the neoclassical model would predict pass-through of at most 0.22 . We estimate passthrough of mandated savings to total pensions of $\phi_{G}=0.88$, similar to the estimates obtained from the variation in employer pensions. Column 2 shows that including the control vector used in Panel B of Table III does not change this estimate significantly. Column 3 shows that using a quadratic control function instead of a linear control function for income $Y_{i}$ when estimating (6) yields similar estimates.

To obtain an estimate of pass-through that is unaffected by corners, we implement a threshold approach similar to that in Panel $\mathrm{C}$ of Table III. We first define an indicator $\theta_{i}$ for having total pension contributions $P_{i}>\bar{P}=$ DKr 1,265 , the mean level of total pension contributions for individuals within DKr 5,000 of the MSP eligibility cutoff. Figure IVc shows the fraction of individuals with $P_{i}>\bar{P}$ jumps by $3.3 \%$ at the eligibility cutoff.

To translate this impact into a measure of the degree of pass-through, we estimate the increase in the fraction above the threshold that would have occurred if no one offset the increase in the MSP. We construct this counterfactual by adding $1 \%$ of income to observed pension contributions below the cutoff to estimate what the level of pension contributions would be if the MSP were passed through 1-for-1 into $P_{i}$. We then re-estimate the linear control function below the cutoff shown by the dashed line in the figure - and calculate the size of the jump that would be predicted at the cutoff with no offset (see Online Appendix A for details). Under the binary response model in Section II, pass-through $\phi_{G}$ is the observed increase in $\theta_{i}$ at the eligibility cutoff divided by predicted increase. The resulting estimate is $\phi_{G}=84.5 \%$, as shown in Column 4 of Table IV. Intuitively, pass-through is very close to 1 because the observed increase in the fraction above the threshold in Figure IVc is similar to the predicted increase if no one were to offset the MSP.

In Column 5, we analyze the impacts of the MSP on total saving $S_{i t}^{t o t}=P_{i t}+S_{i t} /\left(1-M T R_{i t}\right)$, measured in pre-tax dollars as in Table III. We follow exactly the same methodology as in Column 4, defining the threshold based on whether total saving exceeds $S=\operatorname{DKr} 1,371$, which is the mean level of total saving for individuals within DKr 5,000 of the eligibility cutoff. This approach yields estimated pass-through of the MSP to total saving of $\phi_{G}=1.268$, with a standard error of 0.363 . 
Figure IVd presents the graphical analog of this regression, constructed in the same way as Figure IVc. Consistent with the regression estimate, the fraction of individuals above the threshold jumps at the MSP eligibility cutoff by an amount similar to what one would predict under full pass-through based on the observations below the cutoff.

In Column 6, we replicate the specification in Column 5, but exclude employer pension contributions $P_{i}^{E}$ from total saving to ensure that individuals are not forced over the threshold by employer contributions that are outside their direct control. The pass-through estimate remains high, implying that the MSP raised total saving even for individuals who could have fully offset the change themselves by reducing $P_{i}^{I}$ or $S_{i}$.

Finally, in Column 7, we replicate the specification in Column 5, defining the threshold based on whether the individual has positive net saving (gross saving net of non-mortgage debt). We continue to find substantial pass-through in this specification, although the noise in liabilities makes the estimate less precise. We assess the robustness of our estimate of $\phi_{G}$ to additional measures of total saving in Panel B of Appendix Table I. We replicate the specification in Column 5 using the same variants described above in the analysis of employer pensions. Across all the specifications, we find estimates of pass-through that are significantly above 0 and not statistically distinguishable from $100 \%$.

The RD design indicates that few individuals offset the MSP by saving less in other accounts. However, this analysis is based on the behavior of individuals around the MSP eligibility cutoff, who have very low incomes. In Online Appendix A, we analyze responses at higher income levels using a difference-in-differences (DD) design that compares changes in savings around the introduction of the MSP in 1998 and its termination in 2003 for individuals with different income levels. We find that the pass-through of MSP to total pension contributions remains high across the income distribution: few individuals act to offset the MSP by reducing voluntary pension contributions irrespective of their income levels.

Using our preferred threshold specifications, the analysis of employer pensions yields an estimate of $\widehat{\alpha}_{E}=1-93.9 \%=6.1 \%$, while the analysis of the government mandate yields an estimate of $\widehat{\alpha}_{G}=1-84.5 \%=15.5 \%$. Both designs imply that only a small group of individuals - at most about $15 \%$ - respond actively to changes in automatic contributions in our two-type model. We now turn to the impacts of price subsidies on saving and analyze whether a similar degree of active response is observed in that domain. 


\section{Impacts of Price Subsidies}

As described in Section III, there are two types of retirement savings accounts in Denmark: capital pensions (paid out as a lump sum) and annuity pensions (paid out as annuities). Starting in 1999, the deduction for capital pensions was reduced from 59 cents per DKr to 45 cents per DKR for individuals in the top income tax bracket. The top tax cutoff was DKr 251,200 (US \$38,600) in 1998, roughly the 80 th percentile of the income distribution. The deduction was unchanged for those in lower tax brackets. The tax treatment of annuity pension contributions was also unchanged. The reform did not change the tax treatment of payouts or capital gains within either account and thus had no effect on the value of existing balances.

We divide our analysis of price subsidies into three parts. First, we analyze the impacts of the 1999 reform on mean contributions to capital pension accounts. Second, we analyze the distribution of responses at the individual level to quantify the amount of active response to the subsidy change. Finally, we investigate crowd-out: how much of the change in capital pension contributions was offset by changes in contributions to other pension accounts and savings in non-retirement accounts?

\section{V.A Effect of Subsidies on Capital Pension Contributions}

Figure Va illustrates the impact of the 1999 top-bracket subsidy reduction by plotting mean capital pension contributions vs. taxable income $\left(Y_{i}^{\operatorname{tax}}\right) \cdot{ }^{24}$ We restrict the sample to workers whose taxable incomes place them within DKr 75,000 of the top income tax cutoff. To construct the figure, we first group individuals into DKr 5,000 income bins based on their current taxable income relative to the top tax cutoff, demarcated by the dashed vertical line. We then plot the mean capital pension contribution in each bin in each year from 1996 to 2001 vs. income. The relationship between income and capital pension contributions is stable from 1996 to 1998, the years before the reform. In 1999, the marginal propensity to save in capital pension accounts falls sharply for those in the top bracket: each DKr of additional income leads to a smaller increase in capital pension contributions.

We quantify the impacts of the capital pension subsidy reduction on individual capital pension contributions using two difference-in-differences estimators. The first estimator compares the level

\footnotetext{
${ }^{24}$ The income base that determines the individual's position relative to the top tax cutoff includes labor income as well as capital income if it is positive, subject to certain rules on the allocation of capital income across spouses. The mean level of $\max ($ Capital Income,0) is DKr 895 for the individuals in Figure Va and $13.8 \%$ of these individuals have positive capital income. For simplicity, we do not include capital income in our definition of $Y_{i}^{\operatorname{tax}}$, creating a small amount of misclassification around the top tax cutoff.
} 
of capital pension contributions, which we denote by $P_{i}^{I, C}$, for individuals above vs. below the top tax cutoff before vs. after the 1999 reform. The second estimator compares the marginal propensity to save (MPS) as income rises $\left(d P^{I, C} / d Y_{i}^{\operatorname{tax}}\right)$ for individuals below vs. above the top tax cutoff before vs. after the reform. Intuitively, our first estimator identifies the impacts of the subsidy change from the change in the average level of contributions for individuals above the top tax cutoff in Figure Va. The second estimator identifies the impacts of the subsidy change from the change in the slope of pension contributions with respect to income in Figure Va. We obtain similar results using both approaches for impacts on pension contributions, but the MPS estimator yields more precise estimates of impacts on taxable saving for reasons described below.

Note that Figure Va shows the impact of the reform on total capital pension contributions, including both employer and individual contributions. Because our primary goal is to characterize individuals' savings behavior, we focus exclusively on voluntary individual pension contributions in the remainder of this section. In Appendix Table II, we replicate the analysis that follows for employer pensions and show that the subsidy reduction induced employers to shift from capital to annuity pensions, leaving total employer pension contributions unchanged.

Estimator 1: Changes in the Level of Contributions. Figure Vb illustrates the levels DD estimator. For each year between 1996 and 2001, we plot mean individual capital pension contributions $P^{I, C}$ for two groups: those with current taxable incomes between DKr 25,000 to 75,000 below the top tax bracket cutoff and those with incomes between DKr 25,000 to 75,000 above the top tax bracket cutoff. The first group constitutes a "control group" in that their incentives to contribute to capital pensions remained unchanged around the 1999 reform. The second is the "treatment" group, whose incentives to contribute to capital pensions fell sharply in $1999 .{ }^{25}$ Capital pension contributions fall sharply for the treated group relative to the control group in 1999, consistent with Figure Va.

We quantify the treatment effect on pension contribution levels by estimating regressions of the following form, including all individuals in the treatment and control groups defined above:

$$
P_{i, t}^{I, C}=\beta_{0}+\beta_{1} \text { post }_{i, t}+\beta_{2} \text { treat }_{i, t}+\mu_{S}^{L} \text { post }_{i, t} \cdot \text { treat }_{i, t}+\beta_{X} X_{i, t}+\varepsilon_{i, t}
$$

where $P_{i t}^{I, C}$ denotes capital pension contributions, post ${ }_{i, t}$ denotes an indicator for the years including and after 1999, treat $i t$ is an indicator for having taxable income above the top tax cutoff $Y_{i, t}^{\operatorname{tax}}>\bar{Y}_{t}$, and $X_{i, t}$ denotes a vector of controls. We restrict the sample to the three years before and after the

\footnotetext{
${ }^{25}$ The set of individuals in these two groups varies across years due to income fluctuations.
} 
reform (1996-2001) when estimating this equation. We cluster standard errors at the DKr 5,000 income bin level to allow for correlated errors by income group over time. Under the identification assumption that unobserved determinants of pension contributions $\varepsilon_{i t}$ do not change differentially on average across the treatment and control groups around the reform, the parameter $\mu_{S}^{L}$ represents the causal effect of the subsidy reduction on the level of capital pension contributions.

Column 1 of Table $\mathrm{V}$ implements (7) without any additional controls (no $X$ vector). We estimate that the reduction of the capital pension subsidy reduced capital pension contributions by $\mu_{S}^{L}=-2,449$ relative to a pre-reform mean of DKr 5,113 for individuals with incomes DKr 25,000-75,000 above the top tax cutoff. This $48 \%$ reduction is significantly different from 0 with $p<0.001$. Column 2 of Table $\mathrm{V}$ shows that adding the standard vector of controls used in Panel $\mathrm{B}$ of Table III to this specification does not change the estimate.

Estimator 2: Changes in the Marginal Propensity to Save. Figure Vc illustrates the MPS DD estimator. To construct this figure, we first run an OLS regression of the following form for each year $t$ between 1996 and 2001 separately, including all individuals with income within DKr 75,000 of the top tax cutoff:

$$
P_{i, t}^{I, C}=\beta_{0, t}+\beta_{1, t} \text { treat }_{i, t}+\beta_{2, t} Y_{i, t}^{t a x}+\gamma_{t} Y_{i, t}^{\text {tax }} \cdot \text { treat }_{i, t}+\varepsilon_{i, t}
$$

where $P_{i t}^{I, C}$ again denotes individual capital pension contributions. The coefficient $\gamma_{t}$ measures the difference between the marginal propensity to contribute to retirement accounts for individuals above the top tax cutoff (the treatment group) versus those below the top tax cutoff (the control group) in year $t$. Figure Vc plots the coefficient estimates $\gamma_{t}$. The marginal propensity to contribute to capital pensions falls sharply after 1999 in the treatment group relative to the control group, consistent with the sharp change in slopes above the top tax cutoff in 1999 in Figure Va.

To quantify the magnitude of the change in the MPS due to the subsidy, we estimate OLS regressions of the following form, including all individuals with income within DKr 75,000 of the top tax cutoff:

$$
\begin{aligned}
P_{i t}^{I, C}= & \beta_{0}+\beta_{1} \text { post }_{i, t}+\beta_{2} \text { treat }_{i, t}+\beta_{3} \text { post }_{i, t} \cdot \text { treat }_{i, t}+ \\
& \beta_{0}^{s} Y_{i, t}^{\text {tax }}+\beta_{1}^{s} \text { post }_{i, t} \cdot Y_{i, t}^{\text {tax }}+\beta_{2}^{s} \text { treat }_{i, t} Y_{i, t}^{\text {tax }}+ \\
& \mu_{S}^{M P S} \text { post }_{i, t} \cdot \text { treat }_{i, t} \cdot Y_{i, t}^{\text {tax }}+\beta_{X} X_{i, t}+\varepsilon_{i, t}
\end{aligned}
$$

In this equation, $\mu_{S}^{M P S}$ is a DD estimate of the impact of the subsidy reduction on the the marginal propensity to save (MPS) in capital pensions. In particular, $\mu_{S}^{M P S}$ is the change in 
$d P_{i, t}^{I, C} / d Y_{i, t}^{t a x}$ for individuals in the top bracket relative to those below the top bracket when the capital pension subsidy is removed in 1999. We again restrict the sample to the three years before and after the reform (1996-2001) and cluster standard errors at the DKr 5,000 income bin by year level to allow for correlated errors by income group over time. Under the identification assumption that unobserved determinants of the MPS $\operatorname{Cov}\left(\varepsilon_{i, t}, Y_{i, t}^{\operatorname{tax}}\right)$ do not change differentially across the treatment and control groups around the reform, the parameter $\mu_{S}^{M P S}$ represents the causal effect of the subsidy reduction on the marginal propensity to save in capital pension accounts.

We implement (9) in Column 3 of Table V. The null hypothesis that the change in the subsidy had no impact on the MPS in capital pension accounts is rejected with $p<0.001$. The coefficient of $\mu_{S}^{M P S}=-0.021$ implies that a DKr 1,000 increase in income led to DKr 21 of additional saving in capital pensions when the additional 13.6 cent subsidy was in place before 1999. The MPS in the treatment group prior to the policy change was $\beta_{0}^{s}+\beta_{2}^{s}=0.019+0.0058=0.025$. The subsidy reduction thus reduced the marginal propensity to save in capital pensions by $0.021 / 0.025=84 \%$. Again, adding controls does not affect this estimate (Column 4).

\section{V.B Estimating the Degree of Active Response}

The aggregate reduction in individual capital pension contributions masks substantial heterogeneity in responses across individuals. Figure VIa plots the distribution of changes to individual capital pension contributions (as a fraction of lagged contributions) for those in the treatment group in Figure $\mathrm{Vb}$ who were contributing to capital pensions in the prior year. We plot the distribution of changes in contributions from 1998 to 1999, the year of the treatment, as well as from 1997 to 1998 as a counterfactual. The difference between the two distributions shows that a substantial fraction of individuals exited capital pensions completely when the subsidy was reduced, i.e. they reduced contributions by $100 \%$. The reform also reduced the fraction of individuals who leave their contributions unchanged across years.

Figure VIb replicates Figure VIa for the control group (individuals DKr 25-75K below the top tax cutoff). The distributions of changes are virtually identical in 1998 and 1999 for individuals who were unaffected by the 1999 tax reform, supporting the view that the difference between the distributions in Figure VIa reflects the causal impact of the subsidy reduction.

We use the distributions in Figure VIa to estimate the fraction of individuals who deliberately reoptimize their pension contributions in response to the 1999 subsidy reduction. To begin, note that $26.1 \%$ of the individuals in the treatment group in Figure VIa leave their capital pension 
contributions literally unchanged in $1999 .^{26}$ As discussed in Section II, every active saver should cut capital pension contributions by some non-zero amount at an interior optimum. Hence, at least $26.1 \%$ of individuals respond passively to the subsidy change. This estimate provides a lower bound on the fraction of passive savers with respect to incentives $\left(1-\widehat{\alpha}_{S}\right)$ because the changes in retirement account contributions made by the remaining $74 \%$ of individuals are not necessarily driven by reoptimization in response to the subsidy change. ${ }^{27}$

To go beyond the upper bound of $\widehat{\alpha}_{S}<74 \%$ and obtain a point estimate of $\widehat{\alpha}_{S}$, we first estimate the impact of the subsidy on the fraction of individuals who leave their capital pension contributions unchanged relative to the previous year $\left(P_{i, t}^{I, C}=P_{i, t-1}^{I, C}\right)$. We estimate this impact using the DD equation in (7) with the dependent variable as an indicator for having $P_{i, t}^{I, C}=P_{i, t-1}^{I, C}$. We restrict the sample to individuals contributing to capital pensions in the prior year $(t-1)$ and to $t \in\{1998,1999\}$, the years shown in Figure VI. Column 5 of Table V shows that the fraction of individuals who leave their capital pension contributions unchanged relative to the previous year falls by 3.3 percentage points when the subsidy is reduced in 1999. In 1998, $29.2 \%$ of individuals in the treatment group did not change their capital pensions at all relative to their 1997 levels. It follows that an additional 3.3/29.2 = 11.3\% respond actively to the subsidy change among those who would not have changed their pensions at all absent the reform.

The $11.3 \%$ figure can be interpreted as an estimate of $\widehat{\alpha}_{S}$ among the subgroup of individuals who do not actively change their pensions for non-tax reasons in 1998. One might expect that the fraction who respond to the subsidy will be larger among those who reoptimize their portfolios for other reasons, a conjecture that we confirm empirically in Section VI below. To estimate $\widehat{\alpha}_{S}$ in the full sample, we must measure the rate of active response among the average individual relative to those who did not change their pension contributions in 1998. To do so, we develop a marker for individuals who are almost certainly responding to the reform: those who exit capital pensions and raise annuity pension contributions (the closest substitute) at the same time. Only $1.2 \%$ of individuals change pensions in this way in the control group in 1999 and the treatment group in 1998. In contrast, in the treatment group after the reform in 1999, $13.5 \%$ of individuals exit capital pensions and raise annuities at the same time. Hence, this measure of "extensive margin substitution" identifies active responders with a very low Type-I (false positive) error rate.

\footnotetext{
${ }^{26}$ This figure is lower than the $43.0 \%$ at 0 in 1999 in the histogram in Figure VIa because the 0 bin in the histogram includes those with changes between $0 \%$ and $5 \%$.

${ }^{27}$ For example, $4 \%$ of individuals in the treatment group have an increase of exactly DKr 900 in 1998 and 1999 , which is the change in the nominal cap on capital pension contribution between 1997 and 1998. These individuals appear to follow a systematic rule of maximizing capital pension contributions each year.
} 
However, this measure may have a large Type-II error rate, as individuals can respond without exiting capital pensions entirely or raising annuities.

We exploit the low Type-I error rate in this marker of active response to identify the relative rate of response in the full sample compared with those who do not adjust their pensions in prior years. Using the same DD specification as in Column 5 of Table V, Column 6 shows that the subsidy change increased the rate of extensive margin (capital to annuity) substitution by 11.6 percentage points on average among treated individuals. Column 7 of Table V replicates this specification for the subset of individuals who did not change their pensions in the previous year $\left(P_{i, t}^{I, C}=P_{i, t-1}^{I, C}\right)$. As predicted, the degree of active response is smaller in this subgroup: $6.8 \%$ of those who kept capital pension contributions fixed between 1997 and 1998 exit capital pensions and raise annuities in 1999. Finally, under the assumption that the rate of extensive margin substitution response is proportional to the overall latent rate of active response to the subsidy, we estimate the fraction of individuals who respond actively to the change in subsidy as $\widehat{\alpha}_{S}=11.3 \times \frac{11.6}{6.8}=19.3 \%$. That is, the aggregate reduction in individual capital pension contributions from 1998 to 1999 shown in Figure Vb is accounted for by just $19.3 \%$ of individuals who actively reoptimize in response to the subsidy reduction.

The vast majority of these $19.3 \%$ of individuals respond by completely exiting capital pensions. Using the DD specification in (7), in Column 8 of Table $\mathrm{V}$ we estimate that $15.9 \%$ of individuals exit capital pensions because of the reform. Hence, only a small portion of the response occurs on the intensive margin: most individuals either recognize the subsidy change and stop contributing to capital pensions entirely or do nothing at all. The response to price subsidies may be concentrated on the extensive margin because gains from reoptimization are second-order (i.e., small) on the intensive margin but first-order (large) on the extensive margin (Chetty, 2012).

One natural question is whether the fraction of individuals who respond to the subsidy $\left(\widehat{\alpha}_{S}\right)$ rises over time. We study the dynamics of response at the individual level in Figure VIc, which plots the fraction of individuals contributing to capital pensions by year for those who were contributing in 1998, the year before the reform. To construct this figure, we first compute the difference in the fraction of individuals contributing to capital pensions in the treatment (above top tax cutoff) and control (below top tax cutoff) groups to remove secular trends due to mean reversion when selecting on contribution in 1998. We then plot one plus this difference to show the causal impact of the reform over time on the fraction of individuals contributing to capital pensions. As with the response to changes in employer pensions in Figure IIIa, there is very little adjustment over time: 
8.7\% of individuals exit immediately in 1999 and an additional $4.2 \%$ exit in 2000, leaving $87.1 \%$ still contributing one year after the reform. Ten years later, the fraction contributing remains at $81.5 \%$.

\section{V.C Crowd-out in Retirement and Taxable Savings Accounts}

When active savers reduce capital pension contributions following the 1999 reform, what do they do with this money? We estimate two crowd-out parameters, each of which is relevant for different policy questions: the degree of shifting between different types of retirement accounts and the degree of shifting from retirement accounts to taxable accounts. Again, we restrict attention to the impacts of changes in individual pension contributions rather than employer contributions. ${ }^{28}$ We follow the same methodology as above, estimating the impacts of the subsidy change in other accounts using two estimators: one based on levels of contributions and another based on the marginal propensity to save.

Crowd-out Within Retirement Accounts. We first estimate the extent to which individuals shift assets from capital pensions to annuity pensions when the subsidy for capital pensions was reduced in 1999. This parameter is relevant for assessing the impacts of changes in the tax treatment of one type of retirement account - such as increasing 401(k) subsidies - while leaving the treatment of other retirement accounts (such as IRA's) unchanged.

We begin by using the levels estimator to identify the impacts of the 1999 reform on contributions to annuity pension accounts. Figure VIIa plots the time series of individual annuity contributions for the treatment (income DKr 25K-75K above the top tax cutoff) and control (DKr 25-75K below the cutoff) groups, as in Figure Vb. The pattern is the mirror image of that in Figure Vb. There is a sharp increase in annuity pension contributions for the treated group in 1999, showing that some of the reduction in capital pension contributions is offset by increased annuity pension contributions.

To quantify the degree of crowd-out, we estimate IV regressions that use the DD levels equation in (7) as a first stage for capital pension contributions. The second stage is specified as:

$$
Z_{i, t}=\beta_{0}+\beta_{1} \text { post }_{i, t}+\beta_{2} \text { treat }_{i, t}+\phi_{S}^{L} P_{i, t}^{I, C}+\beta_{X} X+\varepsilon_{i, t}
$$

where $Z_{i, t}$ denotes a measure of individual pension contributions and $P_{i, t}^{I, C}$ is individual $i$ 's contribution to the capital pension in year $t$. We instrument for $P_{i, t}^{I, C}$ using the interaction post ${ }_{i, t} \cdot$ treat $_{i, t}$

\footnotetext{
${ }^{28}$ We are able to ignore employer contributions when estimating crowd-out of individual pensions because the reduction in employer capital pension contributions is fully offset by increases in employer annuity pension contributions, leaving total employer contributions unchanged, as shown in Appendix Table II.
} 
to isolate changes in capital pension contributions that are induced by the subsidy change. The coefficient $\phi_{S}^{L}$ identifies the crowd-out parameter of interest under the assumption that unobserved determinants of the level of annuity pension contributions do not change differentially on average in the treatment and control groups. This 2SLS coefficient is simply the treatment effect on annuity contributions (the reduced form) - which can be estimated using a DD specification analogous to (7) - divided by the treatment effect on capital pensions $\phi_{S}^{L}$ (the first stage). As above, we cluster standard errors at the DKr 5,000 income bin level.

Table VI presents estimates of (10). In Column 1, we use individual annuity pension contributions as the dependent variable and obtain an estimate of $\phi_{S}^{L}=-0.57$. That is, individuals shift 57 cents of each DKr they would have contributed to capital pension accounts to annuity pensions instead. In Column 2, we use total pensions as the dependent variable. This specification confirms that pass-through to total pensions is $100-57=43$ cents per DKr of capital pension contributions. Column 3 shows that the inclusion of the standard vector of controls does not change this estimate significantly.

One can also estimate crowd-out using changes in the MPS in annuity accounts instead of mean contribution levels. The series in circles in Figure VIIb plots the difference in the MPS in annuity accounts for individuals above vs. below the top tax cutoff by year. This series is constructed in exactly the same way as Figure Vc, using individual annuity pension contributions instead of capital pension contributions as the dependent variable in (8). The change in the MPS in capital accounts is replicated in this figure (in triangles) as a reference to interpret magnitudes. The reduction in the capital pension subsidy in 1999 leads to a sharp increase in the marginal propensity to save in annuity accounts, again consistent with shifting across accounts.

To quantify the degree of crowd-out using the change in the MPS, we again estimate IV regressions, this time using the DD in MPS equation in (9) as the first stage for capital pension contributions. Here, the second stage is specified as:

$$
\begin{aligned}
Z_{i t}= & \beta_{0}+\beta_{1} \text { post }_{i, t}+\beta_{2} \text { treat }_{i, t}+\beta_{3} \text { post }_{i, t} \cdot \text { treat }_{i, t}+ \\
& \beta_{0}^{s} Y_{i, t}^{t a x}+\beta_{1}^{s} \text { post }_{i, t} \cdot Y_{i, t}^{\text {tax }}+\beta_{2}^{s} \text { treat }_{i, t} \cdot Y_{i, t}^{t a x}+ \\
& \phi_{s}^{M P S} P_{i, t}^{I, C}+\beta_{X} X_{i, t}+\varepsilon_{i, t}
\end{aligned}
$$

We instrument for $P_{i t}^{I, C}$ using the interaction post $_{i, t} \cdot$ treat $_{i, t} \cdot Y_{i, t}^{\text {tax }}$ to isolate changes in the MPS in capital pensions induced by the subsidy change. This 2 SLS coefficient $\phi_{S}^{M P S}$ corresponds to the treatment effect on the MPS in annuity accounts (the reduced form) - which can be estimated 
using a DD specification analogous to (9) - divided by the treatment effect on the MPS in capital pensions $\phi_{S}^{M P S}$ (the first stage). We cluster standard errors at the DKr 5,000 income bin level as above.

Columns 4-6 of Table VI report 2SLS estimates of crowd-out for the same dependent variables used in Columns 1-3 using the MPS specification in (11). Consistent with the results of the levels specification, we find that the reduction in capital pension contributions was partially offset by increased contributions to annuity pensions. The specification without controls in Column 4 yields an estimate of $\phi_{S}^{M P S}=-0.47$, implying that individuals shift 47 cents of each DKr they would have contributed to capital pension accounts to annuity pensions.

Crowd-out of Taxable Saving. Next, we analyze whether the changes in pension contributions documented above are offset by changes in saving in taxable (non-retirement) accounts, which has been the focus of the prior literature on crowd-out. The degree of shifting between retirement accounts and taxable saving is of interest because it determines how subsidies that apply to all tax-deferred accounts affect total wealth accumulation. We use the change in the capital pension subsidy as an instrument for total pension contributions $P^{I}$ to estimate crowd-out in non-retirement accounts.

As discussed above, when analyzing shifting between retirement accounts and taxable accounts, one must account for the difference in the tax treatment of the two forms of saving. The literature on crowd-out has addressed this issue by measuring crowd-out in taxable accounts in two ways. One definition, used e.g. by Poterba, Venti and Wise (1996), is $\rho_{1}=\frac{d S}{d P^{I}}$, the fraction of retirement account balances that come from reduced taxable saving. This definition includes the subsidy from the government to the individual in the denominator and is bounded in magnitude between 0 and 1-MTR if individuals do not offset $\$ 1$ of post-tax pension contributions by more than $\$ 1$ of taxable saving. An alternative definition, used e.g. by Engen, Gale and Scholz (1996), is $\rho_{2}=\frac{d S}{d P^{I} \times(1-M T R)}$, the fraction of retirement account contributions net of the government subsidy that come from taxable saving. The first definition is the relevant concept for determining what fraction of retirement balances are "new" savings from the individual's perspective. The latter definition is the relevant concept for determining the increase in total national savings, as the subsidy itself is a transfer from the government to individuals that does not affect consumption or total national savings. ${ }^{29}$ We report estimates of $\rho_{2}$ here by measuring taxable saving in pre-tax

\footnotetext{
${ }^{29}$ The latter definition also corresponds to our definition of total saving $S^{t o t}$ above: a 1 DKr increase in $P^{I}$ raises $S^{t o t}$ by $1+\rho_{2}$. If the subsidy does not affect the individual's consumption, $\rho_{2}=-1$ and hence the change in $S^{t o t}=0$.
} 
dollars $\left(S_{i, t} /(1-M T R)\right)$, where $M T R=60 \%$ denotes the marginal income tax rate in the top tax bracket. One can calculate $\rho_{1}$ by multiplying the crowd-out estimates we report by 0.4 .

We can estimate crowd-out in taxable saving accounts using IV regressions paralleling those in (10) and (11) above, replacing the endogenous variable $P_{i, t}^{I, C}$ with total individual pension contributions $P_{i, t}^{I}$ and the dependent variable with taxable saving $S_{i, t} /(1-M T R)$. The levels specification in (10) yields very imprecise estimates of crowd-out in taxable savings - rejecting neither full crowdout nor zero crowd-out - because the MPS in taxable accounts fluctuates substantially across years (see Online Appendix B for details). We therefore focus on the MPS estimator for the remainder of this section.

Figure VIIIa illustrates the estimation of crowd-out in taxable accounts using changes in the MPS. This figure plots the difference in the marginal propensity to save in retirement accounts and taxable accounts for individuals above vs. below the top tax cutoff. We construct these series as in Figure VIIb, using total pension contributions $\left(P^{I}\right)$ and taxable saving $\left(S_{i, t} /(1-M T R)\right)$ as the dependent variables in (8). When the subsidy is reduced in 1999, the MPS in retirement accounts falls sharply for individuals in the top tax bracket (the treatment group) relative to individuals below the top bracket (the control group). The MPS in taxable accounts jumps in the treatment group relative to the control group by almost the same amount. Hence, individuals appear to have simply shifted the money they were saving in retirement accounts into taxable saving accounts when the retirement savings subsidy was cut in 1999.

To quantify the degree of crowd-out in taxable saving, we use the 2SLS specification as in (11), using taxable saving as the dependent variable and total pension contributions $P_{i}^{I}$ as the endogenous variable. We obtain an estimate of $\rho_{2}=-1.2$ using this specification, as shown in Column 1 of Table VII. ${ }^{30}$ Although we reject the hypothesis of zero crowd-out with $p=0.05$, the $95 \%$ confidence interval for the crowd-out estimate is wide, spanning $(-2.40,0)$. This imprecision is because the distribution of taxable saving has large outliers.

We use two approaches to obtain more precise estimates. First, we trim extreme values. In Column 2 of Table VII, we replicate the specification in Column 1, recoding taxable saving values in the top decile to the 90 th percentile and values in the bottom decile to the 10th percentile. We obtain a point estimate of $\rho_{2}=-0.98$, implying that 98 cents of each DKr 1 withdrawn from retirement savings accounts is shifted to taxable savings accounts. The standard error of the

\footnotetext{
${ }^{30}$ Crowd-out can in principle exceed $100 \%$ in neoclassical models because of wealth effects (Gale, 1998); intuitively, individuals may choose to save less when offered a pension subsidy if they are targeting a fixed level of wealth in retirement.
} 
crowd-out estimate in this specification is 0.267 , less than half that of the untrimmed estimate.

An alternative method of improving precision is to analyze medians instead of means, as in Engen et al. (1994) and Poterba et al. (1995). We first characterize the reduced-form impact of the subsidy reduction on median taxable saving and then translate this reduced-form impact to a crowd-out estimate. Figure VIIIb illustrates the impact of the subsidy on median savings levels in taxable accounts. This figure shows the difference in the median level of taxable saving within each DKr 5,000 income bin around the top tax cutoff in the 3 years after the reform (1999-2001) relative to the three years before the reform (1996-1998). The sharp increase in the slope of this series at the top tax cutoff implies that the MPS in taxable accounts increased for the treated group relative to the control after the subsidy was reduced in 1999.

To estimate the magnitude of the change in the MPS in Figure VIIIb, one would ideally estimate a quantile regression using the reduced-form specification in (9). Unfortunately, estimating a quantile regression with 7 million observations proved to be infeasible. As a computationally tractable alternative, we follow Chamberlain (1994) and use a least-squares approximation to the conditional quantile function. We calculate the median level of taxable saving within each DKr 5,000 income bin around the top tax cutoff in each year from 1996-2001. Using the binned dataset of medians, we then estimate (9) using OLS with the median level of taxable saving in each year by income bin as the dependent variable, weighting by the number of observations in each bin. This approach is analogous to running an OLS regression using the binned data in Figure VIIIb rather than on the microdata, with standard errors clustered by bin.

Column 3 of Table VII shows that the reduced-form coefficient obtained from this approach is 0.010 , i.e. the subsidy reduction increased the MPS in median taxable saving by $1 \%$ of income. The magnitude of this change is similar to the reduction in the MPS in retirement accounts of -0.012 , suggesting that much of the reduction in retirement saving was offset by increased saving in taxable accounts. We confirm this finding in Column 4 by replicating Column 3 using median total individual saving $S_{i, t}^{I, t o t}=S_{i, t} /(1-M T R)+P_{i, t}^{I}$ as the dependent variable. The reduced-form change in the MPS in median total saving is 0.0003 (s.e. $=0.0030$ ), showing that the subsidy reduction induced little or no change in median total savings rates.

To quantify the degree of crowd-out implied by the reduced-form change in median taxable saving, one would ideally estimate (11) using a quantile instrumental variables specification. As a computationally tractable alternative, we use a threshold approach that can be implemented using OLS. We measure crowd-out based on the extent to which individuals cross the median level of 
taxable saving relative to the number who would cross this threshold if they were to fully offset the mean change in pension contributions. Let $\bar{S}=\operatorname{DKr} 1,062$ denote the median level of taxable saving for individuals in the top tax bracket and $\theta_{i}$ denote an indicator for having taxable saving above this cutoff. Based on the density of the taxable saving distribution around this threshold, the fraction with above-median savings would increase by 1.84 percentage points if a DKr 1,000 reduction in pension contributions were entirely offset by increasing taxable saving. We estimate the actual impact using the 2SLS specification in (11), with $\theta_{i}$ as the dependent variable. The resulting estimate implies that a DKr 1,000 increase in pension contributions reduces the number of individuals with above-median taxable savings by 1.83 percentage points. The ratio of the actual change to the predicted change $(-0.994)$ is the threshold-based estimate of crowd-out $\rho_{2}$ reported in Column 5 of Table VII. ${ }^{31}$ The confidence interval for this estimate is $(-1.47,-0.52)$.

Column 6 of Table VII shows that the threshold-based crowd-out estimate remains similar when we include the standard control vector used above. In Column 7, we replicate the specification in Column 5 using taxable saving net of changes in liabilities as the dependent variable. The point estimate is consistent with substantial crowd-out, but the confidence interval is wider because of the substantial fluctuation in debt holding across years. ${ }^{32}$ We assess the robustness of the crowdout estimates to additional definitions of taxable saving in Panel C of Appendix Table I. Column 2 replicates the threshold specification in Column 5 for renters. Column 3 defines taxable saving at the household level and Column 4 restricts the sample to single individuals. Across all specifications, we find estimates of crowd-out that are significantly different from 0 but not from the baseline estimates of crowd-out close to $100 \%$.

In summary, once we reduce the influence of outliers, we obtain point estimates of crowdout exceeding $90 \%$ and a lower bound on the $95 \%$ confidence interval of approximately $50 \%$. As a robustness check on the precision of these estimates, we conduct permutation tests in Online

\footnotetext{
${ }^{31}$ This approach yields a consistent estimate of crowd-out under two assumptions: (1) the impact of the subsidy reduction on the MPS in retirement accounts does not vary across the distribution of taxable saving and (2) the degree of crowd-out $\rho_{2}$ does not vary with taxable savings locally around the median. The second assumption is a regularity condition which requires that mean crowd-out rates do not vary with the distance to the threshold $(\bar{S})$ for individuals who would cross the threshold if they were to fully offset the change in pension contributions. The first assumption is a substantive restriction that allows us to use the mean treatment effect on pension contributions to predict the degree of offset one would expect under $100 \%$ crowd-out around the median level of taxable saving. Although this is a strong assumption, we note that the estimates of crowd-out in Columns 1 and 2 , which are based on comparisons of means, do not rely on this assumption. Hence, this estimate complements the estimates obtained using other approaches.

${ }^{32}$ In order for the subsidy to have an impact on net saving despite having no effect on gross saving, active savers would have to shift money from taxable savings accounts to retirement accounts when subsidies rise and then reduce debt holding. There is no reason to expect such behavior in existing neoclassical or behavioral models, supporting the view that the subsidy has little impact on net saving.
} 
Appendix B. We choose placebo values for the top income tax cutoff and the year of the reform and re-estimate the baseline specifications in Columns 2 and 6 using these placebo values. The p values obtained from the permutation test (i.e., based on the empirical CDF of the placebo distribution) are closely aligned with the p values based on our standard errors clustered by DKr 5,000 income bin. Moreover, the t-statistic for the actual treatment in Column 6 is smaller than all 309 placebo t statistics, confirming that the subsidy reduction increased taxable saving significantly.

Note that even after accounting for outliers, our estimates of the impact of automatic contributions on total saving in Table III remain an order of magnitude more precise than the estimated impacts of the subsidy. The reason is that automatic contributions vary differentially across individuals over time, whereas the subsidy varies only at the aggregate level across broad income groups in a single year. Because fluctuations in taxable saving are correlated across individuals due to aggregate shocks, research designs that exploit individual-level variation yield greater precision. Using such variation to estimate the impacts of subsidies on total saving (e.g. via firm matches) would be a valuable direction for future work.

\section{V.D Impacts of Tax Expenditures on Total Saving}

We now use the preceding estimates to calculate the savings impact of each DKr of government expenditure on subsidies for retirement savings. This "bang-for-the-buck" measure can be directly compared to the marginal cost of public funds or the benefits of other government expenditures.

First, based on the estimates in Column 1 of Table V and Column 5 of Table VI, the 1999 subsidy reduction resulted in a DKr $2,449 \times 0.529=1,295$ reduction in total pension contributions among treated individuals, raising post-tax disposable income by DKr $1,295 \times(1-0.6)=518$. The estimate in Column 5 of Table VII implies that taxable saving rose by DKr $0.994 \times 518=515$ as a result, so that the net reduction in post-tax savings due to the subsidy change was DKr 3 .

We estimate that the 1999 subsidy reduction raised the present value of government revenue by DKr 883 on average across individuals in the treatment group, taking into account the impacts of deferred taxation and differential treatment of capital gains in retirement accounts (see Online Appendix C). The capital pension subsidy reduction therefore reduced total saving by $3 / 883$, less than 1 cent per DKr reduction in tax expenditure on the subsidy. At the upper bound of the $95 \%$ confidence interval for the crowd-out estimate in Column 2, we obtain an estimate of 28 cents of savings per DKr of tax expenditure on the subsidy. If we include the fiscal cost of the subsidy for employer pensions, which as we show in Appendix Table II has no effect on total employer pension 
contributions, the point estimate remains below 1 cent per DKr of tax expenditure and the upper bound of the $95 \%$ confidence interval is 10 cents. The subsidy has small impacts on total saving because (1) it is an infra-marginal transfer that has no impact on the behavior of passive savers and (2) the active savers who respond to the subsidy exhibit a low interest elasticity of saving.

The preceding analysis considers only the direct impacts of subsidies on individual saving. Subsidies could potentially raise total saving indirectly by increasing the efficacy of automatic contributions by employers or the government. For instance, individuals might be less likely to undo defaults when large subsidies make the default attractive. To evaluate this possibility, we test whether pass-through rates of employer pensions to total pensions fall after the 1999 subsidy reduction for individuals in the top tax bracket. Using the specification in Column 1 of Table IIIa for individuals in the top tax bracket, we find a pass-through rate of 0.826 (s.e. $=0.005$ ) when limiting the sample to $1996-1998$ vs 0.885 (s.e. $=0.004$ ) when limiting the sample to 1999-2001. Hence, the size of the subsidy appears to have little effect on the impact of automatic contributions in practice.

\section{Heterogeneity: Identifying Active and Passive Savers}

In this section, we test whether the differences between the impacts of automatic contributions and subsidies are driven by active vs. passive choice by studying the heterogeneity of responses across individuals. We organize our analysis around the three testable predictions on heterogeneity described in Section II.B.

First, we test whether individuals currently making active choices are more responsive to price subsidies. We proxy for active choice by focusing on individuals who are starting a new pension account. Define "new contributors" in year $t$ as those who contribute to either individual annuity or capital pensions in year $t\left(P_{i, t}^{I}>0\right)$ but did not contribute to either account in year $t-1$ $\left(P_{i, t-1}^{I}=0\right)$. Conversely, define prior contributors as individuals who contribute in year $t\left(P_{i, t}^{I}>0\right)$ and were already contributing to an individual pension account in year $t-1$. Are new contributors more sensitive to the change in the relative subsidy for capital vs. annuity pensions in 1999? To answer this question, we regress an indicator for contributing to capital pensions $\left(P_{i, t}^{I, C}>0\right)$ on an indicator for the 1999 reform, an indicator for being a new pension contributor, and the interaction of the two indicators. We limit the sample to individuals whose taxable incomes are between DKr 25,000 and 75,000 above the top tax cutoff, the treatment group in Figure Vb, and use data from 1998 and 1999. The estimates are reported in Column 1 of Table VIII. The reduction in the subsidy 
for capital pensions reduces the probability of contributing to the capital pension by 15 percentage points for prior contributors. For new contributors, the impact is an additional 23 percentage points. These estimates are not sensitive to the inclusion of controls, as shown in Column 2 of Table VIII.

Second, we test for differences in responsiveness across individuals by correlating the response to the 1999 subsidy reduction with the frequency of changes in pension contributions in other years. We identify individuals who responded to the 1999 subsidy change using the sharp indicator of response developed in Section V.A: exiting capital pensions and increasing annuity contributions. In Column 3 of Table VIII, we regress this indicator for extensive margin substitution in 1999 on the fraction of other years in which the individual changes his pension contributions, restricting the sample to the treatment group in 1999 (see Online Appendix Figure VIa for the corresponding non-parametric binned scatter plot). We find a highly significant positive relationship: roughly $20 \%$ of individuals who adjust their pensions in every year respond to the 1999 reform by exiting capital pensions and raising annuities, compared with less than $5 \%$ of individuals who never adjusted their pensions in other years. Column 4 shows that this result is robust to controls.

Next, we test if frequent reoptimizers are also more likely to offset automatic employer contributions $P_{i, t}^{E}$ by reducing their individual pension contributions $P_{i, t}^{I}$. In Column 5 of Table VIII, we replicate the specification in Column 1 of Table IIIa, interacting the change in employer pensions $\Delta p_{i}^{E}$ and total compensation $\Delta w_{i}$ with the fraction of other years in which the individual changes his pension contributions. The coefficient on the interaction effect of -0.096 implies that the passthrough rate from employer pensions to total pensions is 9.6 percentage points lower for individuals who reoptimize their pension contributions every year relative to those who never change their contributions. ${ }^{33}$ Column 6 verifies that this result is again robust to the inclusion of controls. Together, the results in Table VIII support the view that automatic contributions have larger effects on total wealth than price subsidies because they change the total savings rates of passive rather than active savers.

Finally, we study the observable characteristics of active and passive savers in Table IX. In

\footnotetext{
${ }^{33}$ See Online Appendix Figure VIb for a non-parametric graphical analog to this regression. There are two explanations for why pass-through rates remain relatively high even for individuals who reoptimize very frequently. First, the frequency of changes in pension contributions is a noisy proxy for active response. Even among those who change contributions in every other year, the rate of active response to the subsidy change is only about $20 \%$ (Online Appendix Figure VIa). This suggests that the degree of crowd-out among active savers could be up to 40 percentage points larger than passive savers. Another explanation is that those who respond actively to subsidy changes may still be passive with respect to employer pensions. For instance, tax advisers frequently advertise subsidies for retirement contributions but information about employer pension contributions may be less salient.
} 
Panel A, we regress the indicator for exiting capital pensions and raising annuities in 1999 on various observable characteristics. In this panel, we limit the sample to prior capital pension contributors who were in the treatment group in 1999. In Panel B, we include all individuals in our firm switchers sample who were not at a corner prior to the switch (as in Table IIIA) and regress the change in total savings rate on the change in employer pensions and the change in total compensation at the time of the firm switch, both interacted with the characteristics analyzed in each column.

Column 1 of Table IX shows that individuals with higher wealth/income ratios - total financial assets in non-retirement accounts divided by labor income in the prior year - are more responsive to the subsidy change and have lower pass-through rates of employer pensions to total saving. The probability of response to the subsidy change is roughly twice as large for those who have liquid assets equal to or more than their annual income relative to individuals with little or no wealth (Online Appendix Figure VIIa). The pass-through of employer pensions to total saving is close to 0 for those with wealth in the top $5 \%$ of the distribution (Online Appendix Figure VIIb). Column 2 shows that these results are robust to including the standard vector of controls.

Column 3 shows that older individuals are more responsive to the change in the subsidy and are more likely to offset changes in employer pensions. These patterns are consistent with recent evidence that older individuals make financial decisions more actively (Agarwal et al., 2009).

Columns 4 and 5 assess heterogeneity by education. Column 4 shows that individuals with a college education are 4.6 percentage points more responsive to the change in price subsidies. Column 5 shows that individuals who majored in economics, accounting, or finance in their terminal degree are 5.2 percentage points more likely to respond to the subsidy change than those with other college degrees. While we cannot determine whether this effect is caused by learning economics or the sorting of active savers to such courses, the correlation supports the view that active response to financial incentives is correlated with financial sophistication and literacy (Lusardi and Mitchell, 2007; Gale, 1998; Bernheim and Scholz, 1993). However, we find little systematic relationship between education and pass-through rates from employer pensions to total savings, suggesting that even well informed individuals may not be attentive to automatic changes in pension contributions.

Finally, in Column 6, we replicate Column 5 and include gender, marital status, and two-digit occupation indicators. The heterogeneity of treatment effects remains similar when we include these additional controls. ${ }^{34}$ Overall, the results in Table IX indicate that price subsidies tend to

\footnotetext{
${ }^{34}$ We do not control for wealth because wealth is endogenous to education and age.
} 
affect individuals who are already planning for retirement, while automatic contributions increase saving more amongst those who are less prepared for retirement.

\section{Conclusion}

Our analysis shows that price subsidies are less effective than automatic contributions in increasing savings rates for three reasons. First, approximately $85 \%$ of individuals are passive individuals who save more when induced to do so by an automatic contribution but do not respond at all to price subsidies. As a result, much of the subsidy is an inframarginal transfer to pension contributors that induces little change in behavior at the margin. Second, individuals who respond do so primarily by shifting savings across accounts rather than raising the total amount they save. Third, the active savers who respond to price subsidies tend to be those who are planning and saving for retirement already. Hence, price subsidies are not effective in increasing savings amongst those who are least prepared for retirement. In contrast, automatic contribution policies that influence the behavior of passive savers have lower fiscal costs, generate relatively little crowd-out, and have the largest impacts on individuals who are paying the least attention to saving for retirement.

It is natural to ask whether these conclusions apply to other economies, such as the United States. Prior research has shown that individuals in the U.S. exhibit similar patterns of active and passive choice within retirement accounts, where high-quality data are available in both Denmark and the U.S. In particular, studies using U.S. data have also found that automatic employer contributions raise total pension balances (Madrian and Shea, 2001; Card and Ransom, 2011), subsidies induce relatively few individuals to contribute to retirement accounts (Duflo et al., 2006; Engelhardt and Kumar, 2007), and higher socio-economic status households are more likely to change pension defaults (Beshears et al., 2012). The similarity of behavior within retirement accounts between the U.S. and Denmark suggests that the qualitative lessons on crowd-out in taxable savings accounts from the Danish data are likely to apply to the U.S. However, there is no substitute for directly studying the economy of interest empirically and further research on crowd-out using administrative data on savings in the U.S. and other countries would be very valuable.

Our results also raise several other questions for further research. We have provided a positive

analysis of the impacts of retirement savings policies on total saving, but have not compared the welfare consequences of these policies. Such a normative analysis would be a natural next step in understanding the optimal design of retirement savings policies. Beyond retirement savings, a broader implication of our empirical results is that changing quantities directly through defaults 
or regulation may be more effective than providing price incentives to change behaviors such as the consumption of sin goods or the use of preventive healthcare. Because incentives require active reoptimization, they may be less cost-effective and may end up missing the least attentive individuals whose behavior one might want to change most. Comparing price and quantity policies in models where agents make optimization errors is an interesting direction for future research.

Although further work is needed to evaluate the generality of our results and their normative implications, the findings in this study call into question whether subsidies for retirement accounts and reductions in capital income taxation are the best way to increase savings rates. Our findings strengthen recent arguments for using "nudges" such as automatic payroll deductions instead of such policies (e.g. Thaler and Sunstein, 2008; Iwry and John, 2009; Madrian, 2012) 


\section{ACTIVE VS. PASSIVE DECISIONS AND CROWD-OUT IN RETIREMENT SAVINGS ACCOUNTS: ONLINE APPENDICES}

\section{A. Supplementary Results on Mandated Savings Plan}

This appendix has two objectives. First, we formalize how we estimate pass-through using the threshold approach in Columns 4-7 of Table IV. Second, we show that the impacts of the MSP reported in Section IV.B using an RD design for individuals with labor income around DKr 34,500 are similar for higher income individuals using a difference-in-differences design.

Threshold-Based Estimator. We estimate pass-through in Column 4 of Table IV as follows.

First, we define an indicator $\theta_{i}^{\text {pred }}=I\left[P_{i, 1998}^{I}+P_{i, 1998}^{E}+0.01 Y_{i}>\bar{P}\right]$ and run a regression of the following form using the observations in Figure IVc below the eligibility cutoff $\left(Y_{i}<34,500\right)$ :

$$
\theta_{i}^{\text {pred }}=\beta_{0}+\beta_{1} Y_{i}+\varepsilon_{i}
$$

Let $\theta_{\text {cut }}^{\text {pred }}$ denote the predicted value from this regression at the eligibility cutoff $Y_{i}=34,500$. Next, we repeat (12) with $\theta_{i}$ as the dependent variable and compute the predicted value at the cutoff, $\theta_{\text {cut }}$. Finally, we replicate the RD specification in Column 1, changing the dependent variable to the indicator $\theta_{i}$ for having $P_{i}>\bar{P}$, and report the resulting regression coefficient divided by the predicted increase under no offset, $\theta_{\text {cut }}^{\text {pred }}-\theta_{\text {cut }}$. Columns 5-7 are estimated using the same approach, changing the measure of saving used to define the indicator variables.

Difference-in-Difference Estimates. We exploit the variation in the level of MSP contributions across income levels to implement a difference-in-differences design. To illustrate the design, we divide the population into three terciles based on their current individual labor income. Appendix Figure IIa plots the mean level of MSP contributions from 1995 to 2005 for these three groups. Individuals in the top tercile (incomes above DKr 280,400) were forced to contribute approximately DKr 3,480 on average between 1998 and 2003 to the MSP. Individuals in the middle tercile were forced to contribute DKr 2,320 on average, while individuals in the bottom tercile were forced to contribute only DKr 930 on average.

Appendix Figure IIb plots individual retirement saving $\left(P_{i, t}^{I}+P_{i, t}^{G}\right)$ for the same three income terciles. The introduction and termination of the MSP have sharp effects on total contributions 
to retirement accounts that correspond to the magnitudes of the changes in the MSP. ${ }^{35}$ To quantify pass-through to total retirement savings, we first divide the sample into cells of DKr 25,000 income groups for each year and calculate mean government mandated $\left(P_{g, t}^{G}\right)$ and total individual pension contributions $\left(Z_{g, t}\right)$ in each group $g$ in year $t$. We then estimate the following regression specification, weighting by the number of observations in each cell:

$$
\Delta Z_{g, t}=\beta_{t}+\phi_{G} \cdot \Delta P_{g, t}^{G}+\varepsilon_{g, t}
$$

where $\Delta Z_{g, t}$ denotes the change in mean total individual contributions from year $t-1$ to year $t$ in each cell, $\Delta P_{g, t}^{G}$ is defined analogously, and $\beta_{t}$ is a year fixed effect. We limit the sample to $t=1998$ and $t=2004$, the years in which the MSP was introduced and terminated. ${ }^{36}$ We obtain a pass-through estimate of $\phi_{G}=0.81$, as shown in Appendix Figure IIb.

Appendix Figure IIc uses a threshold approach to confirm that these increases in pension contributions are not driven by individuals who make zero individual contributions and are unable to offset the MSP. It plots the fraction of individuals whose total individual (non-employer) pension contributions exceed $1.5 \%$ of income, the mean individual pension saving rate in the sample. Because the MSP was only $1 \%$ of income, any changes in this indicator must be driven by individuals who are not at the corner. The MSP again clearly increased the fraction of individuals saving more than $1.5 \%$ of their income in pension accounts between 1998 and 2003. To estimate pass-through, we repeat the regression in (13) with the dependent variable defined as change in the fraction of individuals whose total individual pension contributions exceed $1.5 \%$ of income. To calculate passthrough, we divide this coefficient by the change one would have obtained by mechanically adding the changes in the MSP to prior-year individual pension contributions. The resulting estimate, shown in Appendix Figure IIc, is 96.6\%.

\footnotetext{
${ }^{35}$ From 1999-2001, the MSP had a redistributive element, so that MSP balances were fixed even though contribution amounts still varied with income as shown in Appendix Figure IIa. The fact that the series in Appendix Figure IIb show no breaks around 1999 and 2001 implies that individuals' pension contributions are unaffected by MSP balances even though they should change in a neoclassical model. This is not surprising given that individuals do not appear to respond to even the changes in the level of contributions in 1998 and 2004.

${ }^{36}$ This synthetic cohort approach isolates variation in MSP due to the law changes in 1998 and 2004; changes in MSP at the individual level confound variation driven by changes in income and changes in the law. An alternative approach is to instrument for the changes at the individual level by simulated changes in MSP due to the law. We find that this approach yields much less stable estimates because the results are sensitive to the control function used to capture mean reversion at the individual level, a well known problem in the literature on estimating taxable income elasticities (Saez, Slemrod and Giertz, 2012).
} 
Unfortunately, when we replicate the analysis in Appendix Figures IIb and IIc for total saving, we obtain very noisy and unstable results. The year-to-year income-specific shocks to taxable saving levels are sufficiently large that we cannot reject pass-through to total saving of 0 or 1 . We explain why estimates based on comparing the level of taxable saving across income groups are so imprecise in Appendix B.

\section{B. Supplementary Results on Crowd-out in Taxable Saving}

This appendix presents three sets of supplementary results on the degree of crowd-out in taxable saving accounts caused by the 1999 subsidy reduction. First, we explain why the levels specification in (10) yields statistically uninformative estimates of crowd-out in taxable saving. Second, we present permutation tests for the MPS specification in (11) to show that our statistical inferences using that specification are valid. Finally, we explain why the income effect created by the 1999 subsidy reduction is unlikely to affect our crowd-out estimates.

Levels Estimates. Appendix Figure IIIa illustrates the levels DD estimator of crowd-out in taxable saving accounts. This figure plots the mean level of taxable saving (measured in pre-tax dollars) in the control (25-75K below the top tax cutoff) and treatment (25-75K above the top tax cutoff) groups. There are very large differential fluctuations in the level of taxable saving across income groups over time relative to the size of the treatment effect on total contributions to individual pension accounts $\left(P^{I}\right)$, shown by the dashed line.

The differential fluctuations in levels in Appendix Figure IIIa are partly due to fluctuations in the marginal propensity to save in taxable accounts across years. This is illustrated in Appendix Figure IIIb, which plots the MPS (the coefficient in an OLS regression of taxable saving on taxable income) for individuals below and above the top tax cutoff. The MPS fluctuates significantly across years in a manner that is correlated with the level of taxable savings. Intuitively, in years with good asset returns or a booming economy, everyone saves more and earns higher returns in taxable accounts, with larger increases for higher income individuals. To see why these shocks to the MPS generate imprecision in the levels estimate, observe that the levels DD estimator essentially compares mean taxable saving for those above the top tax cutoff $\bar{Y}$, whose mean taxable income is $Y_{H}$, with mean taxable saving for those below the top tax cutoff, whose mean taxable income is $Y_{L}$. If the marginal propensity to save $M P S_{t}$ does not vary with income in year $t$, the difference 
between the level of taxable saving for these two groups is

$E\left[S_{i, t} \mid Y_{i, t}^{\operatorname{tax}}>\bar{Y}_{t}\right]-E\left[S_{, i t} \mid Y_{i, t}^{\operatorname{tax}}<\bar{Y}_{t}\right]=M P S_{t} \cdot\left(Y_{H}-Y_{L}\right)+E\left[\varepsilon_{i, t} \mid Y_{i, t}^{\operatorname{tax}}>\bar{Y}_{t}\right]-E\left[\varepsilon_{i, t} \mid Y_{i, t}^{\operatorname{tax}}<\bar{Y}_{t}\right]$.

This equation shows that fluctuations in $M P S_{t}$ contribute to the difference in savings levels across income groups and raise the variance of the error term in the levels DD estimator in (10). ${ }^{37}$ However, the same fluctuations in the MPS are netted out of the error term in the MPS DD estimator because that estimator directly compares the difference in the MPS across low and high income individuals around the reform. Importantly, Appendix Figure IIIb shows that the MPS does not vary differentially across income groups over time prior to the reform. The MPS in taxable saving rises sharply in the treated group relative to the control group only in 1999, the year of the reform. That is, the common trends assumption is satisfied for the MPS, whereas it is not for levels of taxable saving. This is why one obtains more precise and robust estimates of crowd-out in taxable saving accounts using the MPS estimator in (11) than the levels estimator in (10). ${ }^{38}$

We quantify our power to reject the null hypothesis of no change in taxable saving using the levels estimator using a permutation test. Let $t_{p}$ denote a year between 1999 and 2006 and $\bar{Y}_{p t}$ a placebo cutoff for the top tax bracket. We consider a grid of values for $\bar{Y}_{p t}$ from DKr 200,000 below to DKr 200,000 above the actual top tax cutoff in year $t$ in increments of DKr 10,000. For each combination of $\left\{t_{p}, \bar{Y}_{p t}\right\}$, we estimate the baseline levels DD reduced-form model, restricting the sample to 3 years before and after the placebo reform year and incomes $25-75 \mathrm{~K}$ above or $25-75 \mathrm{~K}$ below the placebo top tax cutoff in those years:

$$
S_{i, t}^{\text {pretax }}=\beta_{0}+\beta_{1} \text { postplacebo }_{i, t}+\beta_{2} \text { treatplacebo }_{i, t}+\mu_{S}^{L} \text { postplacebo }_{i, t} \cdot \text { treatplacebo }_{i, t}+\varepsilon_{i, t}
$$

\footnotetext{
${ }^{37}$ Using individuals who are closer to the top tax cutoff to define the treatment and control groups reduces noise due to fluctuations in $\beta_{t}$ by reducing $W_{H}-W_{L}$. However, the magnitude of the first-stage treatment on pension contributions also diminishes at the same rate, and thus narrowing the window does not yield more precise estimates of crowd-out. Conceptually, the subsidy reduction generates a change in the slope of saving with respect to income rather than a change in the level of saving in both retirement and non-retirement accounts. The levels specification therefore yields imprecise estimates irrespective of the bandwidth used to estimate the means given fluctuations in the MPS.

${ }^{38}$ In contrast, there is little or no variation in the MPS in retirement saving accounts across years in the control group, as is evident in Figure Va. This is why the levels and MPS estimator yield very similar estimates of responses within retirement accounts. The observed MPS may fluctuate more in taxable accounts because we directly observe flows in retirement accounts (and thus the MPS is unaffected by fluctuations in asset returns) and because cyclical fluctuations in durable purchases may have greater impacts on balances in taxable accounts.
} 
where $S_{i, t}^{\text {pretax }}=S_{i, t} / 0.4$ denotes taxable saving measured in pre-tax dollars, postplaceboit denotes an indicator for the 3 years including and after the placebo treatment year $t_{p}$, and treatplacebo $i t$ is an indicator for having taxable income above the placebo top tax cutoff $Y_{i, t}^{\operatorname{tax}}>\bar{Y}_{p, t}$.

Appendix Figure IVa plots the empirical distribution of coefficient estimates $\mu_{S}^{L}$ from this regression for all the placebos, excluding the coefficients from 1999 with $\bar{Y}_{p, t}$ within $\mathrm{DKr}$ 100,000 of the true cutoff to avoid biasing the placebo tests with the true treatment effect. Under the assumption that the treatment of the subsidy reduction is exchangeable across the year by top tax cutoff pairs (Rosenbaum, 1996), this empirical CDF represents the distribution of coefficients one would obtain under the null hypothesis that the subsidy has no impact on taxable saving. The vertical line shows the change in taxable saving one would see under perfect crowd-out $\left(\rho_{2}=-1\right)$ given the size of the treatment effect on total individual pension contributions $P^{I}$, which is $\mathrm{DKr}$ 1,058. The permutation test shows that the chance of observing a coefficient $\mu_{S}^{L}$ exceeding this value is greater than 48\%. Appendix Figure IVb replicates Appendix Figure IVa using a trimmed measure of taxable saving (the dependent variable in Column 2 of Table VII). Trimming reduces the dispersion of the estimates, but the chance of observing a coefficient $\mu_{S}^{L}$ exceeding DKr 1058 is still $24 \%$. These results show that the levels estimator does not have adequate power to discriminate between the extremes of perfect crowd-out and no crowd-out, i.e. it is not informative about the degree of crowd-out in taxable savings accounts.

Precision of MPS Estimates. Next, we implement a set of permutation tests analogous to those above to ensure that the MPS approach does in fact yield more precise estimates than the levels approach. Using the same combinations of $\left\{t_{p}, \bar{Y}_{p, t}\right\}$ above, we re-estimate the 2SLS specification for crowd-out in Column 2 of Table VII. Appendix Figure Va plots an empirical distribution of the t-statistics obtained from the set of placebo regressions, computed using standard errors clustered at the DKr 5,000 income bin level as in Table VII. The t-statistic corresponding to the actual treatment is shown by the vertical line. Appendix Figure Vb repeats this analysis for the threshold specification in Column 5 of Table VII. In both cases, the actual t-statistic falls at or below the first percentile of the empirical CDF of placebo t-statistics, confirming that we can reject the null of no crowd-out at conventional levels of significance.

Appendix Figures Vc and Vd plot the empirical CDF of placebo $\mathrm{p}$ values corresponding to these two regressions. Under the assumption of exchangeability, the p values should have a uniform 
distribution if inference based on the clustered standard errors is valid. The CDF of the p values is in fact very close to the 45 degree line, indicating that our baseline approach of clustering standard errors by DKr 5,000 income bins gives valid $\mathrm{p}$ values for the MPS specifications. ${ }^{39}$

Income Effects. The increased taxation of capital pension contributions after the 1999 reform reduces disposable income for those who continued to make capital pension contributions after the reforms. This change in disposable income has a negligible impact on our crowd-out calculation because the $100-19.3=80.7 \%$ of passive savers who do not respond to the reform also do not change taxable saving significantly when their disposable income changes, as shown by the results in Section V. The $19.3 \%$ of individuals who respond to the subsidy change do so primarily by exiting capital pensions entirely, and thus their tax liabilities are unaffected by the change in the tax rate on capital pensions. As a result, our crowd-out estimate is driven purely by the behavior of the active savers: the passive savers affect neither the numerator (change in taxable saving), nor the denominator (change in pension contributions). If a small fraction of passive savers do reduce consumption when their disposable income falls after 1999, we would understate the degree of crowd-out, as the increase in taxable saving after 1999 would have been even larger absent this income effect.

\section{Revenue Gain from 1999 Subsidy Reduction}

In this appendix, we calculate the impact of the 1999 capital pension subsidy reduction on government revenue. The capital subsidy reduction in 1999 changed the current tax rate on contributions, but did not affect rates on withdrawal or accrual. The primary determinant of the fiscal gain from the 1999 reform is therefore simply the mechanical revenue gain from reducing the subsidy on current contributions by 13.6 cents per DKr (ignoring any behavioral responses). Given that mean per capita contributions to capital pensions were DKr 5196 in 1998 in the treatment group, the mechanical subsidy reduction of 13.6 cents per DKr yields a fiscal gain of DKr $5196 \times 0.136=707$ per individual in the top bracket.

The 1999 subsidy reduction induced individuals to reduce contributions to capital pensions

\footnotetext{
${ }^{39}$ Interestingly, the same is not true for the levels estimator: standard errors clustered at the DKr 5,000 income bin level yield a p value below 0.01 in the baseline 2SLS specification. However, a permutation test reveals that $40 \%$ of the $\mathrm{p}$ values from placebo tests fall below 0.01 , indicating that these standard errors substantially overstate the precision of the estimate. This is because there is substantial correlation in the level of taxable saving across individuals within a year that is not accounted for by clustering at the DKr 5,000 income bin level.
} 
by DKr 2449 (Table V, Column 1). This behavioral response induced individuals to shift DKr $0.529 \times 2449=1296$ from retirement accounts to taxable savings accounts (Table VI, Column 5). Because retirement accounts are tax subsidized, this behavioral response further increased government revenue. The revenue gain due to behavioral responses depends upon the net subsidy to capital pensions relative to taxable savings accounts. Calculating this net subsidy requires various assumptions on individual behavior, as it requires accounting for not just the impact of the behavioral response on current tax revenues but also the present value of impacts on revenue when the money is withdrawn from retirement accounts, adjusting for the accrual of capital gains.

We estimate the average value of the net subsidy to capital pension accounts using the following calculation. Assume that the representative individual invests at age 40 and earns a 5\% nominal return per year, of which $40 \%$ (i.e., 2 percentage points) is realized in each year (e.g., through dividends, interest payments, or capital gains from asset reallocation) and reinvested. The money stays in the account until age 60, when it is withdrawn. Retirement accounts are subsidized in two ways. First, individuals pay an effective tax rate of $20 \%$ on capital gains within the retirement account, as compared with $40 \%$ in non-retirement accounts. ${ }^{40}$ Second, withdrawals from nonretirement accounts are taxed as regular income, at an average rate of $45.9 \%$; withdrawals from the capital pension retirement account are taxed at 40\%. Taking these two tax benefits into account, we calculate that the subsidy to capital pension contributions is equivalent to an up-front subsidy of 19.4 cents per DKr in 1999, after the reform. Hence, the revenue gain from individuals shifting money out of capital pensions and into taxable accounts is DKr $1296 \times 0.194=176$.

Combining the mechanical revenue gain and the gain from the behavioral response, we estimate that the 1999 reform generated an NPV fiscal gain of DKr $707+176=883$ on average across treated individuals. $80 \%$ of the fiscal savings came from the first-order mechanical effect of reducing the subsidy on infra-marginal capital pension contributions; hence our estimate of the revenue gain is not very sensitive to the assumptions made when calculating the net subsidy above. Note that the DKr 883 figure understates the true fiscal gain because it ignores the revenue gain that comes from shifting of assets from capital to annuity accounts in 1999 (substitution within retirement accounts).

\footnotetext{
${ }^{40}$ In 1999, savers paid $33.8 \%$ tax on real (that is, inflation adjusted) capital gains in retirement accounts. Assuming a $5 \%$ nominal return and $2 \%$ inflation, this is equivalent to a $20 \%$ nominal tax rate.
} 
Repeating these calculations including employer pensions generates larger revenue gains. Mean per capita contributions to firm capital pensions were DKr 12, 088 in 1998 in the treatment group, so that the mechanical subsidy reduction of 13.6 cents per DKr yields an additional fiscal gain of $12,088 \times 0.136=1644$. The 1999 subsidy induced firms to switch contributions from capital to annuity pensions, which we ignore to be conservative, but did not change total employer pension contributions. Therefore, the total fiscal gain for the government from the 1999 subsidy reduction, including employer contributions to retirement accounts, is DKr $1644+883=2527$ per individual in the top bracket. 


\section{References}

Agarwal, Sumit, John C. Driscoll, Xavier Gabaix, and David Laibson. 2009. "The Age of Reason: Financial Decisions over the Life Cycle and Implications for Regulation." Brookings Papers on Economic Activity, 40 (2): 51-117.

Aizcorbe, Ana M., Authur B. Kennickell, and Kevin B. Moore. 2003. "Recent Changes in U.S. Family Finances: Evidence from the 1998 and 2001 Survey of Consumer Finances." Federal Reserve Bulletin.

Arnberg, Søren and Mikkel Barslund. 2012. "The Crowding-Out Effect of Mandatory Labour Market Pension Schemes on Private Savings: Evidence from Renters in Denmark." Working Paper 2012:1, Danish Economic Council.

Benjamin, Daniel J. 2003. "Does 401(k) Eligibility Increase Saving? Evidence from Propensity Score Subclassification." Journal of Public Economics, 87, 1259-1290.

Bernheim, B. Douglas. 2002. "Taxation and Saving." in A. J. Auerbach and M. Feldstein, eds., Handbook of Public Economics, Vol. 3, Elsevier, p. 1173-1249.

Bernheim, B. Douglas and John Karl Scholz. 1993. "Private Saving and Public Policy." in James M. Poterba, ed., Tax Policy and the Economy, Vol. 7 of NBER Chapters, Cambridge, Mass.: National Bureau of Economic Research, p. 73-110.

Beshears, John, James J. Choi, David Laibson, and Brigitte C. Madrian. 2012. "Default Stickiness among Low-Income Individuals." RAND Working Paper WR-926-SSA, RAND Corporation.

Bingley, Paul, Nabanita Datta Gupta, and Peder J. Pedersen. 2007. "Fiscal Implications of Reforms in Retirement Systems in Denmark." in Jonathan Gruber and David A. Wise, eds., Social Security Programs and Retirement around the World: Fiscal Implications of Reform, NBER Chapters, National Bureau of Economic Research, p. 119-154.

Browning, Martin and Thomas F. Crossley. 2001. "The Life-Cycle Model of Consumption and Saving." Journal of Economic Perspectives, 15 (3): 3-22.

Cagan, Philip. 1965. The Effect of Pension Plans on Aggregate Saving: Evidence from a Sample Survey, New York: National Bureau of Economic Research. 
Campbell, John Y. and N. Gregory Mankiw. 1989. "Consumption, Income and Interest Rates: Reinterpreting the Time Series Evidence." in Olivier J. Blanchard and Stanley Fischer, eds., NBER Macroeconomics Annual 1989, Vol. 4, National Bureau of Economic Research, p. $185-246$.

Card, David and David S. Lee. 2008. "Regression discontinuity inference with specification error." Journal of Econometrics, 142 (2): 655-674.

Card, David and Michael Ransom. 2011. "Pension Plan Characteristics and Framing Effects in Employee Savings Behavior." The Review of Economics and Statistics, 93 (1): 228-243.

Carroll, Christopher D. 1997. "Buffer-Stock Saving and the Life Cycle/Permanent Income Hypothesis." The Quarterly Journal of Economics, 112 (1): 1-55.

Carroll, Gabriel D., James J. Choi, David Laibson, Brigitte C. Madrian, and Andrew Metrick. 2009. "Optimal Defaults and Active Decisions." The Quarterly Journal of Economics, 124 (4): 1639-1674.

Chamberlain, Gary. 1994. "Quantile Regression, Censoring and the Structure of Wages." $A d$ vances in Econometrics, pp. 171-209.

Chetty, Raj. 2012. "Bounds on Elasticities With Optimization Frictions: A Synthesis of Micro and Macro Evidence on Labor Supply." Econometrica, 80 (3): 969-1018.

Chetty, Raj, John N. Friedman, and Emmanuel Saez. 2013. "Using Differences in Knowledge Across Neighborhoods to Uncover the Impacts of the EITC on Earnings." American Economic Review, 103 (7): 2683-2721.

Chetty, Raj, John N. Friedman, Tore Olsen, and Luigi Pistaferri. 2011. "Adjustment Costs, Firm Responses, and Micro vs. Macro Labor Supply Elasticities: Evidence from Danish Tax Records." The Quarterly Journal of Economics, 126 (2): 749-804.

Cochrane, John H. 1991. "A Simple Test of Consumption Insurance." Journal of Political Economy, 99 (5): 957-76.

Danish Ministry of Taxation. 2002. Skatteberegningsreglerne for personer - før og nu. 
Duflo, Esther, William Gale, Jeffrey Liebman, Peter Orszag, and Emmanuel Saez. 2006. "Saving Incentives for Low- and Middle-Income Families: Evidence from a Field Experiment with H\&R Block." The Quarterly Journal of Economics, 121 (4): 1311-1346.

Dynan, Karen E., Jonathan Skinner, and Stephen P. Zeldes. 2004. "Do the Rich Save More?" Journal of Political Economy, 112 (2): 397-444.

Engelhardt, Gary V. and Anil Kumar. 2007. "Employer matching and 401(k) saving: Evidence from the health and retirement study." Journal of Public Economics, 91 (10): 1920-1943.

Engen, Eric M., William G. Gale, and John Karl Scholz. 1994. "Do Saving Incentives Work?" Brookings Papers on Economic Activity, 25 (1): 85-180.

Engen, Eric M., William G. Gale, and John Karl Scholz. 1996. "The Illusory Effects of Saving Incentives on Saving." Journal of Economic Perspectives, 10 (4): 113-38.

Ericson, Keith M. Marzilli. 2012. "Consumer Inertia and Firm Pricing in the Medicare Part D Prescription Drug Insurance Exchange." NBER Working Paper 18359, National Bureau of Economic Research.

Gale, William G. 1998. "The Effects of Pensions on Household Wealth: A Reevaluation of Theory and Evidence." Journal of Political Economy, 106 (4): 706-723.

Gale, William G. and John Karl Scholz. 1994. "IRAs and Household Saving." American Economic Review, 84 (5): 1233-60.

Gelber, Alexander M. 2011. "How Do 401(k)s Affect Saving? Evidence from Changes in 401(k) Eligibility." American Economic Journal: Economic Policy, 3 (4): 103-22.

Green, Francis G. 1981. "The Effect of Occupational Pension Schemes on Saving in the United Kingdom: A Test of the Life Cycle Hypothesis." The Economic Journal, 91 (361): 136-44.

Green-Pedersen, Christoffer. 2007. "Denmark: A 'World Bank' Pension System." in Ellen M. Immergut, Karen M. Anderson, and Isabella Schulze, eds., The Handbook of West European Pension Politics, New York: Oxford University Press, p. 454-495.

Imbens, Guido W. and Thomas Lemieux. 2008. "Regression Discontinuity Designs: A Guide to Practice." Journal of Econometrics, 142 (2): 615-635. 
Iwry, Mark J. and David C. John. 2009. "Pursuing Universal Retirement Security Through Automatic IRAs." Retirement Security Project Paper, Brookings Institute.

Johnson, David S., Jonathan A. Parker, and Nicholas S. Souleles. 2006. "Household Expenditure and the Income Tax Rebates of 2001." American Economic Review, 96 (5): 1589-1610.

Kleven, Henrik Jacobsen, Martin B. Knudsen, Claus Thustrup Kreiner, Søren Pedersen, and Emmanuel Saez. 2011. "Unwilling or Unable to Cheat? Evidence From a Tax Audit Experiment in Denmark." Econometrica, 79 (3): 651-692.

Leth-Petersen, Soren. 2010. "Intertemporal Consumption and Credit Constraints: Does Total Expenditure Respond to an Exogenous Shock to Credit?" American Economic Review, 100 (3): 1080-1103.

Lusardi, Annamaria and Olivia S. Mitchell. 2007. "Baby Boomer Retirement Security: The Roles of Planning, Financial Literacy, and Housing Wealth." Journal of Monetary Economics, 54 (1): 205-224.

Madrian, Brigitte C. 2012. "Matching Contributions and Savings Outcomes: A Behavioral Economics Perspective." NBER Working Paper 18220, National Bureau of Economic Research.

Madrian, Brigitte C. and Dennis F. Shea. 2001. "The Power of Suggestion: Inertia in 401(k) Participation and Savings Behavior." The Quarterly Journal of Economics, 116 (4): 1149-1187.

Mankiw, N. Gregory. 2000. "The Savers-Spenders Theory of Fiscal Policy." American Economic Review, 90 (2): 120-125.

OECD. 2009. "Pension Country Profile: Denmark." in "OECD Private Pensions Outlook 2008," Paris: OECD Publishing.

Poterba, James M., Steven F. Venti, and David A. Wise. 1995. "Do 401(k) Contributions Crowd Out Other Personal Saving?" Journal of Public Economics, 58 (1): 1-32.

Poterba, James M., Steven F. Venti, and David A. Wise. 1996. "How Retirement Saving Programs Increase Saving." Journal of Economic Perspectives, 10 (4): 91-112.

Poterba, James M., Steven F. Venti, and David A. Wise. 1998. "Personal Retirement Saving Programs and Asset Accumulation: Reconciling the Evidence." in "Frontiers in the Economics of Aging" NBER Chapters, National Bureau of Economic Research, Inc, pp. 23-124. 
Reis, Ricardo. 2006. "Inattentive Producers." Review of Economic Studies, 73, 793-821.

Rosenbaum, Paul R. 1996. "Observational Studies and Nonrandomized Experiments." Design and Analysis of Experiments, pp. 181-97.

Saez, Emmanuel, Joel Slemrod, and Seth H. Giertz. 2012. "The Elasticity of Taxable Income with Respect to Marginal Tax Rates: A Critical Review." Journal of Economic Literature, 50 (1): $3-50$.

Samuelson, William and Richard Zeckhauser. 1988. "Status Quo Bias in Decision Making." Journal of Risk and Uncertainty, 1 (1): 7-59.

Samwick, Andrew. 2003. "Patience, Pensions, and Saving." http://www.dartmouth.edu/ samwick/adp_samwick.pdf.

Thaler, Richard H. and Cass R. Sunstein. 2008. Nudge: Improving Decisions About Health, Wealth, and Happiness, New Haven: Yale University Press.

Thaler, Richard H. and Shlomo Benartzi. 2004. "Save More Tomorrow (TM): Using Behavioral Economics to Increase Employee Saving." Journal of Political Economy, 112 (S1): S164-S187.

Venti, Steven F. and David A. Wise. 1990. "Have IRAs Increased U.S. Saving? Evidence from Consumer Expenditure Surveys." The Quarterly Journal of Economics, 105 (3): 661-98. 


\section{TABLE I}

\section{Predicted Impacts of Retirement Saving Policies for Active vs. Passive Savers}

\begin{tabular}{lcccc}
\hline \hline & \multicolumn{2}{c}{ Automatic Contribution } & \multicolumn{2}{c}{ Price Subsidy } \\
\cline { 2 - 5 } & $\begin{array}{c}\text { Raises Total } \\
\text { Pension } \\
\text { Contributions? }\end{array}$ & $\begin{array}{c}\text { Raises Total } \\
\text { Saving? }\end{array}$ & $\begin{array}{c}\text { Raises Total } \\
\text { Pension } \\
\text { Contributions? }\end{array}$ & $\begin{array}{c}\text { Raises Total } \\
\text { Saving? }\end{array}$ \\
\hline $\begin{array}{l}\text { Active Savers } \\
\text { (Neoclassical) }\end{array}$ & No & No & Yes & Uncertain \\
Passive Savers & Yes & Uncertain & No & No \\
\hline \hline
\end{tabular}

Notes: This table summarizes the predictions of the stylized model in Section II, which assumes that individuals are at an interior optimum and do not face any corners in choosing pension contributions $\left(P_{i}^{I}\right)$ or taxable saving $\left(S_{i}\right)$. Active savers follow the neoclassical life-cycle model when choosing $P_{i}^{I}$ and $S_{i}$. Passive savers set $P_{i}^{I}$ at a fixed level irrespective of government and employer policies. 


\section{TABLE II}

\section{Summary Statistics for Analysis Dataset}

\begin{tabular}{|c|c|c|c|c|c|c|}
\hline \multirow[t]{2}{*}{ Variable } & \multicolumn{3}{|c|}{ Full Sample } & \multicolumn{3}{|c|}{ Top Tax Threshold Sample } \\
\hline & $\begin{array}{c}\text { Mean } \\
(1)\end{array}$ & $\begin{array}{c}\text { Median } \\
\quad(2)\end{array}$ & $\begin{array}{l}\mathrm{SD} \\
(3)\end{array}$ & $\begin{array}{c}\text { Mean } \\
(4)\end{array}$ & $\begin{array}{c}\text { Median } \\
(5)\end{array}$ & $\begin{array}{l}\mathrm{SD} \\
(6)\end{array}$ \\
\hline \multicolumn{7}{|l|}{ Income } \\
\hline Labor Income $(Y)$ & 202,981 & 207,475 & 171,439 & 277,585 & 278,525 & 71,964 \\
\hline Total Compensation $(W)$ & 250,506 & 232,164 & 168,319 & 310,554 & 304,738 & 71,336 \\
\hline Taxable Income $\left(Y^{\operatorname{tax}}\right)$ & 217,284 & 202,474 & 139,375 & 264,698 & 261,173 & 53,800 \\
\hline \multicolumn{7}{|l|}{ Assets and Saving } \\
\hline Fraction with Individual Pension Contribs. & $27.6 \%$ & & & $36.0 \%$ & & \\
\hline Individual Pension Contribution $\left(P^{I}\right)$ & 3,081 & 0 & 8,786 & 4,007 & 0 & 9,586 \\
\hline Individual Pension Contribution Rate & $1.2 \%$ & $0.0 \%$ & $2.9 \%$ & $1.2 \%$ & $0.0 \%$ & $2.7 \%$ \\
\hline Individual Capital Pension Contribution $\left(P^{I, C}\right)$ & 1,868 & 0 & 5,817 & 2,589 & 0 & 6,661 \\
\hline Individual Annuity Pension Contribution & 1,213 & 0 & 5,674 & 1,417 & 0 & 5,908 \\
\hline Fraction with Employer Pension Contribs. & $60.4 \%$ & & & $83.0 \%$ & & \\
\hline Employer Pension Contribution $\left(P^{E}\right)$ & 15,205 & 6,314 & 21,375 & 21,220 & 19,722 & 19,255 \\
\hline Employer Pension Contribution Rate & $5.8 \%$ & $5.5 \%$ & $5.2 \%$ & $7.0 \%$ & $7.5 \%$ & $5.0 \%$ \\
\hline Fraction with Any Pension Contribution & $68.3 \%$ & & & $90.0 \%$ & & \\
\hline Non-Pension Assets (not incl. home equity) & 54,431 & 14,400 & 109,102 & 62,706 & 20,312 & 112,227 \\
\hline Non-Pension Assets $>10 \%$ of Labor Inc. & $52.1 \%$ & & & $41.7 \%$ & & \\
\hline Non-Pension Assets/Labor Inc. Ratio & $37.0 \%$ & $8.2 \%$ & $99.2 \%$ & $20.8 \%$ & $6.9 \%$ & $37.6 \%$ \\
\hline Taxable Saving $(S)$ & 4,921 & 306 & 43,665 & 6,482 & 976 & 48,756 \\
\hline Total Saving $\left(S^{t o t}\right)$ & 29,920 & 13,544 & 98,980 & 39,974 & 26,112 & 109,629 \\
\hline Total Savings Rate & $12.8 \%$ & $8.7 \%$ & $57.6 \%$ & $13.8 \%$ & $9.6 \%$ & $37.7 \%$ \\
\hline Liabilities (not incl. home mortgage) & 78,995 & 34,644 & 111,440 & 95,444 & 59,635 & 116,175 \\
\hline Change in Liabilities & 5,892 & 0 & 47,668 & 5,567 & 0 & 54,609 \\
\hline Net Savings Rate & $0.9 \%$ & $8.8 \%$ & $103.6 \%$ & $9.3 \%$ & $11.4 \%$ & $63.1 \%$ \\
\hline \multicolumn{7}{|l|}{ Demographics } \\
\hline Age & 38.3 & 38.0 & 11.8 & 40.5 & 40.0 & 10.2 \\
\hline Female & $52.0 \%$ & & & $44.3 \%$ & & \\
\hline Married & $49.4 \%$ & & & $57.7 \%$ & & \\
\hline Has Partner & $63.7 \%$ & & & $73.0 \%$ & & \\
\hline Homeowner & $52.9 \%$ & & & $68.0 \%$ & & \\
\hline College Degree & $29.3 \%$ & & & $44.8 \%$ & & \\
\hline Economics Major in Terminal Degree & $4.0 \%$ & & & $4.0 \%$ & & \\
\hline Number of Individuals & & $4,001,015$ & & & $1,345,753$ & \\
\hline Number of Observations & & $41,159,806$ & & & $16,457,106$ & \\
\hline
\end{tabular}

Notes: This table presents means, medians, and standard deviations of key variables in the full sample and for those with taxable income within DKr 75,000 of the top tax threshold. All monetary values are reported in nominal Danish Kroner; the exchange rate was approximately 6.5 DKr per US $\$ 1$ during the period we study. We top code all pension contribution levels at the 99th percentile. We trim taxable savings measures and all pension contribution rates (measured as a percentage of income) at the 1st and 99th percentiles. Labor income is total pre-tax wage earnings before pension contributions. Total compensation adds employer pension contributions to labor income. Taxable income adds non-labor taxable income to labor income. Non-pension assets are measured at the end of each calendar year and exclude home equity. Taxable saving is the change in non-pension assets relative to the previous year. Total saving is the change in non-pension assets (measured in pre-tax dollars, i.e. divided by (1-MTR)) plus pension contributions in each year. All rates are calculated relative to a base of labor income. Liabilities measures total non-mortgage debt, including other secured debt and unsecured debt. Net savings rate is defined as total saving minus the change in liabilities (also measured in pre-tax dollars) divided by labor income. Age is measured at the end of the calendar year. An individual has a partner if he/she is married or cohabitates with any non-blood relative of the opposite gender that is within fifteen years of age. An individual is a home-owner if he or his partner has positive home equity. Economics major is an indicator for majoring in economics, accounting, or finance in one's terminal degree. 


\section{TABLE III}

\section{Employer Pensions: Pass-Through Estimates}

\begin{tabular}{|c|c|c|c|c|c|c|c|}
\hline Sample: & $\begin{array}{l}\text { All Firm } \\
\text { Switches }\end{array}$ & $\begin{array}{l}\text { All Firm } \\
\text { Switches }\end{array}$ & $\begin{array}{c}\text { Mass } \\
\text { Layoffs }\end{array}$ & $\begin{array}{l}\text { Top Tax } \\
\text { Sample }\end{array}$ & $\begin{array}{l}\text { All Firm } \\
\text { Switches }\end{array}$ & $\begin{array}{c}\text { First } \\
\text { Switches }\end{array}$ & $\begin{array}{l}\text { Switches } \\
\text { Age 46-54 }\end{array}$ \\
\hline Dep. Var.: & $\begin{array}{c}\Delta \text { Tot. } \\
\text { Pension } \\
\text { Rate } \\
(1)\end{array}$ & $\begin{array}{c}\Delta \text { Tot. } \\
\text { Savings } \\
\text { Rate } \\
(2)\end{array}$ & $\begin{array}{c}\Delta \text { Tot. } \\
\text { Savings } \\
\text { Rate } \\
(3)\end{array}$ & $\begin{array}{c}\Delta \text { Tot. } \\
\text { Savings } \\
\text { Rate } \\
(4)\end{array}$ & $\begin{array}{c}\Delta \text { Net } \\
\text { Savings } \\
\text { Rate } \\
(5)\end{array}$ & $\begin{array}{c}\Delta \text { Tot. } \\
\text { Savings } \\
\text { Rate } \\
(6)\end{array}$ & $\begin{array}{c}\Delta \\
\text { Accrued } \\
\text { Wealth } \\
\quad(7)\end{array}$ \\
\hline \multicolumn{8}{|c|}{ Panel A: Lagged Saving $>0$} \\
\hline $\begin{array}{l}\Delta \text { Employer } \\
\text { Pension Rate }\end{array}$ & $\begin{array}{c}0.949 \\
(0.0015)\end{array}$ & $\begin{array}{c}0.777 \\
(0.0224)\end{array}$ & $\begin{array}{c}0.828 \\
(0.1865)\end{array}$ & $\begin{array}{c}0.750 \\
(0.0376)\end{array}$ & $\begin{array}{c}0.745 \\
(0.0372)\end{array}$ & $\begin{array}{c}0.784 \\
(0.0403)\end{array}$ & $\begin{array}{c}4.541 \\
(0.4255)\end{array}$ \\
\hline $\begin{array}{l}\Delta \text { Total } \\
\text { Compensation }\end{array}$ & $\begin{array}{c}0.007 \\
(0.0002)\end{array}$ & $\begin{array}{c}0.118 \\
(0.0033)\end{array}$ & $\begin{array}{c}0.178 \\
(0.0250)\end{array}$ & $\begin{array}{c}0.133 \\
(0.0069)\end{array}$ & $\begin{array}{c}0.059 \\
(0.0048)\end{array}$ & $\begin{array}{c}0.078 \\
(0.0053)\end{array}$ & $\begin{array}{c}0.089 \\
(0.0042)\end{array}$ \\
\hline Observations & 867,075 & $1,890,220$ & 37,432 & 876,922 & $1,880,642$ & 727,372 & 54,147 \\
\hline \multicolumn{8}{|c|}{ Panel B: Lagged Saving $>0$ with Controls } \\
\hline $\begin{array}{l}\Delta \text { Employer } \\
\text { Pension Rate }\end{array}$ & $\begin{array}{c}0.949 \\
(0.0015)\end{array}$ & $\begin{array}{c}0.762 \\
(0.0228)\end{array}$ & $\begin{array}{c}0.816 \\
(0.1883)\end{array}$ & $\begin{array}{c}0.753 \\
(0.0371)\end{array}$ & $\begin{array}{c}0.715 \\
(0.0374)\end{array}$ & $\begin{array}{c}0.762 \\
(0.0393)\end{array}$ & $\begin{array}{c}4.603 \\
(0.4289)\end{array}$ \\
\hline $\begin{array}{l}\Delta \text { Total } \\
\text { Compensation }\end{array}$ & $\begin{array}{c}0.007 \\
(0.0002)\end{array}$ & $\begin{array}{c}0.127 \\
(0.0032)\end{array}$ & $\begin{array}{c}0.178 \\
(0.0239)\end{array}$ & $\begin{array}{c}0.141 \\
(0.0068)\end{array}$ & $\begin{array}{c}0.076 \\
(0.0047)\end{array}$ & $\begin{array}{c}0.102 \\
(0.0049)\end{array}$ & $\begin{array}{c}0.082 \\
(0.0041)\end{array}$ \\
\hline Observations & 867,075 & $1,890,220$ & 37,432 & 876,922 & $1,880,642$ & 727,372 & 54,147 \\
\hline \multicolumn{8}{|c|}{ Panel C: Threshold Approach } \\
\hline $\begin{array}{l}\Delta \text { Employer } \\
\text { Pension Rate }\end{array}$ & $\begin{array}{c}0.939 \\
(0.0025)\end{array}$ & $\begin{array}{c}0.936 \\
(0.0131)\end{array}$ & $\begin{array}{c}0.817 \\
(0.0447)\end{array}$ & $\begin{array}{c}0.887 \\
(0.0316)\end{array}$ & $\begin{array}{c}0.977 \\
(0.0236)\end{array}$ & $\begin{array}{c}0.910 \\
(0.0108)\end{array}$ & \\
\hline $\begin{array}{l}\Delta \text { Total } \\
\text { Compensation }\end{array}$ & $\begin{array}{c}0.030 \\
(0.0006)\end{array}$ & $\begin{array}{c}0.150 \\
(0.0033)\end{array}$ & $\begin{array}{c}0.200 \\
(0.0152)\end{array}$ & $\begin{array}{c}0.181 \\
(0.0097)\end{array}$ & $\begin{array}{c}0.114 \\
(0.0025)\end{array}$ & $\begin{array}{c}0.150 \\
(0.0030)\end{array}$ & \\
\hline Observations & $3,582,391$ & $3,582,391$ & 65,554 & $1,655,486$ & $3,565,267$ & $1,306,354$ & \\
\hline
\end{tabular}

Notes: This table presents estimates of the impact of changes in employer pension contribution rates around firm switches on total pension contributions and total saving. Panel A and B report OLS estimates using the specification in (4); Panel $\mathrm{C}$ reports 2SLS estimates using the specification in (5). In Panel A, all independent and dependent variables are measured as a percentage of labor income in the year before the switch. The independent variables are the change in the employer contribution rate from the year before to the year of the switch $\left(\Delta p^{E}\right)$ and the change in total compensation over the same period $(\Delta w)$. In Column 1, the dependent variable is the change in the total pension contribution rate $\left(\Delta p^{E}+\Delta p^{I}\right)$. In this specification, we include only individuals not at a corner in individual pensions (defined as positive lagged individual pension contributions) at $t=-1$. In Columns $2-6$, the dependent variable is the change in savings rate $\left(\Delta s^{\text {tot }}\right)$ over the same period. We include only individuals not at a corner in individual savings (defined as either positive lagged individual pension contributions or lagged wealth greater than $10 \%$ of current labor income) at $t=-1$. Column 3 repeats Column 2 , restricting to the sample of workers whose firm switch is classified as coming from a mass layoff. We define mass layoffs as more than $90 \%$ of workers leaving a firm with more than 50 employees within a single year, with no more than $50 \%$ of the original employees ending up at the same new firm. Column 4 repeats Column 2 for the "top tax cutoff" sample described in Table II, i.e. individuals within DKr 75,000 of the top tax cutoff. Column 5 repeats Column 2 using saving net of liabilities as the dependent variable instead of gross saving. Column 6 repeats Column 2 restricting to the first firm switch for each individual. The dependent variable in Column 7 is the cumulative change in total saving between the time of the first firm switch and age 60 for those workers switching before age 55 and reaching 60 in our data. Panel B replicates Panel A controlling for age, marital status, gender, college attendance, and two-digit occupation indicators. Panel $\mathrm{C}$ replicates Panel A using the threshold approach to calculate pass-through described in the text. In Column 1, we regress the change in an indicator for having a total pension contribution rate above the threshold (defined as the maximum of the employer contributions at the new and old firm) on the change in total compensation and the change in an indicator for crossing the same threshold if the pass-through rate were $100 \%$ and savings in other accounts stayed at their year $t-1$ level. We instrument for the change in the indicator with the change in the employer contribution rate and include an indicator for having a positive change in the employer contribution rate as a regressor in these specifications. The remaining columns in Panel $\mathrm{C}$ repeat this procedure using the relevant dependent variable and subsample. In all specifications, we exclude individuals with $\Delta w<-50 \%$ or $\Delta w>$ $100 \%$ and, within this group, those with $\Delta p^{E}$ or $\Delta s^{\text {tot }}$ in the top or bottom $1 \%$ of the distribution. Standard errors, reported in parentheses, are clustered by the firm to which the individual switches. 
TABLE IV

\section{Government Mandated Savings Plan: Pass-Through Estimates}

\begin{tabular}{|c|c|c|c|c|c|c|c|}
\hline \multirow[t]{2}{*}{ Dep. Var.: } & \multicolumn{3}{|c|}{$\Delta$ Total Pensions } & \multirow{2}{*}{$\begin{array}{c}\text { Total } \\
\text { Pension } \\
\text { Threshold } \\
\text { (4) }\end{array}$} & \multirow{2}{*}{$\begin{array}{c}\text { Total } \\
\text { Saving } \\
\text { Threshold } \\
\text { (5) }\end{array}$} & \multirow{2}{*}{$\begin{array}{c}\text { Total Ind. } \\
\text { Saving } \\
\text { Threshold } \\
\text { (6) }\end{array}$} & \multirow{2}{*}{$\begin{array}{c}\text { Net } \\
\text { Saving } \\
\text { Threshold } \\
(7)\end{array}$} \\
\hline & (1) & $(2)$ & (3) & & & & \\
\hline Pass-Through RD & $\begin{array}{c}0.883 \\
(0.204)\end{array}$ & $\begin{array}{c}1.052 \\
(0.200)\end{array}$ & $\begin{array}{c}0.801 \\
(0.310)\end{array}$ & $\begin{array}{c}0.845 \\
(0.113)\end{array}$ & $\begin{array}{c}1.268 \\
(0.363)\end{array}$ & $\begin{array}{c}1.336 \\
(0.349)\end{array}$ & $\begin{array}{c}2.188 \\
(0.587)\end{array}$ \\
\hline $\begin{array}{l}\text { Income Control } \\
\text { Function }\end{array}$ & Linear & Linear & Quadratic & Linear & Linear & Linear & Linear \\
\hline Controls & & $\mathrm{X}$ & & & & & \\
\hline Observations & 35,578 & 35,578 & 35,578 & 158,229 & 148,380 & 148,380 & 128,988 \\
\hline
\end{tabular}

Notes: This table presents pass-through estimates using an RD design based on the eligibility cutoff for the Mandated Savings Program (MSP) in 1998. All cells report estimates from regression specifications with separate linear or quadratic control functions above and below the eligibility cutoff, using the specification in (6). In Columns 1-3, the dependent variables are the change in the level of total pension contributions $P^{I}+P^{E}$ from 1997 to 1998 . The estimates reported are for the discontinuity at the threshold divided by DKr 345 (the increase in mandated saving at the threshold) and hence can be interpreted as pass-through estimates $\phi_{G}$. Column 1 estimates the specification with no controls. Column 2 replicates Column 1 controlling for age, marital status, gender, college attendance, and two-digit occupation indicators. Column 3 replicates Column 1 using a quadratic rather than a linear control function for income. We restrict the sample to individuals who are making positive total pension contributions in 1997 in Columns 1-3. Columns 4-7 use the threshold approach described in the text to estimate pass-through in the full sample. In Column 4, the dependent variable is an indicator for having total pension contributions above DKr 1,265, the mean level of total pension contributions for individuals within DKr 5,000 of the MSP eligibility cutoff. The coefficient reported, which can be interpreted as an estimate of $\phi_{G}$, is the discontinuity divided by the counterfactual effect of the policy under full pass-through, which is calculated by mechanically increasing savings on the left-hand side of the discontinuity by $1 \%$ and estimating the predicted jump at the eligibility cutoff (see Online Appendix A for details). Columns 5,6 , and 7 replicate Column 4 with total saving $\left(S^{\text {tot }}\right)$, total saving excluding employer pensions $\left(S^{I, t o t}\right)$, and net saving as the dependent variables. The thresholds in those cases are DKr 1,317, DKR 1,078, and DKr 0. In all specifications, we exclude observations with individual pension contributions below the 1st or above the 99th percentile of the estimation sample. We also exclude 401 Ph.D. students that earn exactly DKr 49,987.50. Standard errors, reported in parentheses, are clustered by DKr 1,000 income bin in all specifications. 
TABLE V

\section{Impact of 1999 Subsidy Reduction on Capital Pension Contributions}

\begin{tabular}{|c|c|c|c|c|c|c|c|c|}
\hline \multirow[t]{2}{*}{ Dep. Var.: } & \multicolumn{4}{|c|}{ Individual Capital Pension Contributions } & \multirow{2}{*}{$\begin{array}{c}\text { No } \\
\text { Change } \\
\text { in Indiv. } \\
\text { Contrib. } \\
(5)\end{array}$} & \multirow{2}{*}{$\begin{array}{c}\text { Ext. } \\
\text { Margin } \\
\text { Substitution } \\
\text { (6) }\end{array}$} & \multirow{2}{*}{$\begin{array}{c}\text { Ext. Margin } \\
\text { Substitution, } \\
\text { No Change in } \\
\text { Prior Year } \\
(7)\end{array}$} & \multirow{2}{*}{$\begin{array}{c}\text { Indiv. } \\
\text { Exits } \\
\text { Capital } \\
\text { Pension } \\
(8)\end{array}$} \\
\hline & (1) & $(2)$ & (3) & (4) & & & & \\
\hline $\begin{array}{l}\text { Above Cutoff } \\
\times \text { Post }\end{array}$ & $\begin{array}{c}-2,449 \\
(121)\end{array}$ & $\begin{array}{c}-2,342 \\
(115)\end{array}$ & & & $\begin{array}{l}-0.033 \\
(0.003)\end{array}$ & $\begin{array}{c}0.116 \\
(0.005)\end{array}$ & $\begin{array}{c}0.068 \\
(0.004)\end{array}$ & $\begin{array}{c}0.159 \\
(0.007)\end{array}$ \\
\hline $\begin{array}{l}\text { Income } \times \text { Above } \\
\text { Cutoff } \times \text { Post }\end{array}$ & & & $\begin{array}{l}-0.021 \\
(0.002)\end{array}$ & $\begin{array}{l}-0.022 \\
(0.002)\end{array}$ & & & & \\
\hline $\begin{array}{l}\text { Mean of Dep. } \\
\text { Var. for Treated } \\
\text { Pre } 1999\end{array}$ & 5,113 & 5,113 & 5,113 & 5,113 & 0.292 & 0.012 & 0.005 & 0.087 \\
\hline Controls & & $\mathrm{X}$ & & $\mathrm{X}$ & & & & \\
\hline Years Included & $1996-2001$ & $1996-2001$ & $1996-2001$ & 1996-2001 & 1998-1999 & 1998-1999 & 1998-1999 & 1998-1999 \\
\hline Observations & $4,707,788$ & $4,707,788$ & $7,026,187$ & $7,026,187$ & 536,612 & 536,612 & 196,768 & 536,612 \\
\hline
\end{tabular}

Notes: This table characterizes the response to the 1999 reduction in the capital pension subsidy on savings behavior within individual capital pension accounts. In Columns 1-4, the dependent variable is individual capital pension contribution $P^{I, C}$. Column 1 presents an estimate of the effect of the 1999 reform on the level of capital pension contributions using the levels specification in equation (7). In this column, the treatment group includes individuals with taxable income between DKr 25,000 and DKr 75,000 above the top tax threshold; the control group includes individuals with taxable income between DKr 75,000 and DKr 25,000 below the threshold. The reported coefficient is the interaction between between in the treatment group and the post-reform indicator, which measures the change in the level of pension contributions for those above the top tax cutoff relative to those below the top tax cutoff around the 1999 reform. Column 3 presents an estimate of the effect of the 1999 reform on the marginal propensity to save in capital pension accounts using all individuals with taxable income within DKr 75,000 of the threshold, estimated using the specification in equation (9). The reported coefficient is the triple interaction, which measures the change in the MPS for those above the top tax cutoff relative to those below the top tax cutoff around the 1999 reform. Columns 2 and 4 replicate Columns 1 and 3 controlling for age, marital status, gender, college attendance, and two-digit occupation indicators. In Columns 5-8, we report estimates of the impact of the reform on various indicators for individual response, using only data from 1998-1999 and restricting to individuals with positive lagged capital pension contributions. These specifications use the levels DD specification in Column 1 with different dependent variables. In Column 5 , the dependent variable is an indicator for leaving capital pension contributions unchanged relative to the previous year. In Column 6, the dependent variable is "extensive margin substitution," defined as decreasing capital pension contributions to zero while increasing annuity pension contributions. Column 7 replicates Column 6, restricting to individuals who did not change their capital pension contributions in the previous year. In Column 8, the dependent variable is an indicator for decreasing capital pension contributions to zero. In all specifications, we exclude individuals with taxable saving below the 1st and above the 99th percentile for consistency with Table VII. Standard errors, reported in parentheses, are clustered by DKr 5,000 income bin in all specifications. 
TABLE VI

\section{Crowd-Out within Retirement Accounts Induced by Capital Pension Subsidy}

\begin{tabular}{|c|c|c|c|c|c|c|}
\hline \multirow[b]{2}{*}{ Dep. Var.: } & \multicolumn{3}{|c|}{ Estimates Based on Levels } & \multicolumn{3}{|c|}{ Estimates Based on MPS } \\
\hline & $\begin{array}{c}\text { Annuity } \\
\text { Contrib. } \\
\text { (1) }\end{array}$ & $\begin{array}{c}\text { Total } \\
\text { Pension } \\
\text { Contrib. } \\
\quad(2)\end{array}$ & $\begin{array}{c}\text { Total } \\
\text { Pension } \\
\text { Contrib. } \\
(3)\end{array}$ & $\begin{array}{c}\text { Annuity } \\
\text { Contrib. } \\
(4)\end{array}$ & $\begin{array}{l}\text { Total } \\
\text { Pension } \\
\text { Contrib. } \\
\quad(5)\end{array}$ & $\begin{array}{c}\text { Total } \\
\text { Pension } \\
\text { Contrib. } \\
\quad(6)\end{array}$ \\
\hline $\begin{array}{l}\text { Individual Capital } \\
\text { Pension Contrib. }\end{array}$ & $\begin{array}{l}-0.568 \\
(0.019)\end{array}$ & $\begin{array}{c}0.432 \\
(0.019)\end{array}$ & $\begin{array}{c}0.387 \\
(0.019)\end{array}$ & $\begin{array}{l}-0.471 \\
(0.056)\end{array}$ & $\begin{array}{c}0.529 \\
(0.056)\end{array}$ & $\begin{array}{c}0.558 \\
(0.045)\end{array}$ \\
\hline Controls & & & $\mathrm{X}$ & & & $\mathrm{X}$ \\
\hline Observations & $4,707,788$ & $4,707,788$ & $4,707,788$ & $7,026,187$ & $7,026,187$ & $7,026,187$ \\
\hline
\end{tabular}

Notes: This table presents estimates of the degree to which changes in individual capital pension contributions induced by the 1999 subsidy reduction were offset by increases in individual annuity pension contributions. All specifications are estimated using data from 1996-2001. The independent variable of interest in all specifications is the level of individual capital pension contributions $P^{I, C}$. The dependent variables are the level of individual annuity pension contributions (Columns 1 and 4 ) or total individual pension contributions (Columns 2-3 and 5-6). Columns 1-3 use the levels estimator in (10) to estimate crowd-out using 2SLS. In these specifications, we instrument for capital pension contributions with the double interaction term shown in equation (7) and restrict the sample to individuals with DKr 25,000-75,000 either below or above the top tax cutoff. Columns 4-6 use the MPS estimator in (11) to estimate crowd-out using 2SLS. In these specifications, we instrument for capital pension contributions with the triple interaction term shown in equation (9) and include all individuals within DKr 75,000 of the top tax cutoff. Columns 3 and 6 replicate Columns 2 and 5 controlling for age, marital status, gender, college attendance, and two-digit occupation indicators. In all specifications, we exclude individuals with taxable saving below the 1st and above the 99th percentile for consistency with Table VII. Standard errors, reported in parentheses, are clustered at the DKr 5,000 income bin level. 


\section{TABLE VII}

\section{Crowd-Out of Taxable Saving Induced by Subsidy}

\begin{tabular}{|c|c|c|c|c|c|c|c|}
\hline Dep. Var.: & $\begin{array}{c}\text { Taxable } \\
\text { Saving } \\
(1)\end{array}$ & $\begin{array}{c}\text { Trimmed } \\
\text { Taxable } \\
\text { Saving } \\
(2)\end{array}$ & $\begin{array}{c}\text { Median } \\
\text { Taxable } \\
\text { Saving } \\
(3)\end{array}$ & $\begin{array}{c}\text { Median } \\
\text { Total } \\
\text { Saving } \\
(4)\end{array}$ & $\begin{array}{c}\text { Taxable } \\
\text { Saving } \\
\text { Threshold } \\
(5)\end{array}$ & $\begin{array}{c}\text { Taxable } \\
\text { Saving } \\
\text { Threshold } \\
(6)\end{array}$ & $\begin{array}{c}\text { Net } \\
\text { Saving } \\
\text { Threshold } \\
(7)\end{array}$ \\
\hline $\begin{array}{l}\text { Individual Pension } \\
\text { Contributions }\end{array}$ & $\begin{array}{l}-1.200 \\
(0.588)\end{array}$ & $\begin{array}{l}-0.984 \\
(0.267)\end{array}$ & & & $\begin{array}{l}-0.994 \\
(0.241)\end{array}$ & $\begin{array}{l}-0.940 \\
(0.215)\end{array}$ & $\begin{array}{l}-1.462 \\
(0.379)\end{array}$ \\
\hline Above Cutoff $\times$ Post $\times Y^{\operatorname{tax}}$ & & & $\begin{array}{c}0.0098 \\
(0.0025)\end{array}$ & $\begin{array}{c}0.0003 \\
(0.0030)\end{array}$ & & & \\
\hline Controls & & & & & & $\mathrm{X}$ & \\
\hline Observations & $7,026,187$ & $7,026,187$ & $7,026,187$ & $7,026,187$ & $7,026,187$ & $7,026,187$ & $7,026,187$ \\
\hline
\end{tabular}

Notes: This table presents estimates of the degree to which the reductions in individual pension contributions induced by the 1999 subsidy reduction were offset by increases in taxable saving. The independent variable of interest in columns 1-2 and 5-7 is the level of individual pension contributions $P^{I}$. Column 1 uses the MPS estimator in (11) to estimate crowd-out using 2SLS. We instrument for total individual pension contributions $P^{I}$ with the triple interaction term shown in equation (9) and include all observations with taxable income within DKr 75,000 of the top tax cutoff. The dependent variable in Column 1 is taxable saving, measured in pre-tax dollars given the marginal tax rate of $60 \%$ in the top income tax bracket $\left(S^{t o t}=S /(1-0.6)\right)$. Column 2 replicates Column 1, winsorizing taxable saving at the 10th and 90th percentile. Column 3 presents estimates from a least-squares approximation to a median regression. We compute medians of taxable saving within DKr 5,000 income bins centered around the top tax cutoff in each year (as shown in Figure VIIIb). We then estimate a specification analogous to that in (9) using OLS, with the median in each bin as the dependent variable, weighting by the number of observations in each bin. The resulting coefficient estimate can be interpreted as the reduced-form impact of the subsidy change on the marginal propensity to save in taxable accounts at the median. Column 4 replicates Column 3 , changing the dependent variable to median total saving $\left(S^{\text {tot }}\right)$ instead of median taxable saving within each DKr 5,000 bin. Column 5 implements the threshold approach described in the text to estimate crowd-out. We first replicate the 2SLS specification in Column 1, changing the dependent variable to an indicator for having taxable saving above the median level of taxable saving for individuals in the top tax bracket. We then divide the coefficient from this regression by the predicted change if the reduction in pension contributions were entirely offset by increasing taxable saving, based on the density of the taxable saving distribution around the threshold. The resulting estimate reported in the table can be interpreted as an estimate of crowd-out (see text for details). Column 6 replicates Column 5 controlling for age, marital status, gender, college attendance, and two-digit occupation indicators. Column 7 replicates Column 5 using net taxable saving instead of gross taxable saving to define the dependent variable. All specifications are estimated using data from 1996-2001. In all specifications, we exclude individuals with taxable saving below the 1st and above the 99th percentile. Standard errors, reported in parentheses, are clustered at the DKr 5,000 income bin level. 


\section{TABLE VIII}

\section{Active vs. Passive Choice and Responses to Subsidies and Employer Pensions}

\begin{tabular}{|c|c|c|c|c|c|c|}
\hline \multirow[t]{2}{*}{ Dep. Var.: } & \multicolumn{2}{|c|}{$\begin{array}{l}\text { Contributes to } \\
\text { Capital Pension }\end{array}$} & \multicolumn{2}{|c|}{$\begin{array}{c}\text { Extensive Margin } \\
\text { Substitution in } 1999\end{array}$} & \multicolumn{2}{|c|}{$\begin{array}{l}\Delta \text { Total Pension } \\
\text { Contrib. Rate }\end{array}$} \\
\hline & (1) & $(2)$ & (3) & (4) & (5) & (6) \\
\hline Post 1999 & $\begin{array}{c}-0.150 \\
(0.0057)\end{array}$ & $\begin{array}{c}-0.151 \\
(0.0058)\end{array}$ & & & & \\
\hline Post $1999 \times$ New Saver & $\begin{array}{c}-0.226 \\
(0.0073)\end{array}$ & $\begin{array}{c}-0.225 \\
(0.0079)\end{array}$ & & & & \\
\hline New Saver & $\begin{array}{c}-0.052 \\
(0.0037)\end{array}$ & $\begin{array}{c}-0.065 \\
(0.0041)\end{array}$ & & & & \\
\hline$\Delta$ Employer Pension & & & & & $\begin{array}{c}0.996 \\
(0.0016)\end{array}$ & $\begin{array}{c}0.996 \\
(0.0015)\end{array}$ \\
\hline $\begin{array}{l}\text { Fraction of Other Years } \\
\text { with Change in Pension }\end{array}$ & & & $\begin{array}{c}0.176 \\
(0.0059)\end{array}$ & $\begin{array}{c}0.159 \\
(0.0054)\end{array}$ & $\begin{array}{c}-0.005 \\
(0.0001)\end{array}$ & $\begin{array}{c}-0.005 \\
(0.0002)\end{array}$ \\
\hline $\begin{array}{l}\Delta \text { Employer Pension } \\
\times \text { Fraction of Other Years } \\
\text { with Change in Pension }\end{array}$ & & & & & $\begin{array}{c}-0.096 \\
(0.0044)\end{array}$ & $\begin{array}{c}-0.096 \\
(0.0044)\end{array}$ \\
\hline $\begin{array}{l}\text { Mean of Dep. Var. pre } \\
1999\end{array}$ & 0.871 & 0.871 & 0.015 & 0.015 & 0.091 & 0.091 \\
\hline Controls & & $\mathrm{X}$ & & $\mathrm{X}$ & & $\mathrm{X}$ \\
\hline Observations & 146,256 & 146,256 & 64,783 & 64,783 & 864,482 & 864,482 \\
\hline
\end{tabular}

Notes: Column 1 regresses an indicator for positive individual contributions to capital pensions on a post-1999 indicator, a new saver indicator, and the interaction of these two variables. The new saver variable is an indicator for making zero individual annuity and capital pension contributions in the prior year. We use data from 1998 and 1999 and include only individuals with taxable income between DKr 25,000 and DKr 75,000 above the top tax cutoff who are currently contributing to either capital or annuity pensions. Column 3 regresses an indicator for extensive margin substitution in response to the 1999 capital pension reform, defined as exiting capital pensions and raising annuity pension contributions, on the fraction of other years in which an individual changes individual capital or annuity pension contributions relative to the prior year. We use data from 1999 and restrict the sample to individuals with taxable income between DKr 25,000 and DKr 75,000 above the top tax cutoff who made positive contributions to individual capital pensions in 1998 in this regression. Column 5 replicates Column 1 of Table IIIA to measure the pass-through of changes in employer pension contribution rates to total pension contribution rates, except that we include an interaction of the change in the employer pension contribution rate $\Delta p^{E}$ with the fraction of other years (excluding the year of the firm switch) in which an individual adjusted the level of annuity or capital pension contributions. We also include the interaction between this variable and the change in total compensation $\Delta w$. Columns 2,4 , and 6 replicate Columns 1, 3, and 5 controlling for age, marital status, gender, college attendance, and two-digit occupation indicators. Standard errors are reported in parentheses. In Columns 1-4, we cluster standard errors at the DKr 5,000 income bin level; in Columns 5-6, we cluster by the firm to which the individual switches. 


\section{TABLE IX}

\section{Observable Heterogeneity in Responses to Subsidies and Employer Pensions}

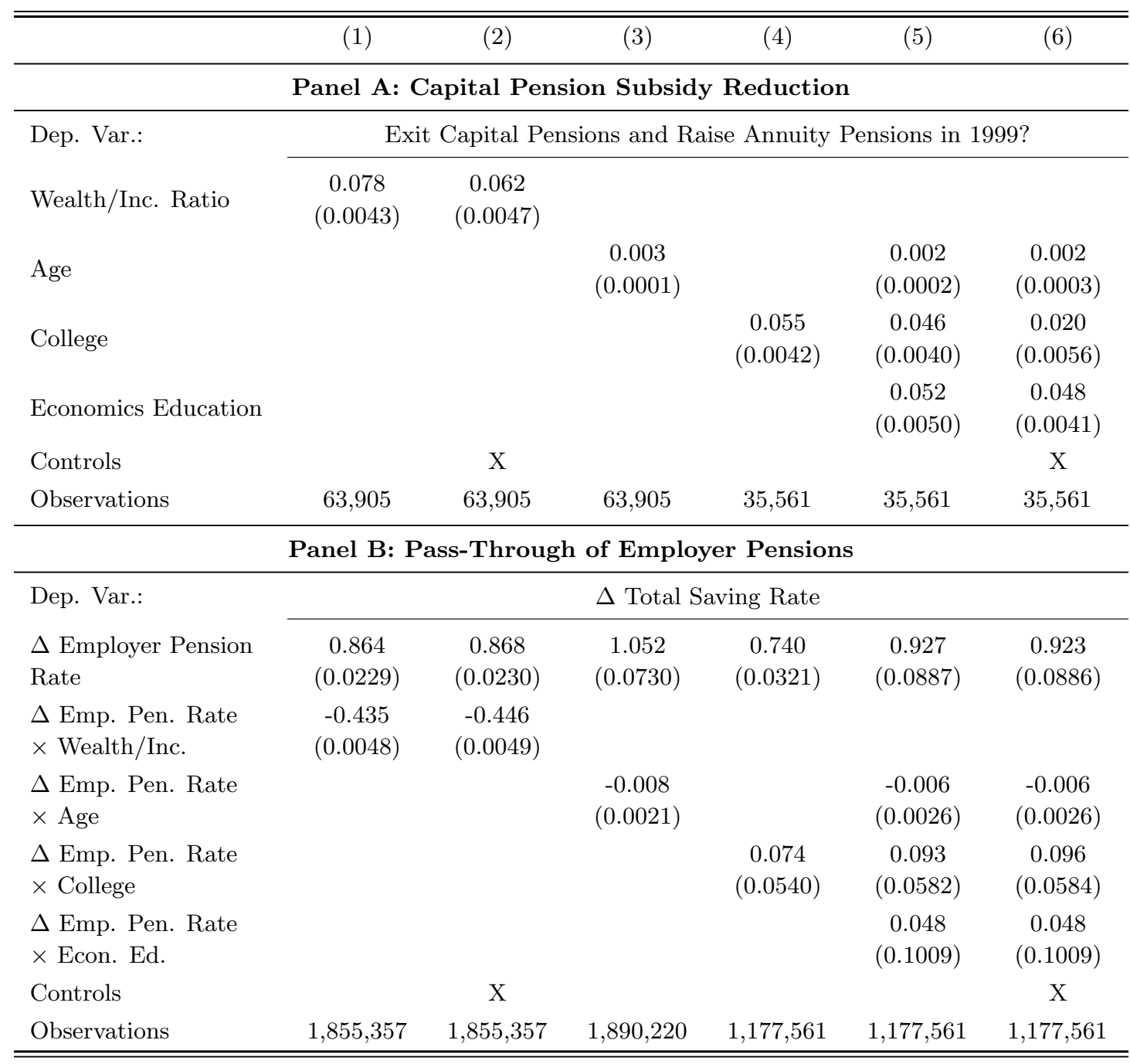

Notes: This table investigates observable heterogeneity in response to the 1999 capital pension reform (Panel A) and changes in employer pension contribution rates (Panel B). In Panel A, we regress an indicator for extensive margin substitution in response to the 1999 capital pension reform, defined as exiting capital pensions and raising annuity pension contributions, on various individual characteristics. We use 1999 data for individuals with taxable income between DKr 25,000 and DKr 75,000 above the top tax cutoff. The lone independent variable in Column 1 is the lagged ratio of non-pension assets to labor income. Column 2 replicates Column 1 with controls for age, marital status, gender, college, and two-digit occupation indicators. In Column 3, the lone independent variable is age; in Column 4, it is an indicator for college attendance. Column 5 includes both age and the college attendance indicator, as well as an indicator for having some training in economics, either in college or at lower levels if the individual did not attend college. Column 6 replicates Column 5 adding controls for marital status and gender and two-digit indicators for occupation. Columns 4-6 additionally restrict to those observations with non-missing data for college attendance. Panel B replicates the specification in Column 2 of Table IIIA, including interactions of the individual characteristics listed in each column with the change in employer pension contribution rate at the time of the firm switch $\Delta p^{E}$ and the direct effect of the same characteristics. All regressions include interactions between the change in total compensation $\Delta w$ and the individual characteristics listed in each column. The additional controls in columns 2 and 6 are not interacted with the changes in employer pensions or total compensation. All interacted characteristics except indicators are demeaned, so that the raw effect of the change in the employer pension contribution rate can be interpreted as the pass-through rate for individuals with mean values of the continuous variables and all indicator variables equal to zero. In all specifications in Panel B, we exclude individuals with taxable saving below the 1st and above the 99th percentile. We topcode the wealth/income ratio at the 99th percentile in both panels. Standard errors are reported in parentheses. We cluster standard errors in Panel A at the DKr 5,000 income bin level; we cluster standard errors in Panel B by the firm to which the individual switches. 


\section{FIGURE I}

\section{Effects of Employer Pensions on Savings Rates: Event Studies}

a) Switchers to Firms with $\geq 3 \%$ Increase in Employer Contribution

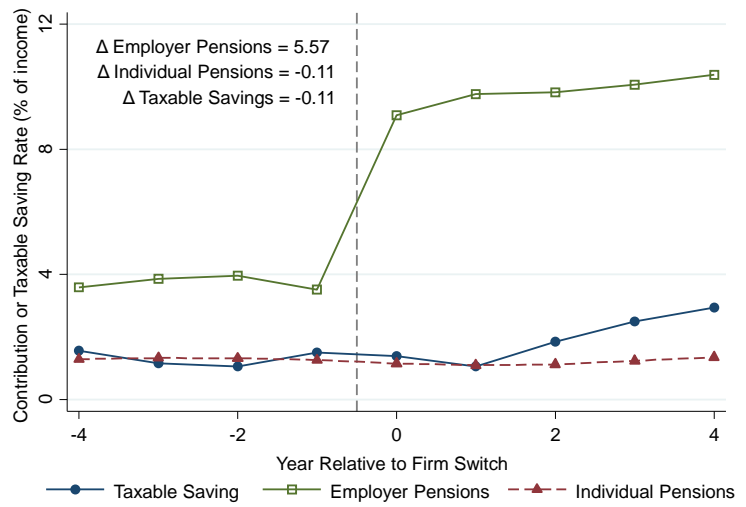

c) Fraction Saving More than New Level of Employer Pension Contribution

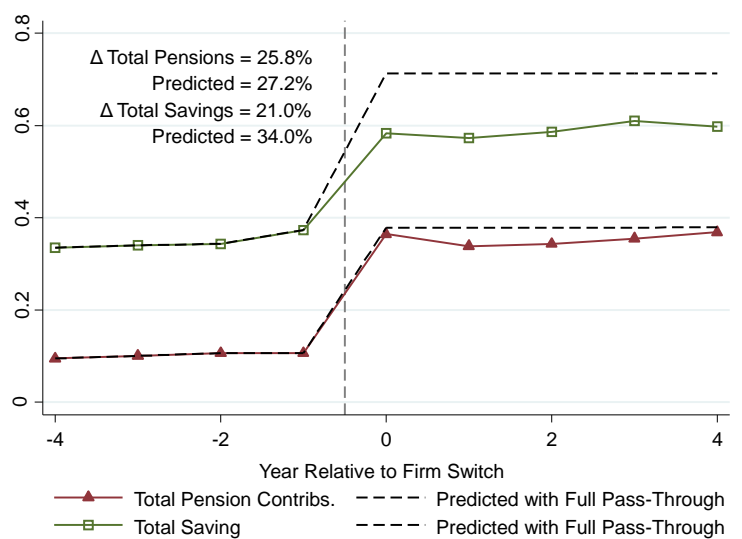

b) Switchers with Positive Individual Pension Contributions Prior to Switch

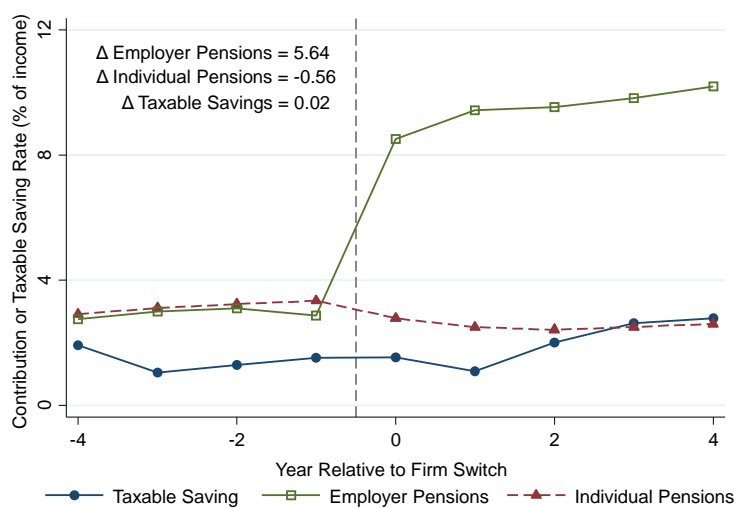

d) Changes in Individual Pension Contributions in Year of Firm Switch for Individuals Contributing Prior to Switch

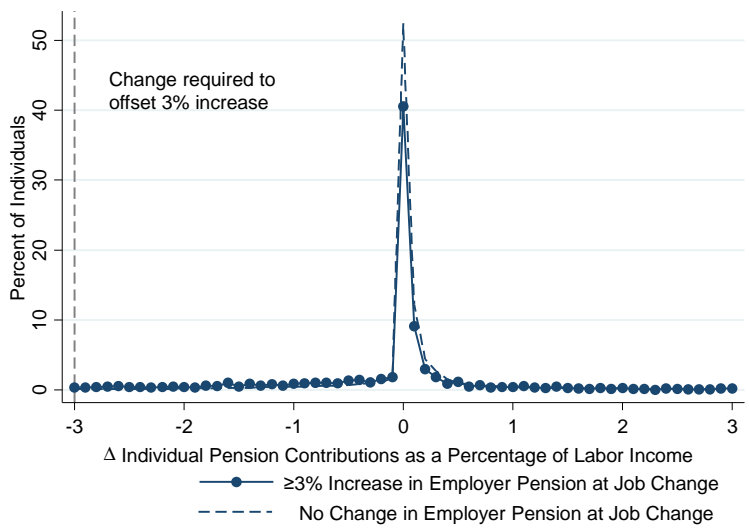

Notes: Panels A and B are event studies of pension contribution and taxable savings rates when workers switch firms. We include only the first firm switch for individuals in our data in these figures; hence, $t=0$ denotes the first year in which the primary firm ID in the data changes for an individual. Panel A plots an individuals mean taxable savings rate $\left(S_{i t}\right)$, individual pension contribution rate $\left(P_{i t}^{I}\right)$, and employer contribution rate $\left(P_{i t}^{E}\right)$, all measured as a percentage of current labor income $Y_{i t}$. We include only workers whose employer pension contribution rate increased by at least 3 percentage points of labor income at $t=0$. We also limit the sample to workers for whom data is available for event years [-4, +4$]$ so that the sample is constant through the figure. Panel B replicates Panel A, restricting further to the sample of workers with positive individual pension contributions prior to the switch $\left(P_{i, t=-1}^{I}>0\right)$. Panel $\mathrm{C}$ plots the effect of changes in employer pensions on total pension contributions and total saving using a threshold approach. The lower series (in red triangles) plots the fraction of individuals in Panel A with total pension contributions $\left(P_{i t}^{I}+P_{i t}^{E}\right)$ greater than the level of firm pension contributions at $t=0$. To isolate changes in individual pension contributions, we fix employer pension contributions at the $t=-1$ level for $t<0$ and at the $t=0$ level for $t>0$. The dashed line plots the predicted change in this threshold measure if there were no change in individual pension contributions. The upper series (in green squares) repeats the lower series using total saving $\left(S_{i t}^{t o t}\right)$ rather than total pension contributions to define the fraction above the threshold. The solid line in Panel D plots a histogram (with bin width of $0.1 \%$ ) of the change in individual pension contributions $P^{I}$, as a percentage of lagged contributions, from $t=-1$ to $t=0$, for the sample in Panel B. The dashed line in Panel D replicates this histogram, limiting attention to workers whose employer pension contributions changed by less than 0.5 percentage points of labor income in absolute value at $t=0$. 


\section{FIGURE II}

\section{Effects of Employer Pensions on Saving: Binned Scatter Plots}

a) Changes in Total Pension Contribution Rates vs.

Changes in Employer Pensions

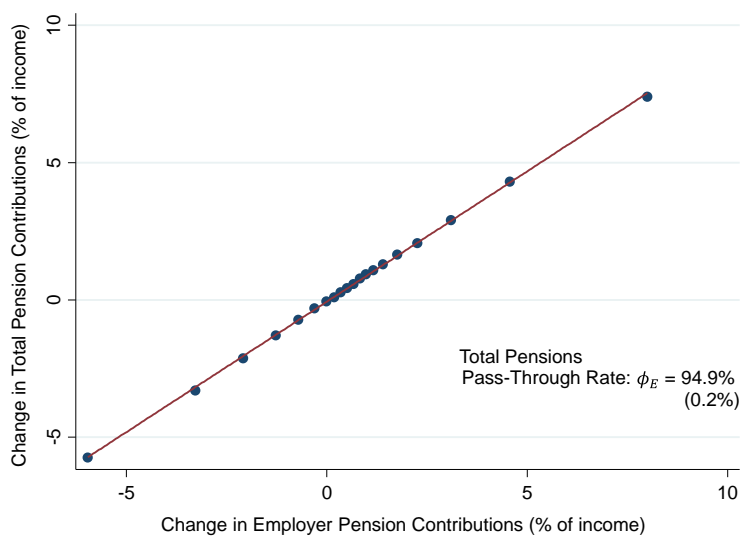

b) Changes in Total Savings Rates vs.

Changes in Employer Pensions

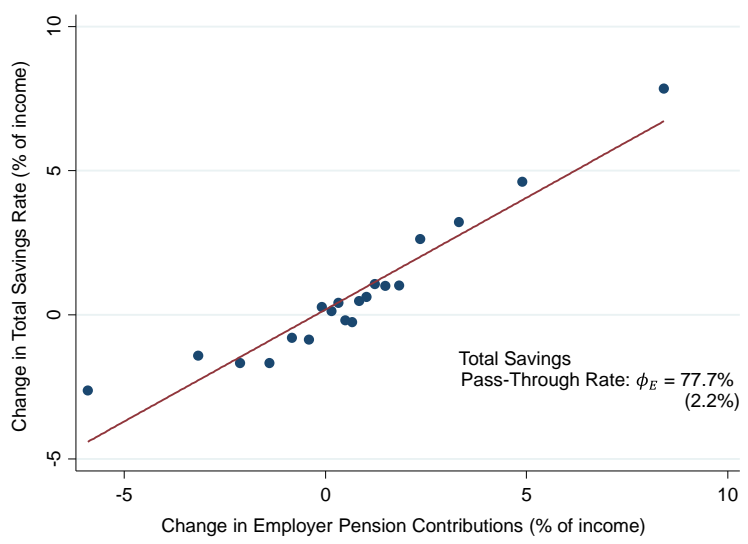

c) Changes in Total Savings Rates vs. Changes in Labor Income

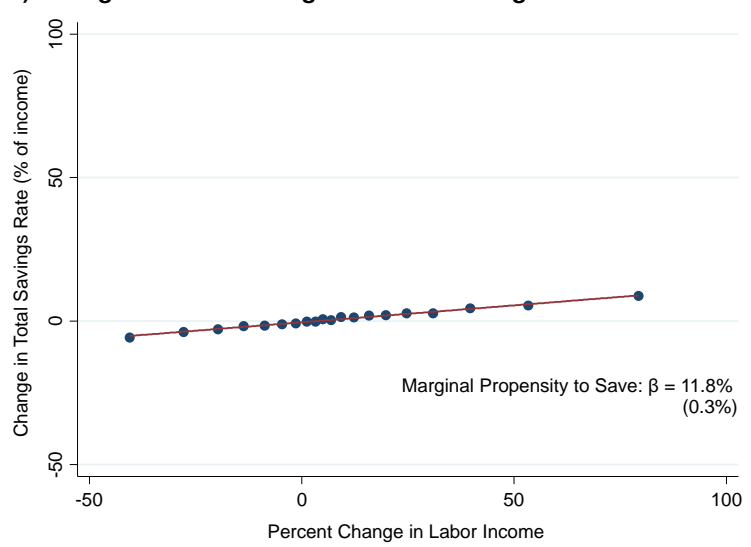

Notes: These figures display binned scatter plots corresponding to the estimates from Table III. All dependent and independent variables are measured as a percentage of gross labor income in the year prior to the switch. Panel A plots the relationship between the changes in total pension contribution rates $\Delta\left(p^{I}+p^{E}\right)$ and employer pension contribution rates $\Delta p^{E}$, controlling for the change in total compensation $\Delta w$. This plot corresponds to Table IIIA, Column 1; see notes to that table for sample definitions and further details. Panels B and C correspond to Table IIIA, Column 2 and use the same sample and definitions as in that column. Panel B plots the relationship between $\Delta s^{\text {tot }}$ and $\Delta p^{E}$, controlling for the change in total compensation $\Delta w$. Panel C plots the relationship between $\Delta s^{t o t}$ and $\Delta w$, controlling for the change in total compensation. To construct each figure, and all binned scatter plots that follow, we first residualize the $\mathrm{y}$ - and x-variables with respect to the control vector using an OLS regression estimated on the underlying regression sample. We then divide the $\mathrm{x}$-variable residuals into twenty ranked equal-sized groups (vingtiles) and plot the mean of the y-residuals against the mean of the x-residuals in each bin. The best-fit line, as well as the coefficient and the standard error reported in parentheses (which is clustered by destination firm in this figure), are calculated from multivariate regressions on the micro-data (corresponding to those in Table III in this figure). The coefficients reported in Panels A and B can be interpreted as the pass-through rate of employer pension rate changes to total pensions and savings, holding fixed total compensation. The coefficient reported in Panel C can be interpreted as the marginal propensity to save out of disposable income. 


\section{FIGURE III}

\section{Long-Term Impacts of Employer Pensions on Wealth Accumulation}

a) Pass-Through of Employer Pension to Total Savings by Years Since Firm Switch

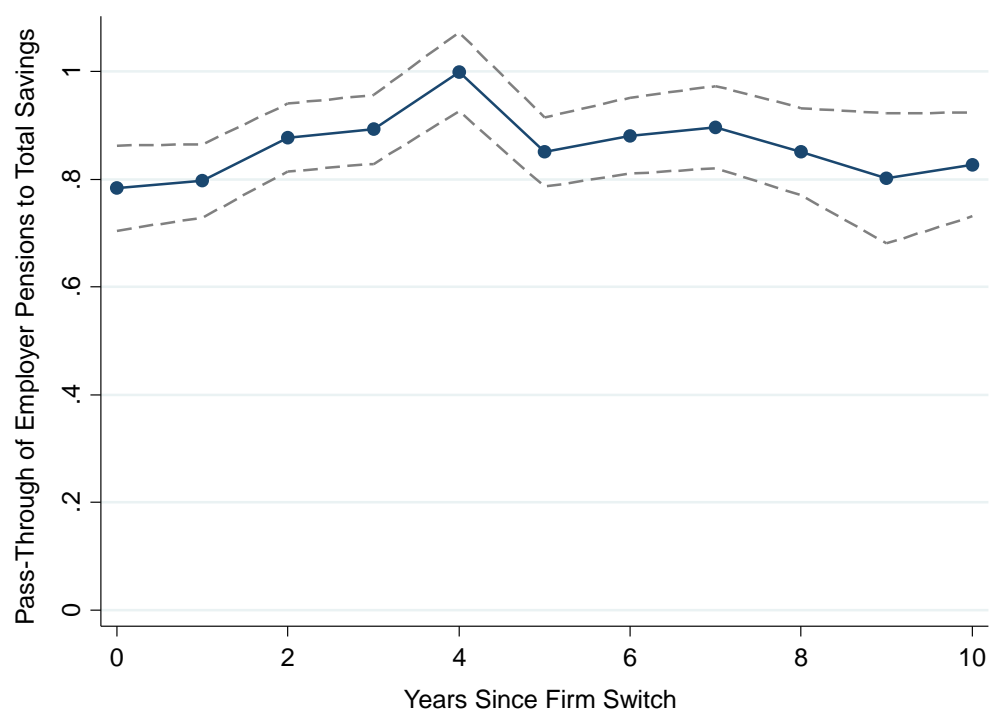

b) Wealth Accrued at Age 60 vs. Changes in Employer Pension Rates at Switch for Individuals who Switch Jobs Before Age 45

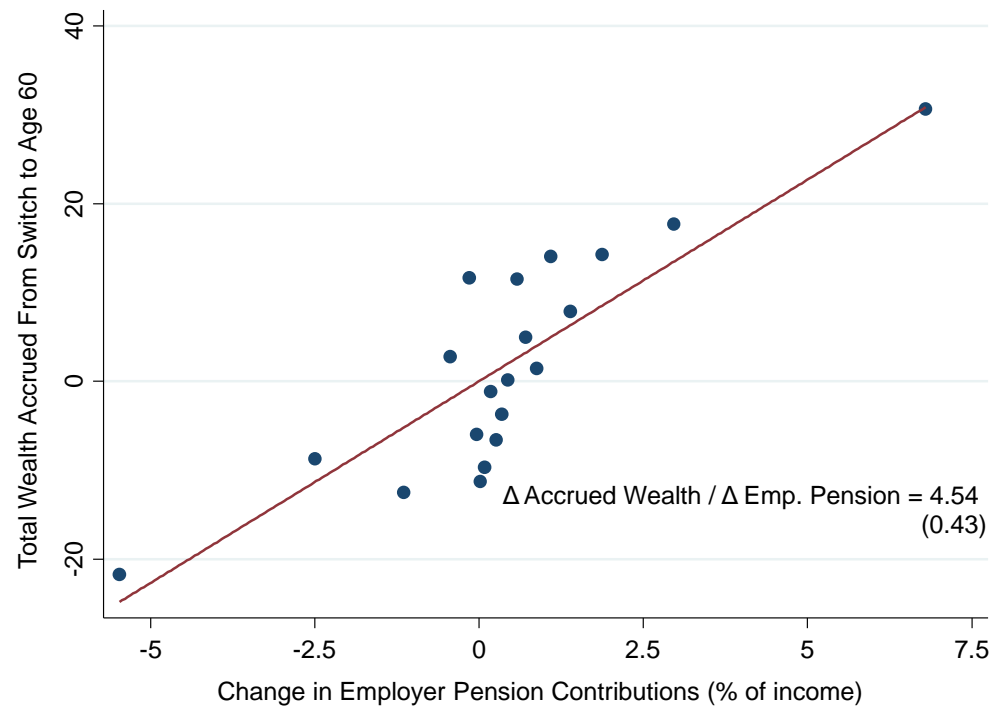

Notes: These figures show the long-term impacts of changes in employer pension contribution rates at the time of firm switches. Panel A plots the pass-through coefficients of changes in employer pension contribution rates to total saving at different horizons, replicating the specification in Table IIIA, Column 6 in each year after the event. For instance, the coefficient for $t=1$ represents the coefficient in a regression of the change from $t=-1$ to $t=1$ in the total savings rate on the change in employer pension rates over the same horizon, controlling for the change in total compensation over that horizon. The dashed lines represent the boundaries of the $95 \%$ confidence interval, using standard errors clustered by destination firm. Panel B is a binned scatter plot of the relationship between the change in employer contribution rates and total wealth accrued between the firm switch and age 60, corresponding to Table III, Panel A, Column 7. See notes to Table III for further details on the specifications and sample definitions; see notes to Figure II for further details on construction of the binned scatter plot. 


\section{FIGURE IV}

\section{Impact of Government Mandated Savings Plan: Regression Discontinuity Estimates}

a) Mandated Savings Around Eligibility Cutoff in 1998

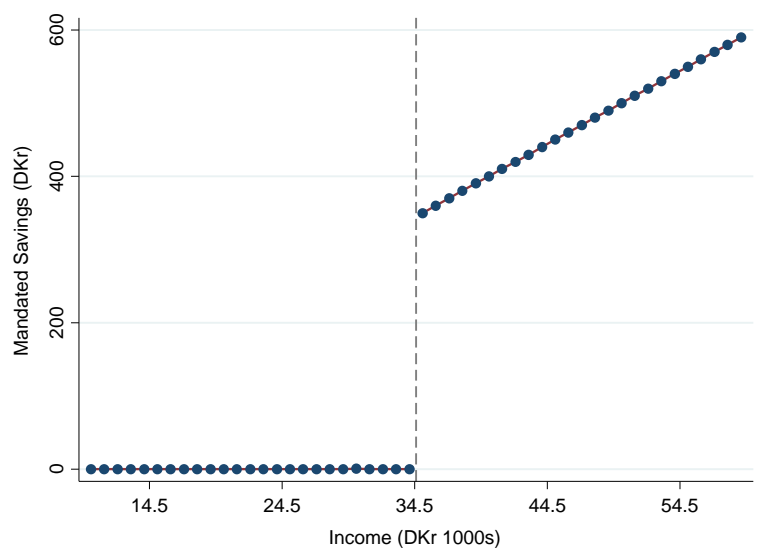

c) Total Pension Contributions Around Eligibility Cutoff

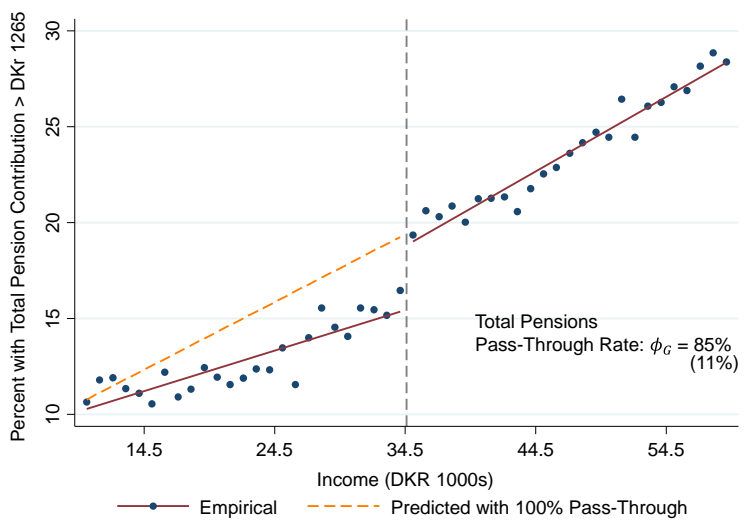

b) Balance Test: Income Distribution Around Eligibility Cutoff

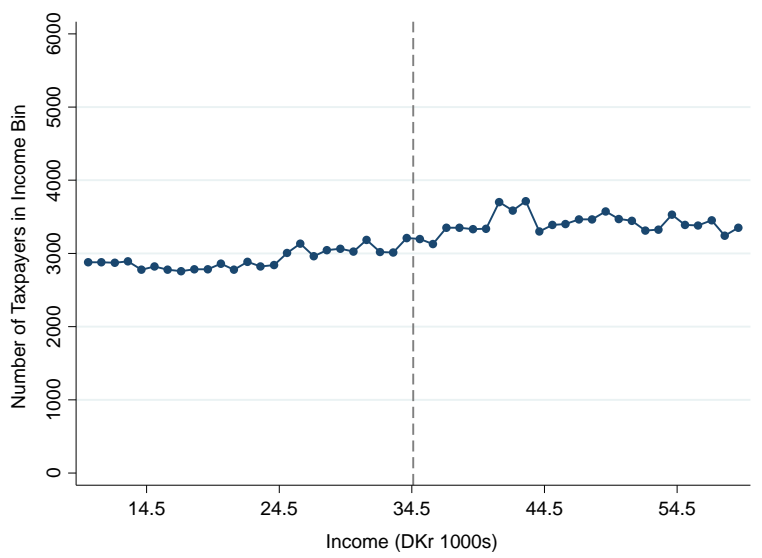

d) Total Saving Around Eligibility Cutoff

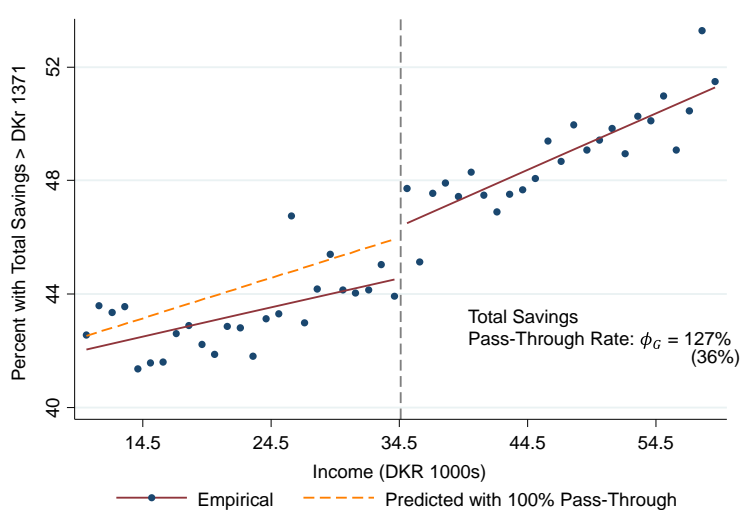

Notes: These figures present a regression discontinuity analysis of the impacts of the Mandated Saving Program (MSP) on total pension contributions and saving in 1998. All panels present the data in DKr 1,000 income bins relative to the threshold, so that the dot at DKr -500 includes all individuals with income in the range $[-1000,0)$. Panel A shows the contributions mandated by the program. Individuals with income below DKr 34,500 were not required to make any contributions; those earning more than this threshold were required to contribute $1 \%$ of income. Panel B plots the count of individuals in each bin around the threshold. Panel C plots the fraction of individuals in each bin with total pension contributions $\left(P=P^{E}+P^{I}+P^{G}\right)$ above DKr 1,265, the mean level of total pension contributions for individuals within DKr 5,000 of the threshold. Panel D plots the fraction of individuals in each bin with total saving $\left(S^{t o t}=P+S /(1-M T R)\right)$ above DKr 1,371 , the mean level of total saving for those within DKr 5,000 of the threshold. The solid lines plot the linear best-fit to the actul data above and below the threshold. The dashed lines plot the counterfactuals we use to calculate the increase one would observe under full pass-through (see Online Appendix A for details). We estimate pass-through in Panels C and D using the specifications in Columns 4 and 5 of Table IV. 


\section{FIGURE V}

\section{Impact of 1999 Subsidy Reduction On Capital Pension Contributions}

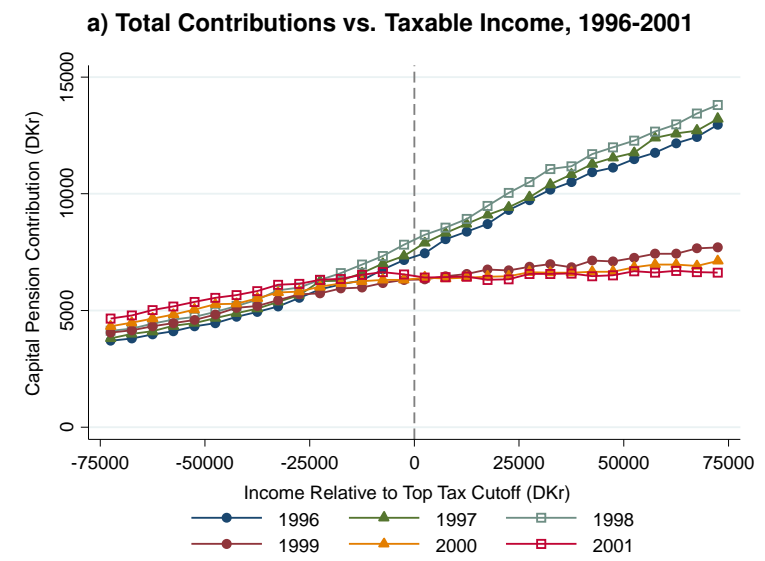

b) Individual Contributions Above vs. Below Top Tax Cutoff by Year

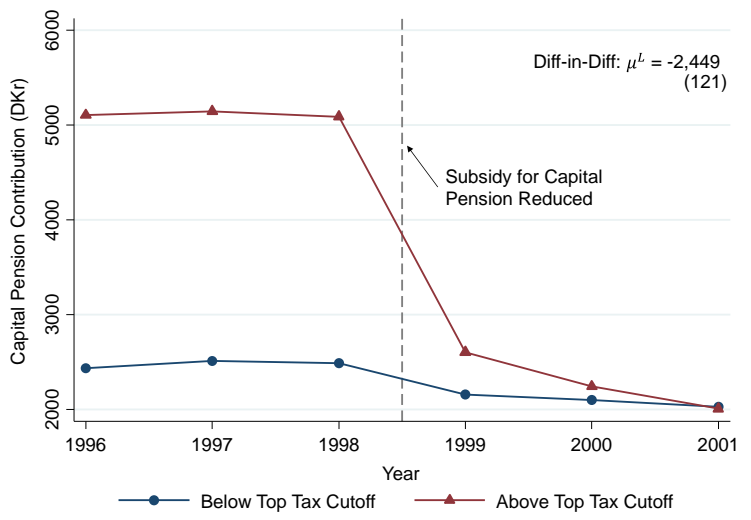

c) Difference in MPS for Individuals Above. vs. Below Top Tax Cutoff in Capital Pension Accounts by Year

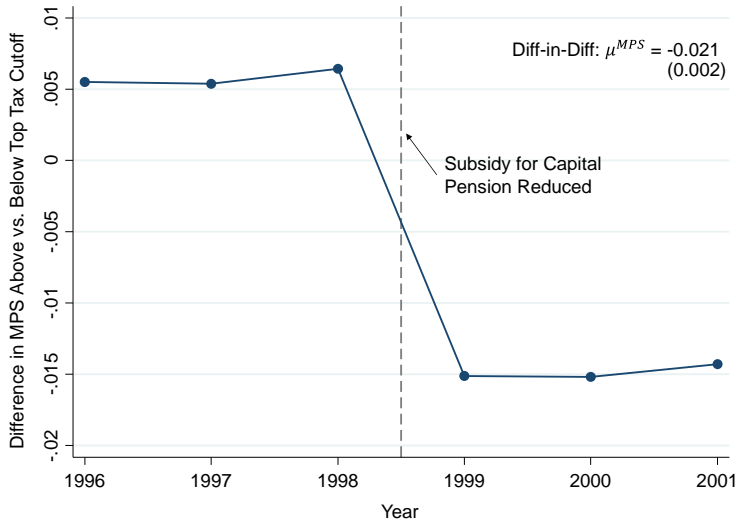

Notes: These figures illustrate the impact of the 1999 capital pension subsidy reduction on capital pension contributions. Panel A plots average total (individual plus employer) capital pension contributions for individuals with income in each DKr 5,000 income bin within DKr 75,000 of the top tax threshold, in each year 1996-2001. Panel B plots average individual capital pension contributions in each year for two income groups: those with income in the range DKr 75,000 to DKr 25,000 below the top tax threshold (control group), and in the range DKr 25,000 to DKr 75,000 above the top tax threshold (treatment group). Panel $\mathrm{C}$ plots the difference in the marginal propensity to save (MPS) in capital pension accounts between individuals above and below the top tax cutoff in each year. We estimate this difference in MPS in each year using equation (8). The coefficients reported in Panels B and C correspond to the specifications in Columns 1 and 3 of Table V. 


\section{FIGURE VI}

\section{Impact of 1999 Subsidy Reduction on Distribution of Individual Capital Pension Contributions}

a) Individuals Above Top Tax Cutoff

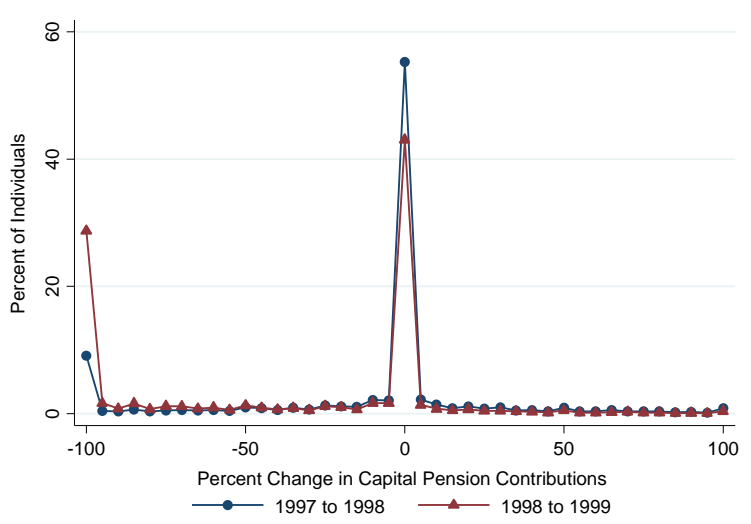

b) Individuals Below Top Tax Cutoff

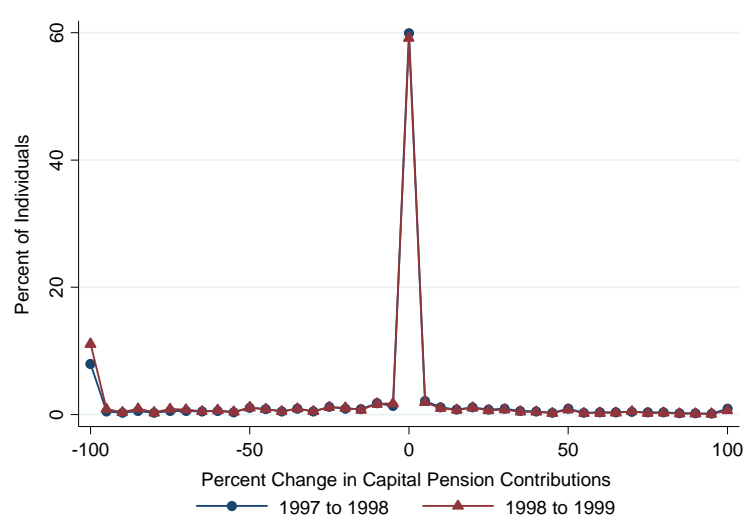

c) Effect of 1999 Reform on Rate of Capital Pension Contributions

for Individuals Contributing Prior to Reform

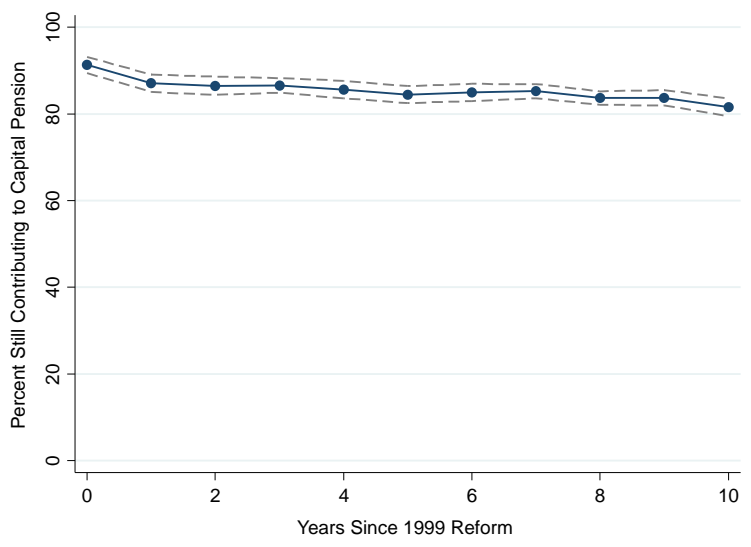

Notes: Panel A plots the distribution of changes to individual capital pension contributions, as a fraction of lagged individual pension contributions, for individuals who are DKr 25-75K above the top tax cutoff in 1998 and 1999 (the treatment group). Panel B replicates Panel A for those DKr 25-75K below the top tax cutoff (the control group). Both panels include only individuals with positive lagged individual pension contributions. The dots represent the floor of bins of $5 \%$ width, so that the dot at $0 \%$ represents individuals with changes in the range $[0 \%, 5 \%)$. Panel $\mathrm{C}$ shows the long-term dynamics of response to the 1999 reform for those who were contributing to capital pensions in 1998. To construct this figure, we first calculate the fraction of individuals with positive individual capital pension contributions in each post-reform year in the treatment and control groups. We then plot the difference between this fraction in the treatment and control groups and add 1 to facilitate interpretation of the scale. For instance, the dot at 91.3 in year 0 implies that the reform induced 8.7 percent of those contributing in 1998 to stop contributing in 1999. The dashed lines represent the boundaries of the $95 \%$ confidence interval, estimated from a DD regression analogous to (7), with standard errors clustered at the DKr 5,000 income bin level. 


\section{FIGURE VII}

\section{Crowd-out Within Retirement Accounts Induced by Subsidy to Capital Pensions}

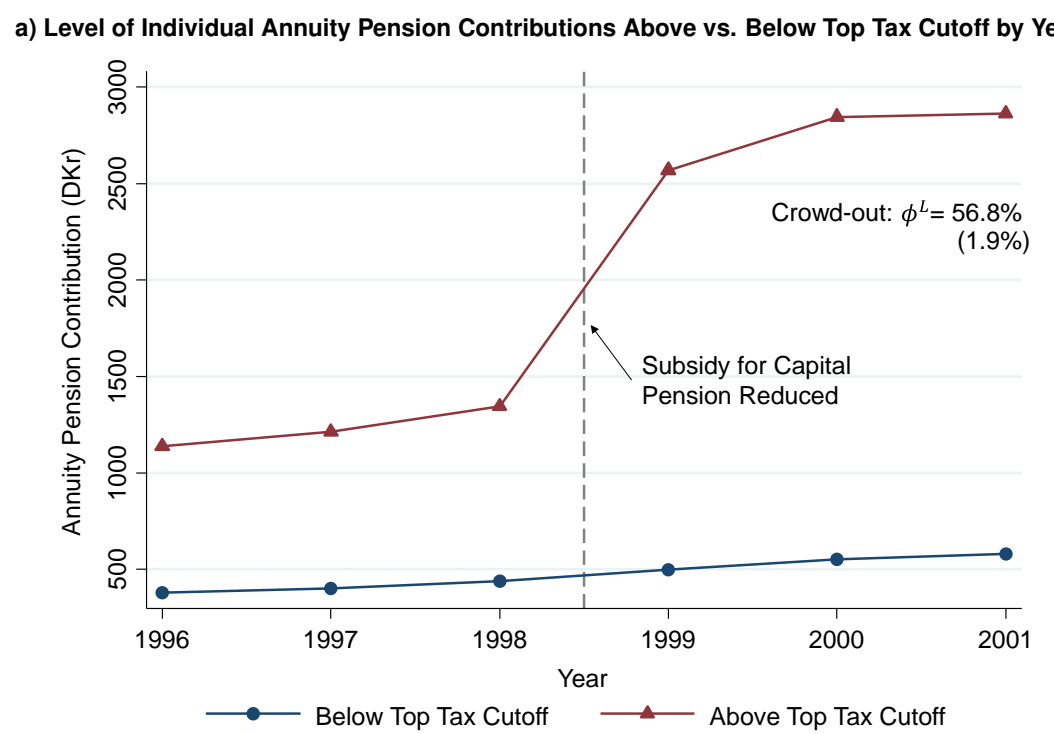

b) Difference in MPS for Individuals Above. vs. Below Top Tax Cutoff in Capital and Annuity Accounts by Year

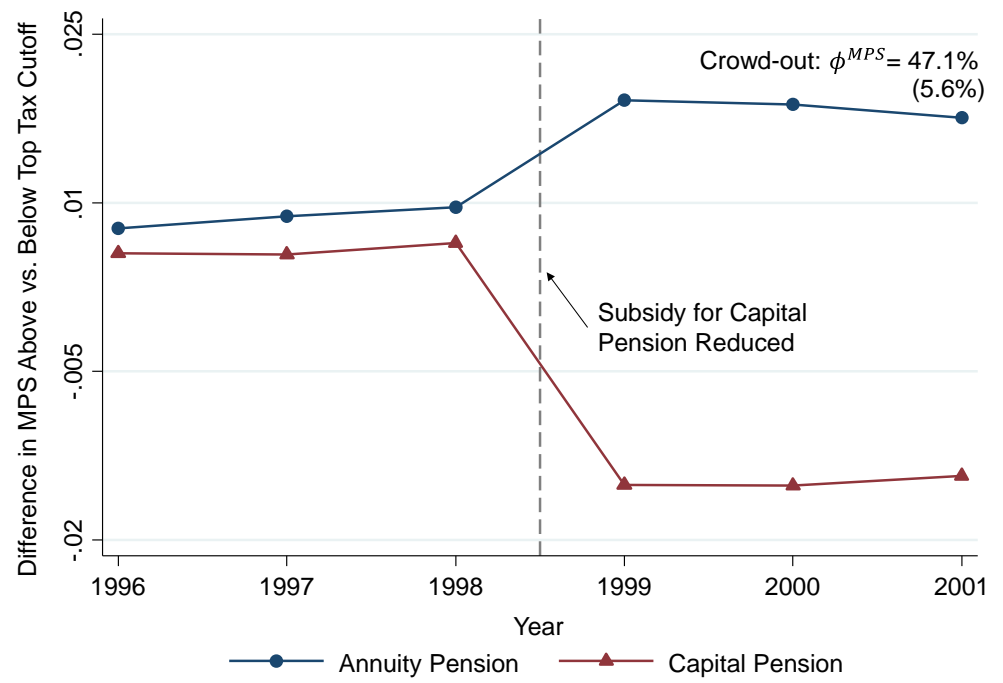

Notes: Panel A replicates Figure Vb, plotting mean individual annuity (rather than capital) pension contributions in the treatment and control groups by year. The series in circles in Panel B replicates Figure Vc, plotting the difference in the marginal propensity to save (MPS) in annuity (rather than capital) accounts between those above vs. below the top tax cutoff. The series in triangles in Panel B replicates the series in Figure Vc exactly as a reference. See notes to Figure V for further details on the construction of these figures. The crowd-out coefficients reported in the figures are estimated using the specifications in Columns 1 and 4 of Table VI, with standard errors clustered at the DKr 5,000 income bin level. 


\section{FIGURE VIII}

\section{Crowd-out of Taxable Saving Induced by Subsidy}

a) Difference in MPS for Individuals Above. vs. Below Top Tax Cutoff in Retirement and Taxable Savings Accounts by Year

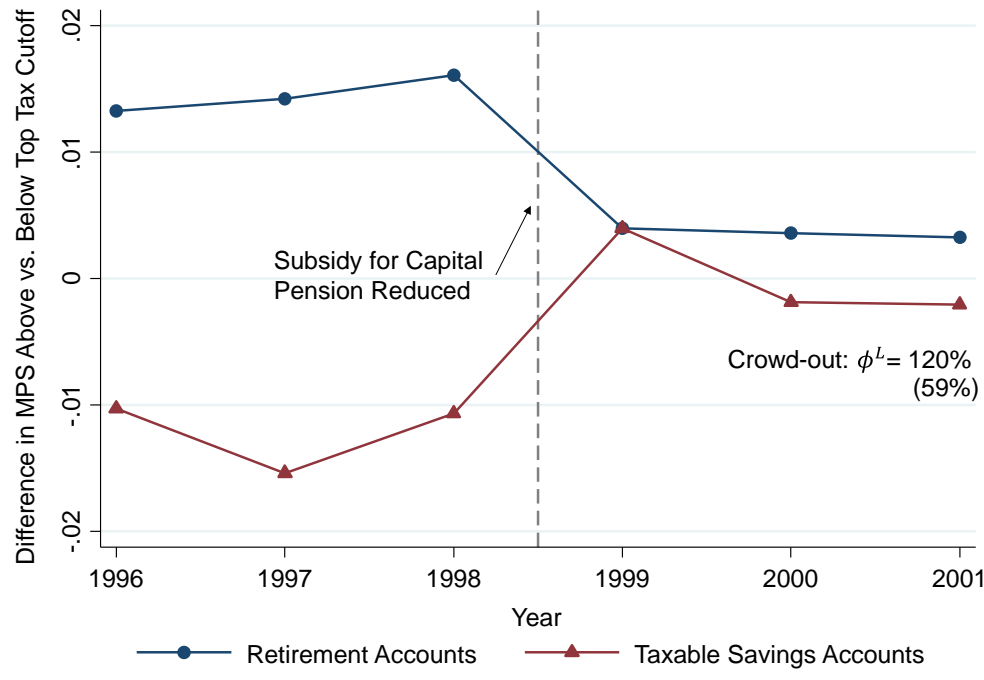

b) Change in Median Taxable Saving After Subsidy Reduction by Income Group

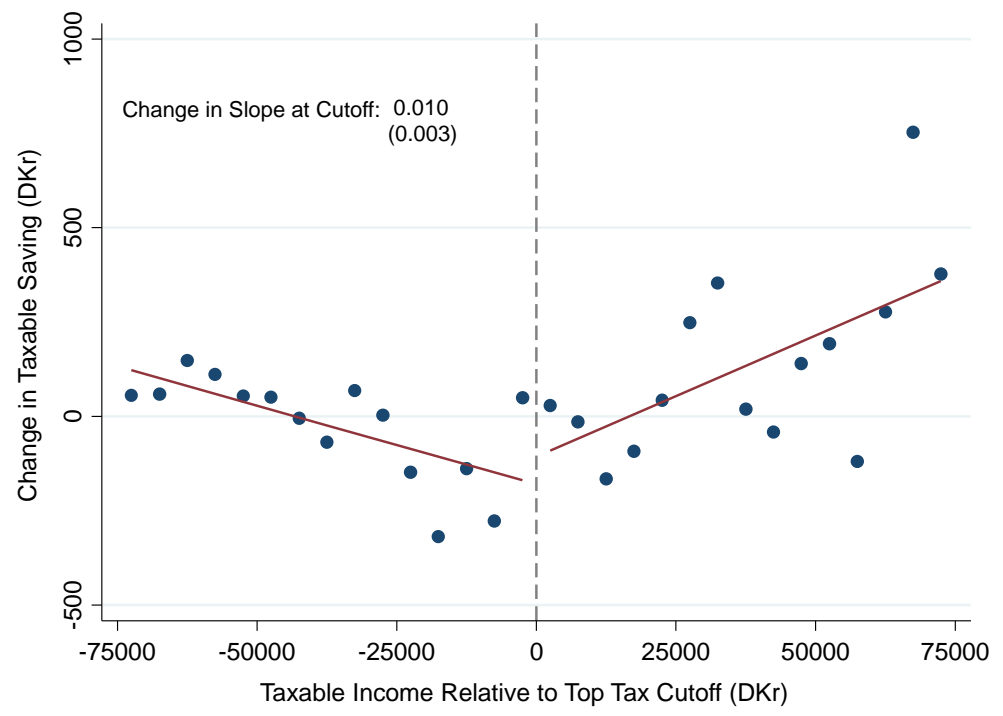

Notes: Panel A is constructed in the same way as Figure Vc. The series in circles plots the difference in the marginal propensity to save (MPS) in retirement accounts (capital plus annuity) between individuals above and below the top tax cutoff in each year. We estimate this difference in MPS in each year using equation (8). The series in triangles repeats this exercise for saving in non-retirement (taxable) accounts, showing the difference in the MPS in taxable accounts for individuals above the top tax cutoff vs. those below the top tax cutoff in each year. Retirement account contributions are total individual contributions $P_{I}$. Taxable saving is measured in pre-tax dollars $(S /(1-0.6)$, using the marginal income tax rate of $60 \%$ in the top tax bracket. The crowd-out estimate reported in Panel A is based on the specification in Column 1 of Table VII. Panel B plots median taxable saving (again measured in pre-tax dollars) in the post-reform years (1999-2001) minus pre-reform years (1996-1998) in each DKr 5,000 taxable income bin. The solid lines show the best linear fits to the points below the cutoff and above the cutoff, estimated on the underlying microdata. The difference in the slopes of these lines can be interpreted as an estimate of the change in the MPS in taxable accounts when the subsidy was reduced for individuals in the top tax bracket in 1999. The coefficient for the change in slope at the threshold reported on the figure is estimated in Column 3 of Table VII. 


\section{APPENDIX TABLE I}

\section{Robustness Checks of Pass-Through Estimates}

\begin{tabular}{|c|c|c|c|c|}
\hline & $\begin{array}{c}\text { Full Sample } \\
\text { Including Corners } \\
(1)\end{array}$ & $\begin{array}{l}\text { Renters } \\
\qquad(2)\end{array}$ & $\begin{array}{c}\text { Household Saving } \\
\text { (3) }\end{array}$ & $\begin{array}{c}\text { Single Individuals } \\
\text { (4) }\end{array}$ \\
\hline \multicolumn{5}{|c|}{ Panel A: Effect of Employer Pensions on Total Saving (Table IIIA, Column 2) } \\
\hline$\Delta$ Employer Pension Rate & $\begin{array}{c}0.747 \\
(0.015)\end{array}$ & $\begin{array}{c}0.818 \\
(0.027)\end{array}$ & $\begin{array}{c}0.739 \\
(0.024)\end{array}$ & $\begin{array}{c}0.775 \\
(0.034)\end{array}$ \\
\hline Observations & $3,582,391$ & 841,398 & $1,840,435$ & 708,579 \\
\hline \multicolumn{5}{|c|}{ Panel B: Effect of MSP on Total Saving (Table IV, Column 5) } \\
\hline Pass-Through RD & $\begin{array}{c}1.021 \\
(0.051)\end{array}$ & $\begin{array}{c}1.577 \\
(0.410)\end{array}$ & $\begin{array}{c}1.328 \\
(0.508)\end{array}$ & $\begin{array}{c}1.769 \\
(0.571)\end{array}$ \\
\hline Observations & 155,735 & 119,033 & 148,380 & 92,647 \\
\hline \multicolumn{5}{|c|}{ Panel C: Subsidy Change and Crowd-out of Taxable Saving (Table VII, Column 5) } \\
\hline Total Pension Contrib. & & $\begin{array}{c}-1.215 \\
(0.453)\end{array}$ & $\begin{array}{l}-0.907 \\
(0.314)\end{array}$ & $\begin{array}{l}-1.409 \\
(0.528)\end{array}$ \\
\hline Observations & & $2,327,951$ & $7,026,187$ & $1,897,831$ \\
\hline
\end{tabular}

Notes: This table replicates key specifications using alternative samples or dependent variables to evaluate the robustness of the results. Panel A replicates the specification in Table IIIA, Column 2, measuring the effect of a change in the employer pension contribution rate on total saving at the time of a firm switch. Panel B replicates the specification in Table IV, Column 5, measuring the effect of the Mandated Savings Plan on total saving using a threshold indicator for having above-average saving. Panel C replicates the specification in Table VII, Column 5, measuring the effect of the 1999 capital pension subsidy reform on crowd-out in taxable saving using a threshold indicator for having taxable saving above the median. See notes to the earlier tables for further details on each specification. In Column 1, we replicate the specifications in the first two panels including all individuals, not just those who are not at the lower corner in saving in the prior year. In Column 2 , we replicate the three original specifications exactly, restricting to individuals who do not own homes (i.e., have zero home equity). In Column 3, we replicate each specification including partner's taxable assets in our savings measure where present. In Panel A of Column 3, the dependent variable is the change in the household saving rate (measured as a percentage of the individual's own labor income, with observations below the 1st or above the 99th percentile of the distribution excluded); in Panels B and $\mathrm{C}$, the dependent variable is a dummy variable for having household saving (or household taxable saving) above the relevant sample mean or median. In Column 4, we replicate the three original specifications exactly, restricting to individuals who do not have a partner, defined as in the notes to Table II. 


\section{APPENDIX TABLE II}

\section{Employer Responses to 1999 Capital Pension Subsidy Reduction}

\begin{tabular}{|c|c|c|c|c|}
\hline Dep. Var. & $\begin{array}{c}\text { Capital Pension } \\
\text { Contribs. } \\
(1)\end{array}$ & $\begin{array}{c}\text { Annuity } \\
\text { Crowd-out } \\
(2)\end{array}$ & $\begin{array}{c}\text { Total Pension } \\
\text { Pass-Through } \\
(3)\end{array}$ & $\begin{array}{c}\text { Total Pension } \\
\text { Pass-Through } \\
(4)\end{array}$ \\
\hline Above Cutoff $\times$ Post & $\begin{array}{r}-2645 \\
(173)\end{array}$ & & & \\
\hline $\begin{array}{l}\text { Capital Pension } \\
\text { Contrib. }\end{array}$ & & $\begin{array}{l}-1.011 \\
(0.041)\end{array}$ & $\begin{array}{c}-0.011 \\
(0.041)\end{array}$ & $\begin{array}{l}-0.078 \\
(0.035)\end{array}$ \\
\hline Controls & & & & $\mathrm{X}$ \\
\hline Observations & $4,707,788$ & $4,707,788$ & $4,707,708$ & $4,707,708$ \\
\hline
\end{tabular}

Notes: Column 1 presents estimates of the impact of the 1999 subsidy reduction on employer contributions to capital pension accounts. This column replicates Column 1 of Table V, changing the dependent variable to employer capital pension contributions. Columns 2-4 replicate Columns 1-3 of Table VI, changing the dependent variables to employer pensions instead of individual pensions and replacing the endogenous independent variable with employer capital pensions instead of individual capital pensions. As in Table VI, we instrument for the endogenous variable with the DD interaction term. All specifications are estimated using data from 1996-2001. Standard errors, reported in parentheses, are clustered at the DKr 5,000 income bin level. 


\section{APPENDIX FIGURE I}

\section{Mandated Savings Account Balance Notification Letter}

Dit árlige overblik over dine pensioner hos ATP

Du har to pensioner hos ATP - ATP Ratepension (ogsa kaldet SP-opsparing) og ATP Livstang

Pension. Pensionerne kan du tidligst fá udbetalt, fra du fylder 65 ár. I brevet her kan du bla

se, hvad der er indbetalt for dig.

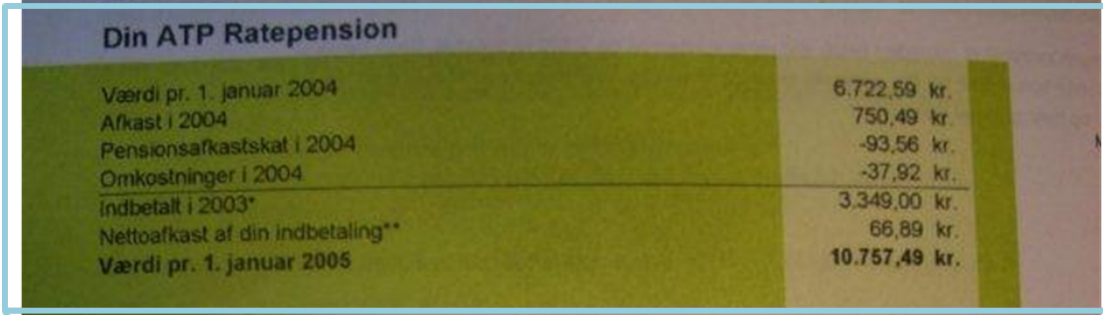

Fia 1 januar 2005 fik du 3 valigmuligheder for din ATP Ratepension (SP-opsparing). Du kan vælge at flytte pengene til et andet selskab, at investere dem selv pà ATP's folkebrrs eller la. de ATP fortsælte med at investere dem for dig.

1

Ved dødsfald udbetaler vi værdien af din ATP Ratepension til dødsboet, efter der er betalt afgift til staten pá $40 \%$.

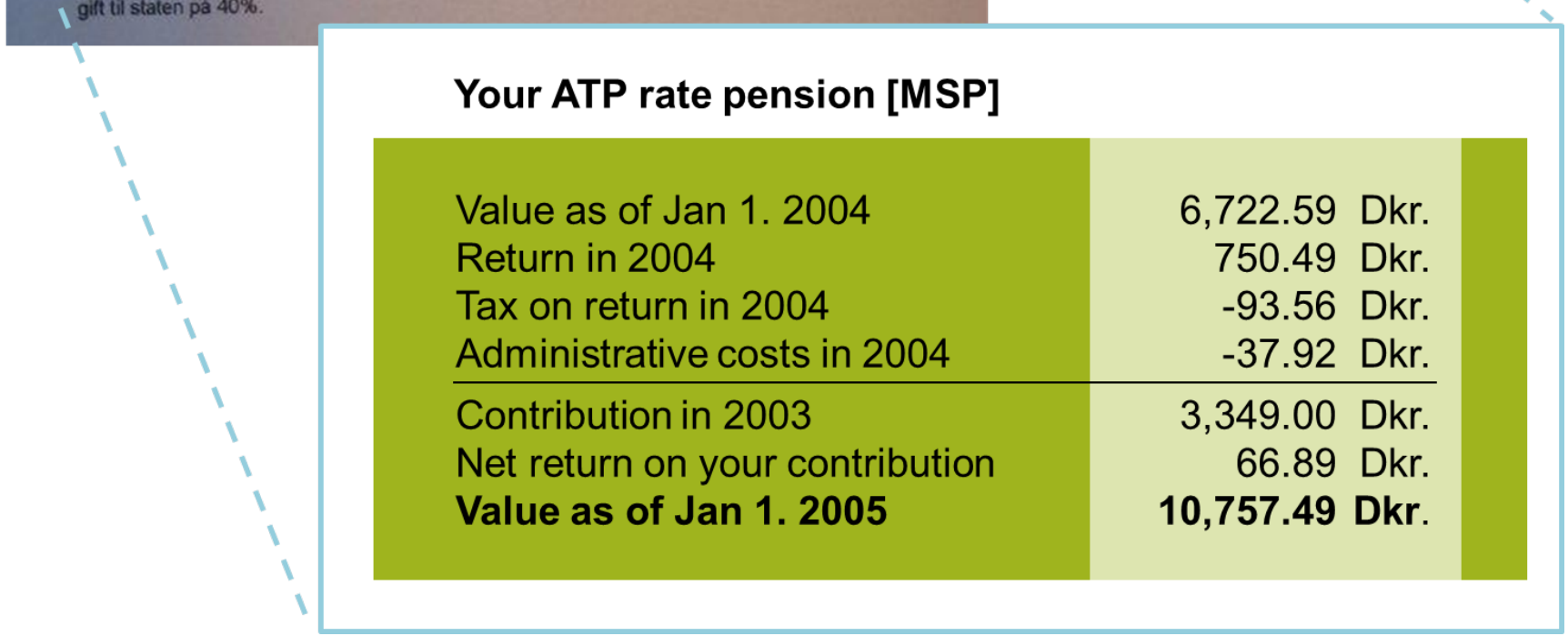

Notes: This figure presents a pension balance notification letter sent to a Danish citizen in 2004. These letters were sent annually by ATP, Denmark's largest pension company, giving citizens information about the balance in their mandated savings account. 


\section{APPENDIX FIGURE II}

\section{Impact of Mandated Savings Plan: Difference-in-Differences Design}

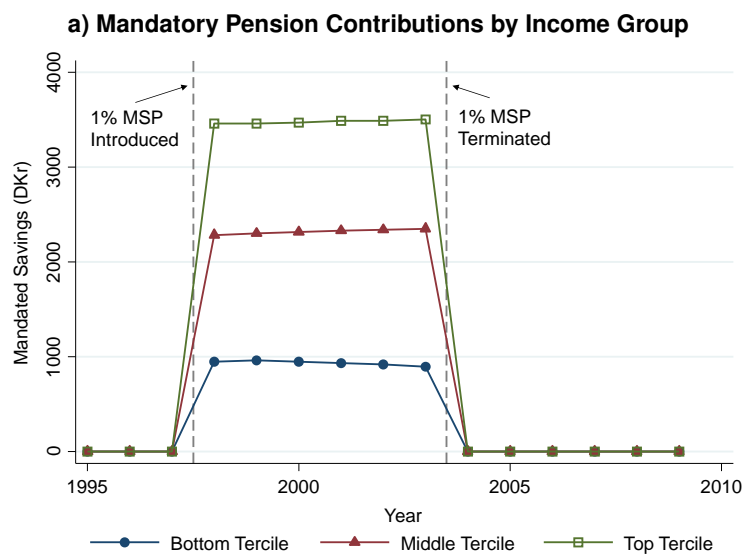

b) Total Non-Employer Pension Contributions by Income Group

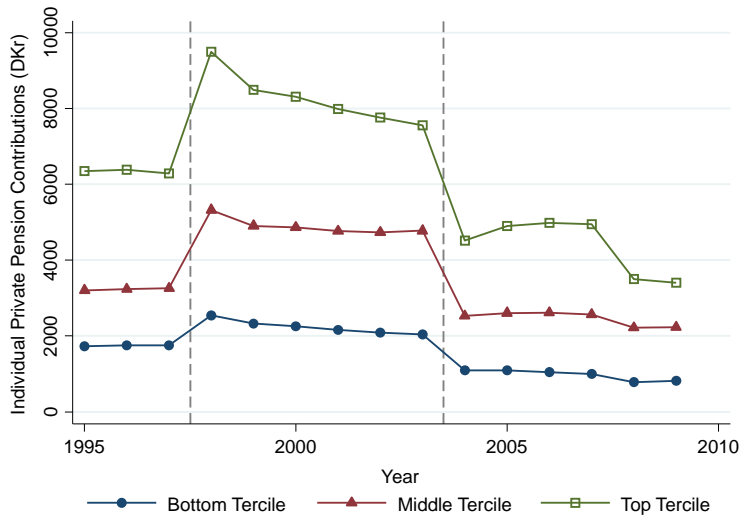

c) Percent of Individuals Contributing More than $1.5 \%$ of Income to Pensions

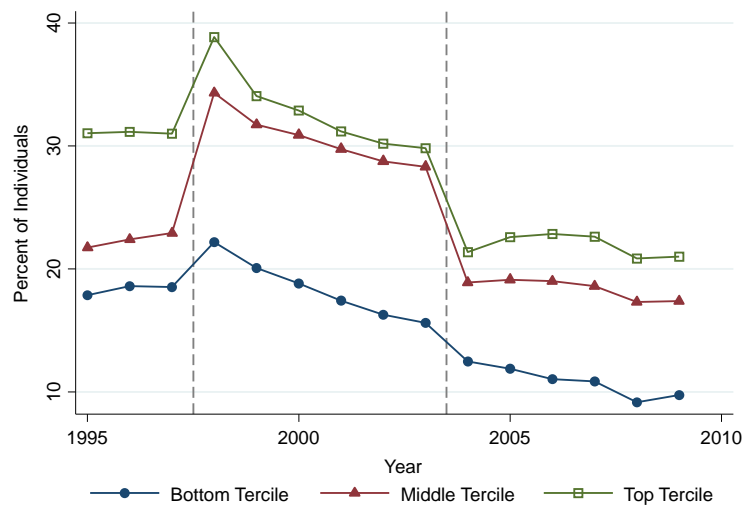

Notes: These figures present the effect of the Mandated Savings Plan (MSP) on total non-employer pension contributions. In all three panels, we split the data into terciles based on labor income in each year. Individuals may therefore switch groups across years. We include only observations with positive labor income. Panel A plots the average contribution to the MSP in each year for these three groups $\left(P^{G}\right)$. Panel B plots the average total non-employer pension contribution $\left(P^{I}+P^{G}\right)$ in each year for the three groups. Panel $\mathrm{C}$ plots the fraction of individuals in each group with total non-employer pension contributions greater than $1.5 \%$ of income, which is the mean total non-employer contribution rate for the sample across all years. 


\section{APPENDIX FIGURE III}

\section{Levels and Marginal Propensity to Save in Taxable Accounts Around 1999 Subsidy Change}

a) Mean Levels of Taxable Saving Above vs. Below Top Tax Cutoff by Year

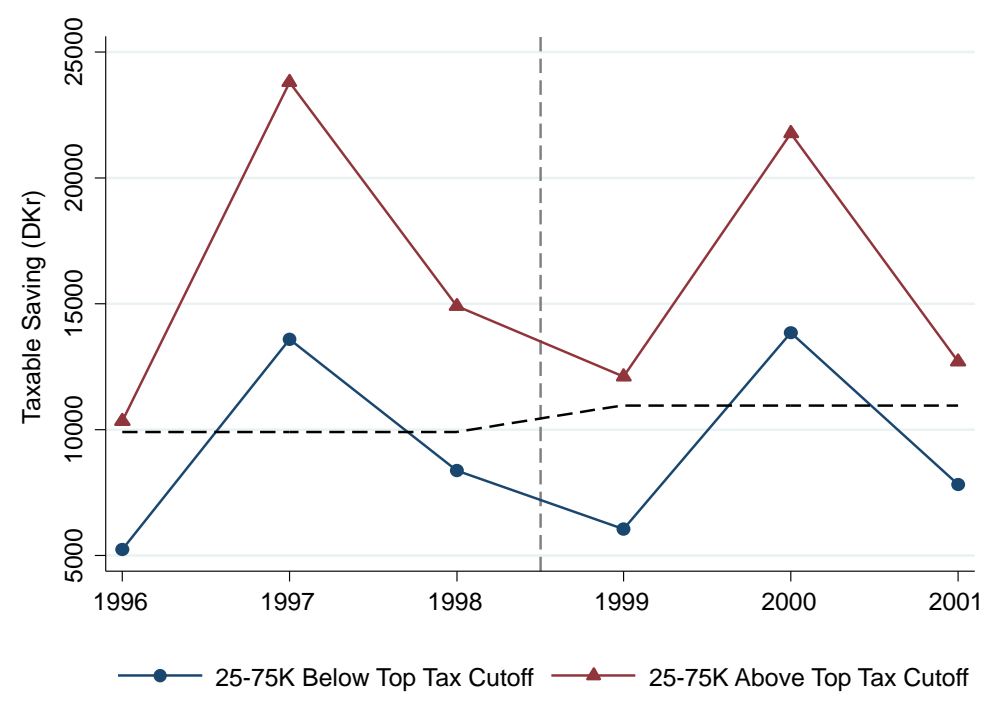

b) Marginal Propensity to Save in Taxable Accounts for Individuals Above vs. Below Top Tax Cutoff by Year

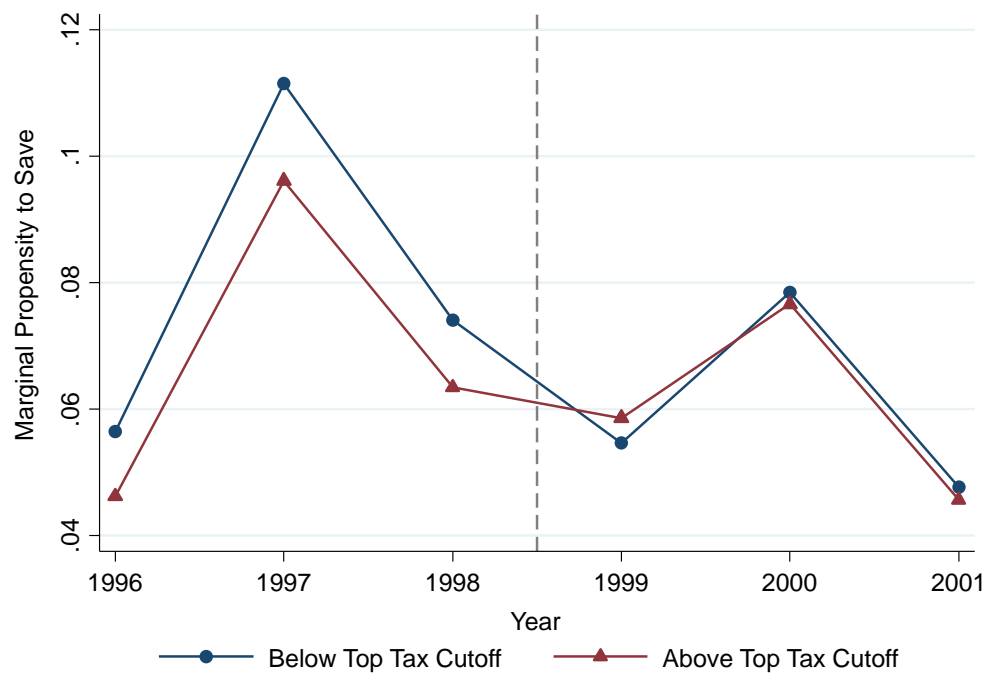

Notes: Panel A plots the mean level of taxable savings for individuals 25-75K above the top tax cutoff (the treatment group) and $25-75 \mathrm{~K}$ below the top tax cutoff (control group) by year. It replicates Figure Vb, replacing mean capital pension contributions with mean taxable saving levels (measured in pre-tax dollars using the top bracket marginal tax rate, $S /(1-0.6)$ ) as the $\mathrm{y}$ variable. The dashed series plots the impact on total pension contributions as a reference (on a separate y scale). Panel B plots the marginal propensity to save in taxable savings accounts for individuals above vs. below the top tax cutoff. We construct this figure by regressing taxable saving $(S /(1-0.6))$ on taxable income separately for each year and for individuals DKr $0-75 \mathrm{~K}$ below the top cutoff and those DKr 0-75K above the top tax cutoff. We then plotting the resulting regression estimates for the two groups. Note that the lower series in Figure VIIIa is simply the difference between the series plotted in Panel B of this figure. 


\section{APPENDIX FIGURE IV}

\section{Permutation Tests for Levels Estimator of Crowd-out in Taxable Saving}

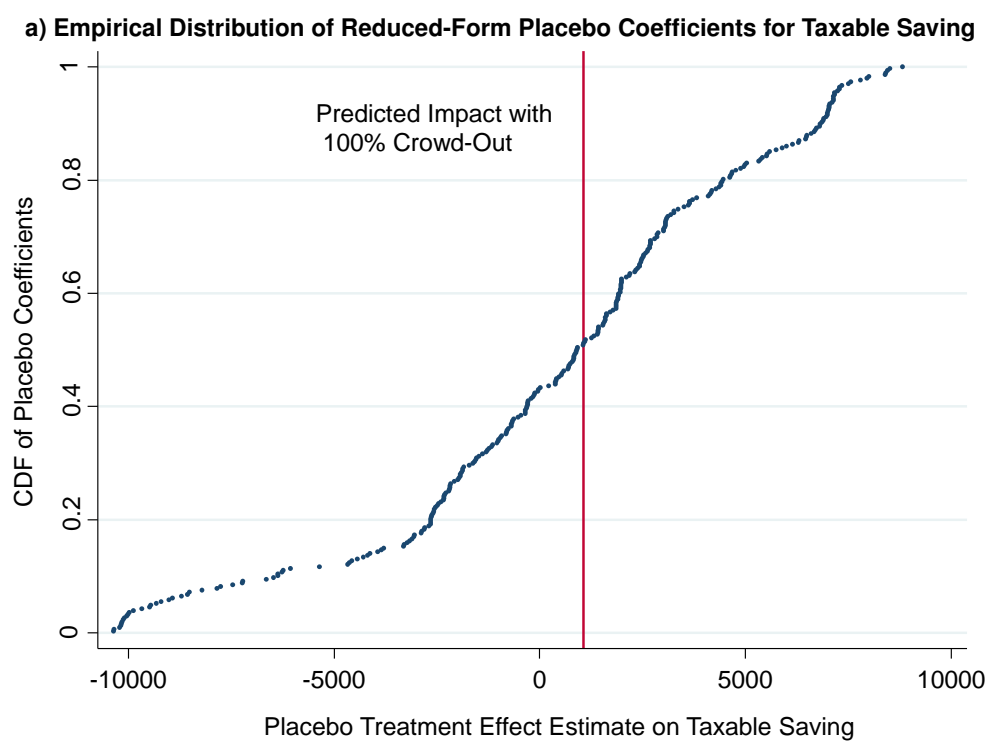

b) Empirical Distribution of Reduced-Form Placebo Coefficients for Trimmed Taxable Saving

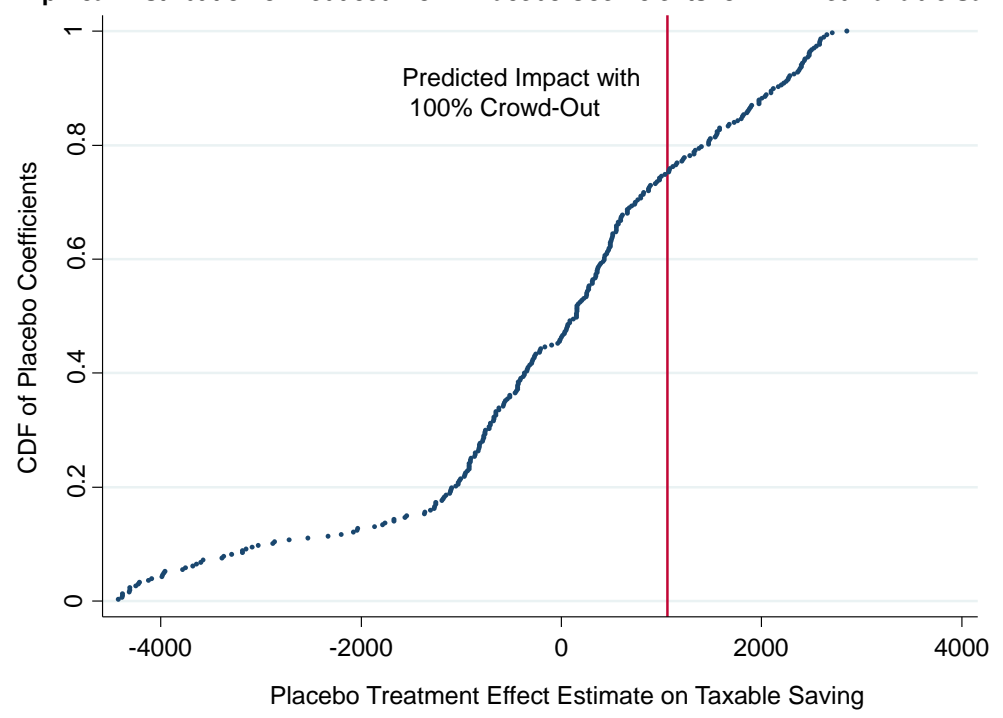

Notes: Panel A shows an empirical CDF of estimated impacts of placebo subsidy changes on taxable saving levels. We construct this figure as follows. Let $t_{p}$ denote a year between 1999 and 2006 and $\bar{Y}_{p t}$ a placebo cutoff for the top tax bracket. We consider a grid of values for $\bar{Y}_{p t}$ from DKr 200,000 below to DKr 200,000 above the actual top tax cutoff in year $t$ in increments of DKr 10,000. For each combination of $\left\{t_{p}, \bar{Y}_{p t}\right\}$, we estimate the levels DD reduced-form model shown in (14), using the level of taxable saving measured in pre-tax dollars $(S /(1-0.6))$ as the dependent variable. We restrict the sample to 3 years before and after the placebo reform year and incomes $25-75 \mathrm{~K}$ above or $25-75 \mathrm{~K}$ below the placebo top tax cutoff in those years. The figure plots the cumulative distribution function of coefficient estimates for all the placebos, excluding the coefficients from 1999 with $\bar{Y}_{p t}$ within DKr 100,000 of the true cutoff to avoid biasing the placebo tests with the true treatment effect. The vertical line shows the treatment effect one would observe under $100 \%$ crowd-out, i.e. if the change in taxable saving (in pre-tax dollars) were equal to the reduction in individual pension contributions shown by the dashed line in Appendix Figure IIIA. Panel B replicates Panel A, winsorizing the taxable saving measure at the 10 th and 90 percentiles, as in Column 2 of Table VII. 


\section{APPENDIX FIGURE V}

\section{Permutation Tests for MPS Estimator of Crowd-out in Taxable Saving}

a) CDF of Placebo t-statistics for Crowd-out Estimates: Trimmed

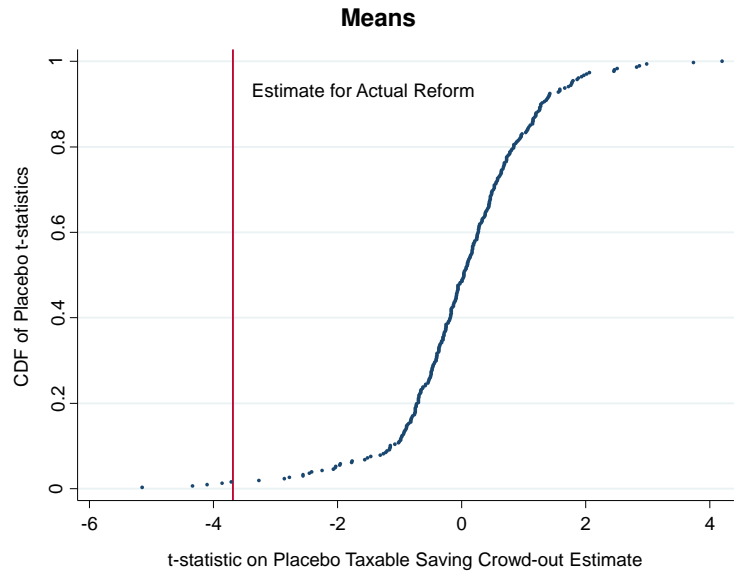

c) CDF of Placebo $p$ values for Crowd-out Estimates: Trimmed

Means

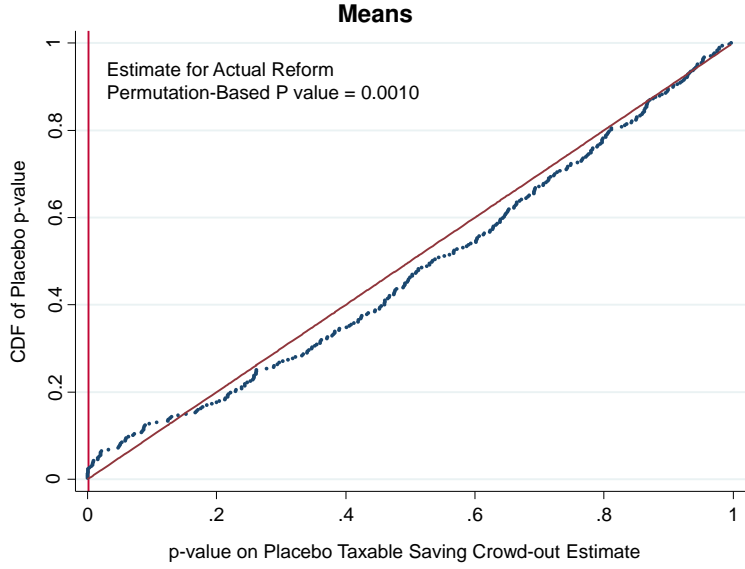

b) CDF of Placebo t-statistics for Crowd-out Estimates: Threshold

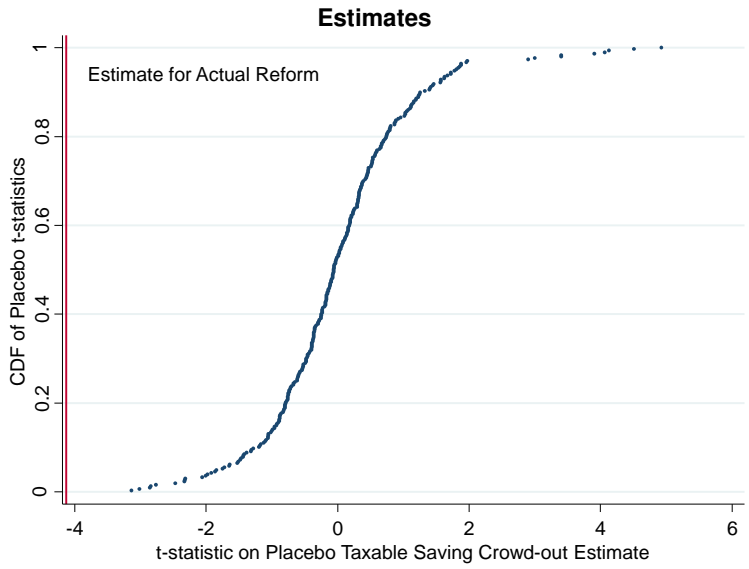

d) CDF of Placebo p values for Crowd-out Estimates: Threshold Estimates

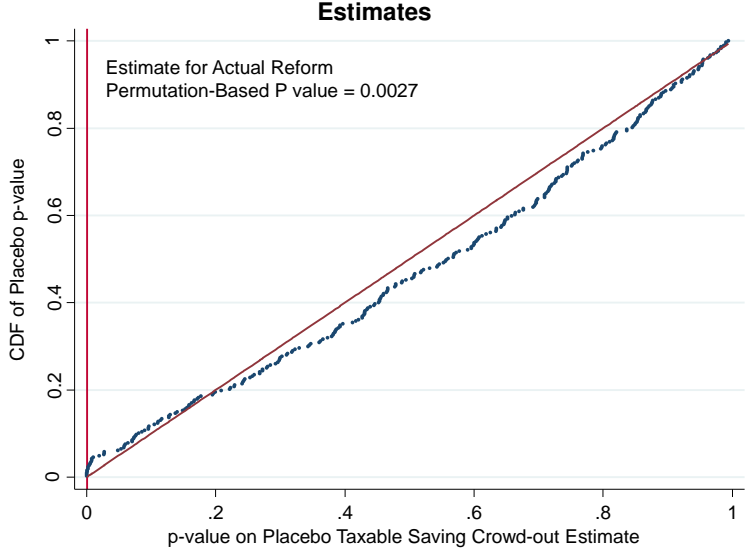

Notes: Panel A shows an empirical CDF of estimated t statistics for the impact of placebo subsidy changes on the crowd-out in taxable savings accounts per DKr change in individual pension contributions estimated using the MPS specification in Table VII. We construct this figure as follows. Let $t_{p}$ denote a year between 1999 and 2006 and $\bar{Y}_{p t}$ a placebo cutoff for the top tax bracket. We consider a grid of values for $\bar{Y}_{p t}$ from DKr 200,000 below to DKr 200,000 above the actual top tax cutoff in year $t$ in increments of DKr 10,000. For each combination of $\left\{t_{p}, \bar{Y}_{p t}\right\}$, we re-estimate the MPS specification in (11) using 2SLS, redefining the regressors based on the placebo variables and restricting the sample to 3 years before and after the placebo reform year and incomes within DKr $75 \mathrm{~K}$ of the placebo top tax cutoff in those years. As in the baseline specification, standard errors are clustered at the DKr 5,000 income bin level. The figure plots the cumulative distribution function of t-statistics for all the placebos, excluding the coefficients from 1999 with $\bar{Y}_{p t}$ within DKr 100,000 of the true cutoff to avoid biasing the placebo tests with the true treatment effect. The vertical line shows the actual t-statistic obtained in Column 2 of Table VII. Panel B replicates Panel A, using the threshold specification in Column 5 of Table VII instead. Panels C and D plot the empirical CDF of $\mathrm{p}$ values corresponding to the t-statistics in Panels A and B. These two panels also show the 45 degree line as a reference; under the exchangeability assumption, the p values should cluster around this 45 degree line if inference based on the parametric clustered standard errors is valid. Both figures also report the non-parametric permutation-based $\mathrm{p}$ value, computed using the empirical cdf. 


\section{APPENDIX FIGURE VI}

\section{Active vs. Passive Choice and Responses to Subsidies and Employer Pensions}

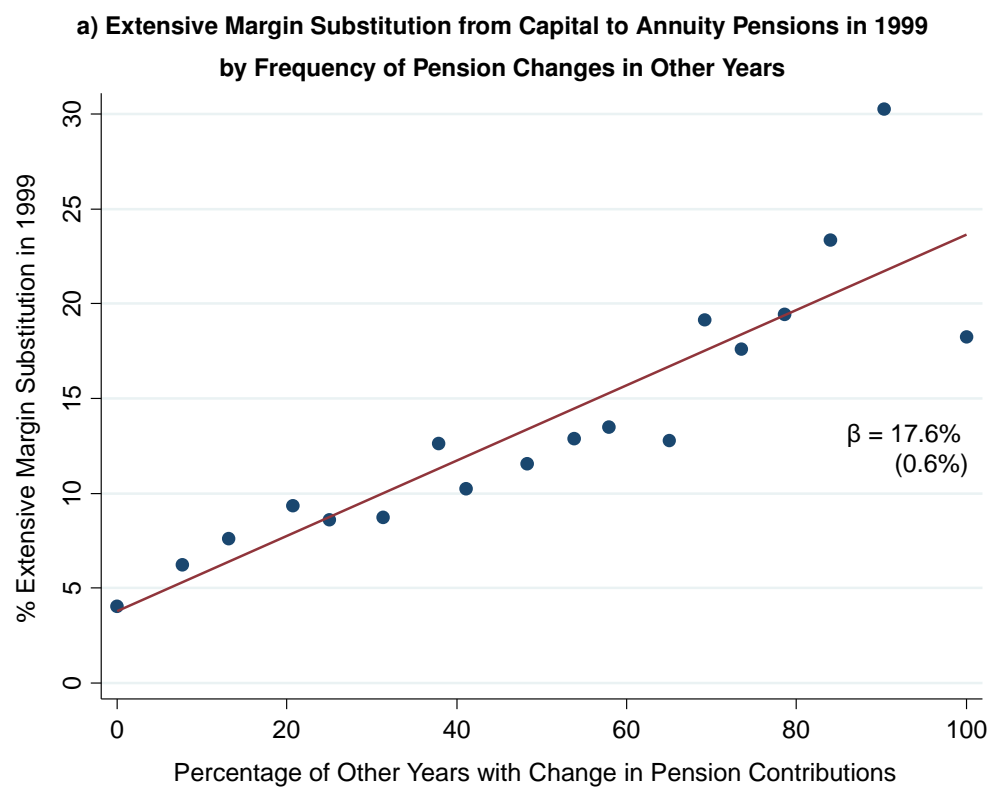

b) Pass-Through of Employer Pensions to Total Pensions for Firm Switchers by Frequency of Pension Changes in Other Years

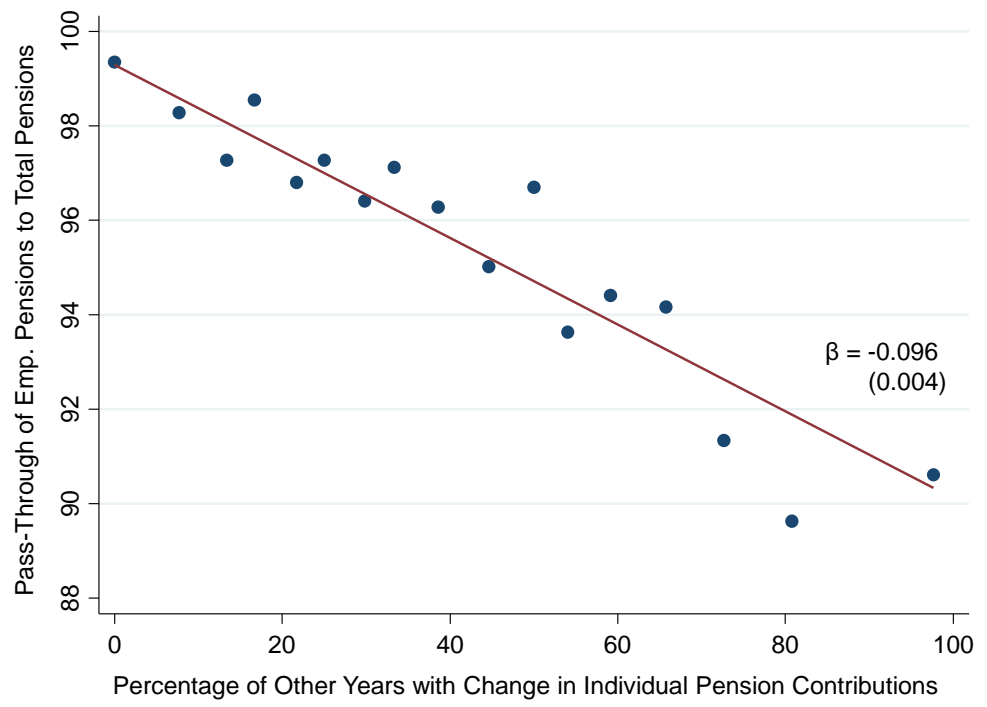

Notes: Panel A is a binned scatter plot. The y variable is an indicator for extensive margin substitution in response to the 1999 capital pension reform, defined as exiting capital pensions and raising annuity pension contributions. The $\mathrm{x}$ variable is the fraction of other years in which an individual changes individual capital or annuity pension contributions relative to the prior year. This plot corresponds to the regression in Column 3 of Table VIII; see notes to Table VIII for further details of sample specification and notes to Figure II for details on construction of binned scatter plots. The best-fit line, coefficient, and standard error in Panel A come Column 3 of Table VIII. Panel B plots pass-through from employer pensions to total pensions vs. the same $\mathrm{x}$ axis variable as in Panel A. To construct this figure, we first split individuals into vingtiles based on the fraction of other years in which an individual changes individual capital or annuity pension contributions relative to the prior year (note that this procedure results in fewer than 20 groups because of point-masses in the distribution). We then estimate and plot the pass-through coefficient of employer pensions to total pensions, estimated from a separate regression in each bin using the specification in Table IIIA, Column 1. This figure is a non-parametric version of the regression in Column 5 of Table VIII; we report the coefficient and standard error from that specification. See notes to Table VIII for further details on sample and variable definitions. 


\section{APPENDIX FIGURE VII}

\section{Heterogeneity in Responses to Subsidies and Employer Pensions by Wealth}

a) Extensive Margin Substitution from Capital to Annuity Pensions in 1999

by Wealth/Income Ratio

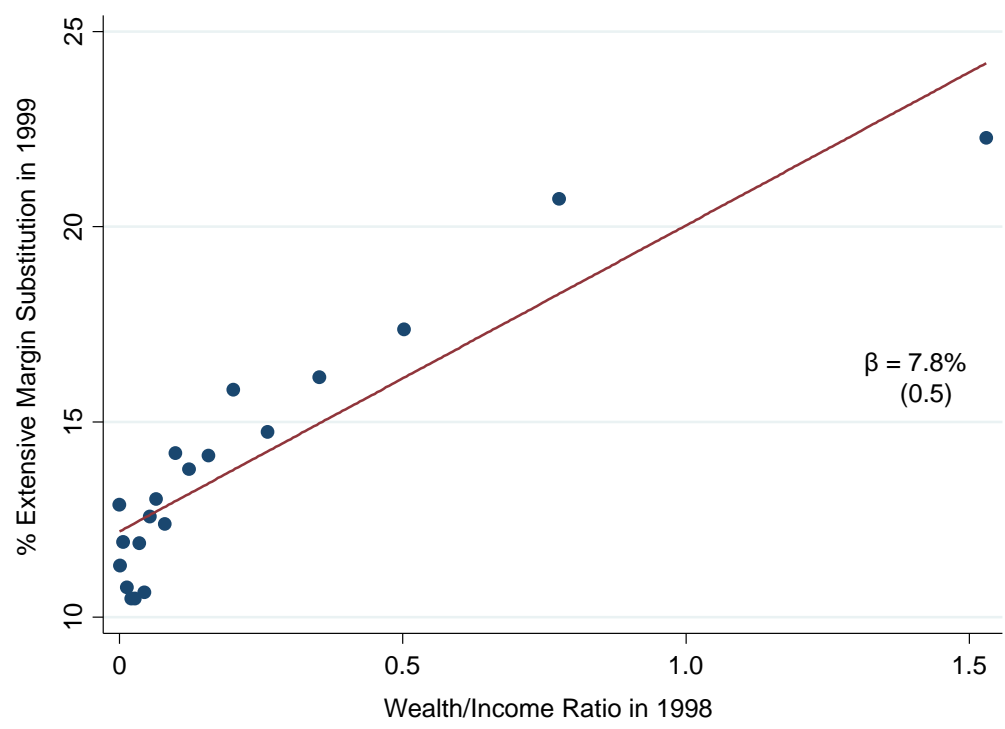

b) Pass-Through of Employer Pensions to Total Pensions for Firm Switchers

by Wealth/Income Ratio

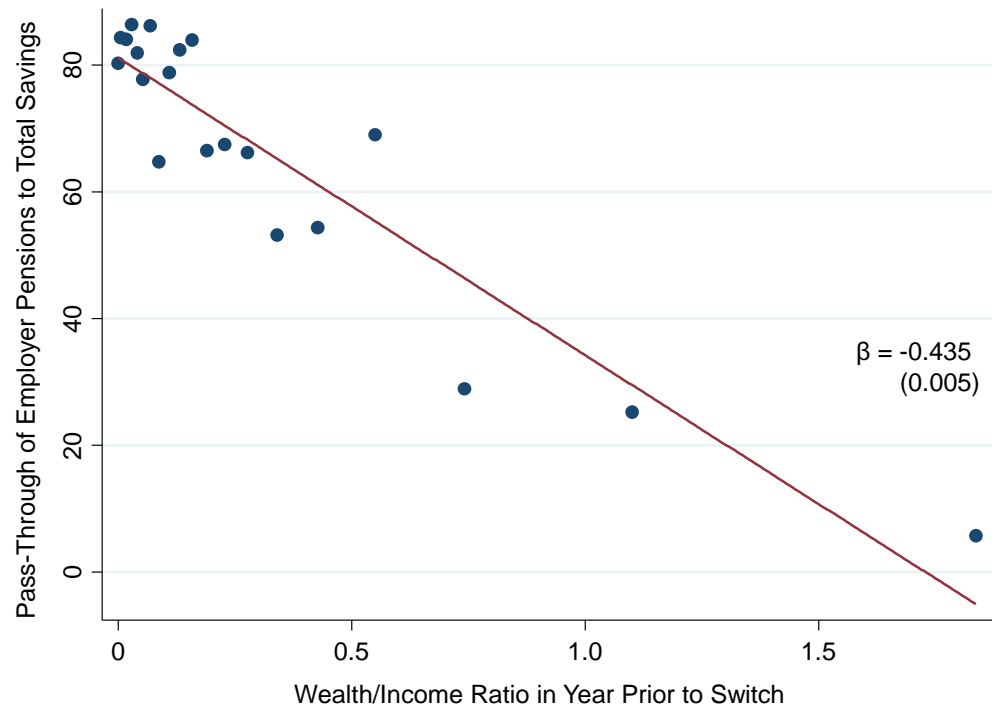

Notes: These figures show the heterogeneity by wealth/income ratios in extensive margin substitution in response to the reduction in the subsidy (Panel A) and pass-through of employer pensions to total saving (Panel B). The two panels replicate Panels A and B of Appendix Figure VI, changing the $\mathrm{x}$ axis variable to the wealth/income ratio, measured as non-pension assets divided by labor income. In Panel A, we measure the wealth income ratio in 1998, the year before the subsidy reduction; in Panel B, we measure it before the firm switch. In Panel B, we measure pass-through to total saving (rather than total pension contributions, as in Appendix Figure VI). See notes to Appendix Figure VI for additional details on construction of these figures. Panel A corresponds to Table IXa, Column 1, while Panel B is a non-parametric analog of the regression in Table IXb, Column 1. See notes to Table IX for further details on sample and variable definitions. 